\title{
A History of Comparative Advertising in the United States
}

Journalism \& Communication Monographs

I5(3) II4-216

(C) 2013 AEJMC

Reprints and permissions: sagepub.com/journalsPermissions.nav DOI: $10.1177 / 1522637913486092$ jcmo.sagepub.com

@SAGE

\section{Fred K. Beard'}

\begin{abstract}
This historical monograph addresses a gap in the extensive scholarly research literature devoted to comparative advertising-especially that which contrasts the advertised product, service, or brand with an identifiable competitor-by exploring advertisers' explanations for its appeal as a tactic throughout the previous century. Prior historical research confirms advertisers have long been aware of and greatly concerned about the unintended consequences of what they often called excessively competitive and combative advertising. Moreover, despite some thirty-five years of systematic scholarly research, two research teams recently concluded that the state of empirical knowledge regarding its effectiveness remains "equivocal." By synthesizing the extensive theoretical and empirical research literature on comparative advertising and interpreting those findings from a historical perspective, this monograph offers uniquely significant insights into modern advertising's history, theory, and practice.
\end{abstract}

\section{Keywords}

comparative advertising, advertising history, advertising message strategy

Comparative advertising - especially that which contrasts the advertised product or service with an identifiable competitor - has been a controversial topic among advertisers throughout the past one hundred years and remains so. Recent historical research suggests that such consequences as the tendency for advertisers to lose focus on their own message strategies, the creation of potentially misleading advertisements, legal challenges from competitors under the Lanham Trademark Act, and damage to advertising's institutional veracity have often occurred when advertisers used comparative

'University of Oklahoma, Norman, OK, USA

\section{Corresponding Author:}

Fred K. Beard, Gaylord College of Journalism and Mass Communication, University of Oklahoma, 395 West Lindsey, Norman, Oklahoma 73019, USA.

Email: fbeard@cox.net 
advertising, especially if they became engaged in advertising wars. ${ }^{1}$ Moreover, and despite some thirty-five years of systematic scholarly research, two independent research teams concluded not long ago that the state of empirical knowledge regarding its effectiveness remains "equivocal.",

Industry concerns regarding comparative advertising and calls for its reform began to appear regularly during the Great Depression and peaked during one of the most contentious periods of advertising self-regulation, the 1970s. Comparative advertising, in fact, set the stage for an extraordinary regulatory battle between the advertising industry and the U.S. Federal Trade Commission (FTC) during the mid- to late-1970s. Advertisers were aware of and concerned about the unintended consequences of what they sometimes called excessively competitive and combative advertising throughout the previous century. ${ }^{3}$ These consequences help explain why surveys of contemporary advertising professionals confirm that despite its frequent use, they continue to retain a healthy skepticism toward comparative advertising's effectiveness. ${ }^{4}$

Problems with comparative advertising also attracted the attention of media owners and managers. By the early-1930s, they were in near-unanimous agreement that comparative advertising represented a serious business and regulatory problem, trapping many between two or more feuding patrons, frequently forcing advertising refusals and revisions to clearance policies, and threatening advertising revenue. ${ }^{5}$

Although comparative advertising was widely criticized by advertisers during the first half of the twentieth century, research confirms they did engage in it, especially during the lean years of the Great Depression. ${ }^{6}$ Richard Pollay, ${ }^{7}$ who content analyzed 2,000 magazine ads published between 1900 and 1980, reported that the generalized mention of competitive standing, or what is called "implied" comparative advertising, ${ }^{8}$ was quite common, with an average of $25 \%$ across the decades. However, when Pollay operationalized comparative advertising as ads that included "clues" to the identity of competitors, or what is called "explicit" comparative advertising, ${ }^{9}$ the average was only $2 \%$. Pollay found the greatest frequency of use, at $4 \%$, in the 1970 s.

Other researchers also report that explicit comparative advertising increased significantly during and after the 1970s in both broadcast and print media. Estimates of comparative ads as a percentage of all ads in the United States range from about $7 \%{ }^{10}$ to $23 \%{ }^{11}$ to between $30 \%$ and $40 \% .^{12}$ Researchers Linda Swayne and Thomas Stevenson found the percentage of comparative ads in business magazines increased from $8.1 \%$ in 1970 to $23.8 \%$ in $1985,{ }^{13}$ and Fahad Al-Olayan and Kiran Karande report that $26 \%$ of their sample of U.S. general interest, family, and women's magazines included comparisons. ${ }^{14}$

Estimates of the use of comparative advertising on television are higher, on average, ranging from $5 \%$ to $10 \%{ }^{15}$ to $14 \%{ }^{16}$ to $50 \%{ }^{17}$ to as high as $80 \% .^{18}$ Industry reports of comparative advertising frequency based on television network analyses also indicate a steady increase, ranging from $23 \%{ }^{19}$ to $35 \%{ }^{20}$ to as high as $50 \% .^{21}$ The number of comparative commercials on prime time television, according to Gallup \& Robinson, soared from one out of thirty during the 1973 season to one out of twelve in 1975.22 Although there has been no recent content analysis of comparative advertising use, some industry observers suggest an increase during the first decade of the twentieth century. ${ }^{23}$ 
There are several theoretical explanations for why the kinds of negative information often found in comparative ads could enhance their effectiveness. For instance, "negativity bias" 24 predicts that negative information may have a greater effect in the decision-making process, compared with positive information. Researchers investigating political attack advertising propose this occurs because negative information is more unexpected and novel, ${ }^{25}$ less ambiguous, ${ }^{26}$ and more credible. ${ }^{27}$ Some of these effects likely occur because negative information is often presented, as it generally is in comparative product and service advertising, within a context that is predominantly positive. ${ }^{28} \mathrm{On}$ the other hand, others suggest negative information encourages greater attention and recall because it appeals to emotion rather than $\operatorname{logic}^{29}$ and because people assign greater weight to negative information when making evaluations in social settings. ${ }^{30}$

Advertising's most important theory, the Elaboration Likelihood Model (ELM), ${ }^{31}$ also offers a valuable framework for understanding comparative advertising and its effectiveness. The ELM proposes two routes to persuasion - one central and one peripheral. The central route predicts that when people are motivated to think about a message (e.g., they are highly involved or the message is especially relevant) and able to think about it (e.g., the message is fairly easy to understand), then they will cognitively elaborate on the claims in the ad and be persuaded by issue-relevant arguments.

Negativity bias suggests that comparative ads containing claims and criticisms about competitors, especially identified ones, likely activate the central route to persuasion, encouraging people to integrate the claims into their existing knowledge structures, leading to message acceptance and possibly long-term attitude change. On the other hand, since some people may be expected to counterargue with comparative ads as well as derogate the source, ${ }^{32}$ these could encourage negative thoughts, leading to rejection of the message. Conversely, the "distraction hypothesis" 33 predicts that after a comparative ad gains people's attention, they might be distracted from counterarguing with the comparative claims and criticisms by peripheral cues, such as humor, music, or celebrity spokespersons. The result would be a weaker, temporary form of attitude change by way of the ELM's peripheral route to persuasion.

Academic researchers have devoted considerable attention to comparative advertising. More than eighty studies on the topic were published in scholarly journals between 1975 and $1994 .{ }^{34}$ Many of these were likely among the seventy-seven studies Dhruv Grewal and his colleagues included in their widely cited meta-analysis. ${ }^{35} \mathrm{~A}$ search of the literature published since 1997 uncovered another fifty studies of comparative advertising.

A review and synthesis of the findings and conclusions from Grewal et al.'s metaanalysis, John Rogers and Terrell Williams's practitioner survey and literature review (forty-two studies), Fred Beard's 2011 update of the Rogers and Williams survey, and the fifty studies of comparative advertising published since 1997 is presented in Table 1's model. ${ }^{36}$ The model's process outcomes (cognitive, affective, and conative) were chosen from the literature based on three criteria: (1) They are the outcomes most frequently investigated, (2) they are of theoretical significance, and (3) they are important to advertisers. 
Table I. Comparative versus Noncomparative Advertising-Process Outcomes and Situational Factors.

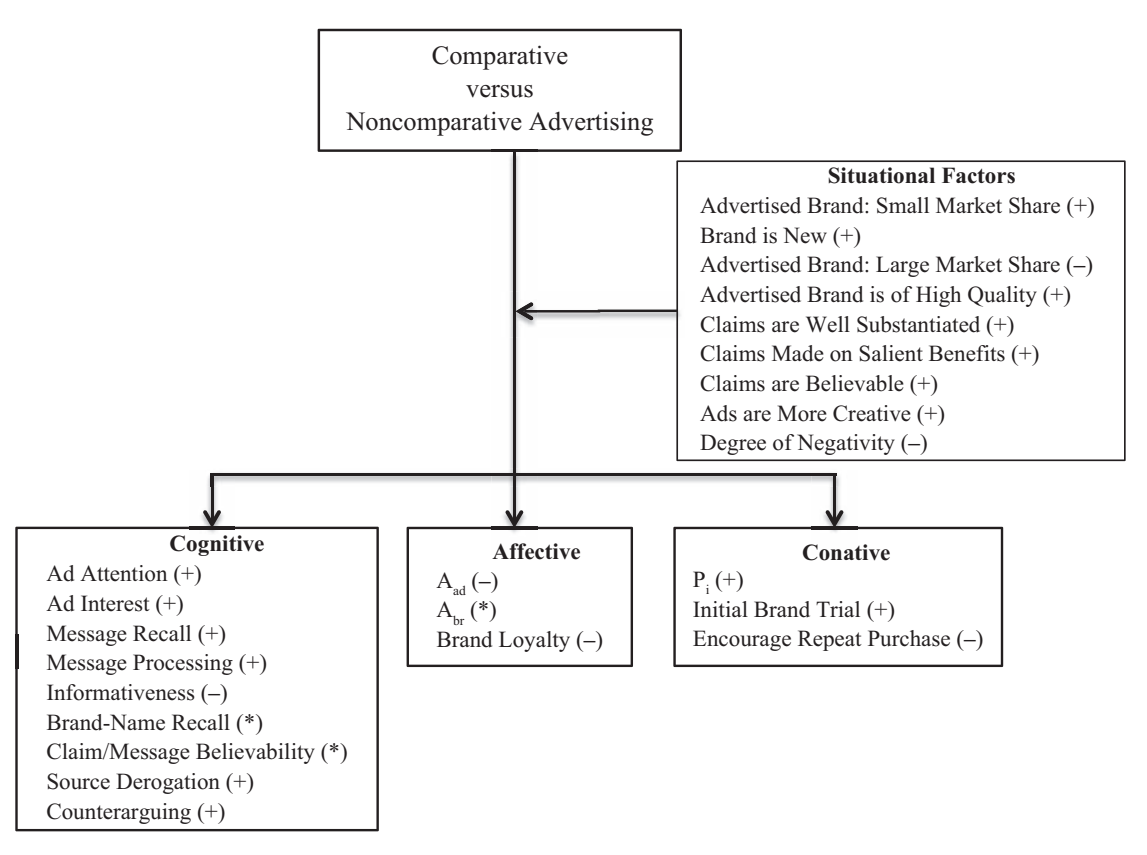

Note: $+=$ positive effect, $=$ negative effect, $*=$ inconclusive

Advertisers recognize that attention to an ad explains only part of its effectiveness. Consumers must also process some of the information cognitively and be able to recall it later. Based on their review of the research literature, Rogers and Williams concluded that comparative, versus noncomparative, advertising increases not only message recall but also counterargument and source derogation. Conversely, they concluded that its effects on informativeness and claim/message believability are likely negative. Grewal and his colleagues similarly concluded that comparative ads generate more attention, encourage greater message processing, and increase brandname recall. Although they also concluded that comparative ads generate lower levels of source credibility, they did not find a significant effect on ad, or message, believability nor on informativeness.

Rogers and Williams's survey of advertising creative executives representing the top 500 U.S. agencies and Beard's recent replication both report that respondents agreed comparative advertising is relatively more effective than noncomparative advertising for achieving recall of message claims and brand attributes, that they encourage greater ad interest, and that their claims and messages are more believable. Conversely, creative practitioners disagreed that comparative ads are more effective at achieving brand-name recall. The differences regarding whether comparative advertising is more informative than noncomparative advertising for both studies were not significant. 
Only one recent study reported the effects of comparative versus noncomparative advertising on message recall. Researcher Naveen Donthu found that both unaided and aided recall were significantly greater for a comparative ad. ${ }^{37}$ The authors of two other recent studies report comparative ads and their claims were significantly more believable than noncomparative ads, although ads in both studies were "partly" comparative (i.e., they contained both comparative and noncomparative information). ${ }^{38}$

Affective process outcomes capture how advertising encourages favorable feelings toward an advertisement or a sponsored brand. Based on their review of the literature, Rogers and Williams concluded that researchers had failed to identify either a positive or negative effect of comparative, versus noncomparative, advertising on attitude toward the ad $\left(\mathrm{A}_{\mathrm{ad}}\right)$ or attitude toward the brand $\left(\mathrm{A}_{\mathrm{br}}\right)$. Grewal and his colleagues concluded that comparative ads generate more negative $A_{a d}$ than noncomparative ones; conversely, they concluded that they generate more favorable $\mathrm{A}_{\mathrm{br}}$.

Rogers and Williams, and Beard report that advertising creative executives believe comparative advertising is less effective than noncomparative advertising for achieving both $A_{a d}$ and $A_{b r}$. The majority of respondents to both surveys also agreed that comparative ads likely have a negative effect on brand loyalty, compared with noncomparative ads.

Findings from six recent studies investigating the effects of comparative versus noncomparative ads on $\mathrm{A}_{\mathrm{ad}}$ were evenly split between those finding a significant negative effect ${ }^{39}$ and those reporting nonsignificant differences. ${ }^{40}$ Six recent studies have measured the effects of a comparative versus noncomparative ad on $\mathrm{A}_{\mathrm{br}}$, with four reporting nonsignificant differences ${ }^{41}$ and two reporting significant positive differences. ${ }^{42}$

Conative process outcomes and advertising objectives capture how advertising can encourage desire among consumers for a product or brand and affect the ultimate decision to purchase it. Rogers and Williams, based on their review, concluded that researchers had failed to identify either a positive or negative effect of comparative, versus noncomparative, advertising on either purchase intention $\left(\mathrm{P}_{\mathrm{i}}\right)$ or initial brand trial. Grewal et al., on the other hand, report that comparative ads increase both $\mathrm{P}_{\mathrm{i}}$ and initial brand trial more than noncomparative ads. Rogers and Williams, and Beard similarly report that creative executives agree that comparative advertising is more effective than noncomparative advertising for achieving $\mathrm{P}_{\mathrm{i}}$ and initial brand trial, but less effective for encouraging repeat purchase.

Since 1997, five works have appeared reporting the direct effects of comparative versus noncomparative advertising on $\mathrm{P}_{\mathrm{i}}$, with three reporting nonsignificant differences ${ }^{43}$ and two reporting positive findings in favor of comparative advertising. ${ }^{44}$

In summary, support for overall conclusions is limited by absent and occasionally contradictory findings among the three literature reviews and two surveys. However, as shown in Table 1, direct effects of comparative versus noncomparative advertising on advertising outcomes and for which there are no directly contradictory findings include its likely positive effects on ad attention, ad interest, message recall, message processing, counterargument, source derogation, $\mathrm{P}_{\mathrm{i}}$, and initial brand trial. Negative effects for which there are multiple supporting findings and no contradictory ones include informativeness, $A_{a d}$, brand loyalty, and repeat purchase. For at least three 
important outcomes - brand-name recall, claim/message believability, and $\mathrm{A}_{\mathrm{br}}$-the direct effects of comparative advertising remain substantially in question.

Grewal and his colleagues also analyzed multiple research findings for several moderators of comparative advertising effects, which Rogers and Williams, and Beard refer to as "situational factors." 45 A search of the literature published between 1998 and 2012 revealed twenty-nine studies investigating twenty-eight moderators and mediators. However, none reported findings for how the main effect of comparative advertising varied by a one-way interaction with any of the moderators previously investigated. Thus, the findings from these studies were not included in Table 1's model.

Grewal et al. concluded that comparative versus noncomparative advertising is more effective when the advertised brand has a small market share, for brands new to the market, and when claims are well substantiated. They concluded that it is less effective when the brand has a large market share. In addition, they also investigated the effects of credibility enhancers (e.g., the use of credible sources, two-sided messages, or the support of claims with factual information). Although they concluded that the use of credibility enhancers does not enhance message awareness nor increase ad believability, they did find that enhancing the credibility of comparative ads leads to more favorable $\mathrm{A}_{\mathrm{br}}$ and greater $\mathrm{P}_{\mathrm{i}}$.

Rogers and Williams, and Beard reported that creative practitioners agree that comparative advertising is relatively more effective than noncomparative advertising when the advertised brand has a small market share, if claims are made on salient product benefits, if claims are well substantiated, if claims are believable, if ads are more creative, and if the advertised brand is of higher quality. They agreed that comparative advertising is less effective when the advertised brand has a large market share.

Although neither Rogers and Williams nor Beard directly questioned their respondents about the degree of negativity in the execution of comparative ads, the factor did emerge in Beard's thematic analysis of responses to an open-ended item on his questionnaire. He reported that some creative executives clearly held the view that denigrating or attacking a competitor can reflect negatively on the advertised brand, that it is important that comparative ads not be perceived as especially mean-spirited, and that their effectiveness critically depends on their tone. The findings of one of the only studies to directly compare high versus low negativity in comparative advertising confirmed that a high-negativity comparative ad scored significantly lower on measures of believability, fairness of content, approval of content, informativeness, and overall ad evaluation. ${ }^{46}$

In summary, comparisons across the literature's findings and conclusions show that comparative advertising is likely more effective than noncomparative advertising under all the situational factors summarized in Table 1, with the exceptions of advertising on behalf of products or services with large market shares and comparative advertising that is perceived by consumers to be excessively negative. 


\section{Research Purpose and Significance of This Monograph}

By synthesizing the theoretical and empirical research literature on comparative advertising and interpreting those findings from a historical perspective, this monograph offers unique insights into modern advertising's history, theory, and practice. The study's findings reveal (1) the most important events, participants, and examples in the history of one of modern advertising's most controversial tactics; (2) for what purposes advertisers believed comparative advertising would be more effective than noncomparative advertising, why, and how these beliefs may have changed over time; (3) the extent to which the views, practices, and experiences of advertisers as revealed in their trade publications are consistent with the findings of decades of theory development, empirical academic research, and practitioner surveys; and (4) additional explanatory insights into the research literature's findings and conclusions.

\section{Historical Method}

Sources for this historical study consist of more than 650 articles published in advertising, marketing, media, and general business trade journals between 1900 and 2012. Trade journals have proven valuable for previous important historical studies of advertising (e.g., Merle Curti's 1967 work $^{47}$ ). Since no index of business publications was available prior to 1913, sources for the earliest period were located by scanning one randomly selected issue from each of the sixty volumes of the industry's most influential trade journal, Printers' Ink, published between 1900 and 1913 (consisting of approximately 780 issues). Any articles that addressed the topic of comparative advertising in any manner were included as potential data.

The search for sources for the remainder of the twentieth century through the present day was conducted using four business periodical indices: the Industrial Arts Index (1913-1957), the Business Periodicals Index (1958-1973), the ABI/Inform Complete database (1971-2012), and the Business Source Premier database (1984-2012). The Industrial Arts Index is the only business periodical index available for the period it covers; it continued in 1958 as the Business Periodicals Index. When primary sources obtained in this manner pointed to the existence of other sources, these, too, were collected and added to the body of data.

Table 1's model of comparative advertising effects and moderators was then used as a thematic framework for the analysis of the historical data. These thematic categories - comparative advertising's direct effects on process outcomes and various situational factors (i.e., moderators) of those effects-were applied to the data deductively in a search for specific data that confirmed or disconfirmed the themes and that helped explain them. Other themes, however, were also allowed to emerge from the data in an inductive, qualitative fashion.

The periodization scheme ${ }^{48}$ was established a priori and is similar to those used for other advertising histories and for similar reasons. ${ }^{49}$ What is considered "modern" advertising emerged at the beginning of the twentieth century ${ }^{50}$ and steadily progressed 
in its sophistication and the professionalism of its practitioners throughout the 1900s, 1910s, and 1920s. The Great Depression of the 1930s and the war years of the 1940s, however, severely affected advertising spending, message strategy, and the tactical execution of advertisements. Prior research also shows that problems with comparative advertising began attracting the attention of advertisers, media executives and managers, and federal regulators during the $1930 \mathrm{~s}^{51}$ The 1950 s capture the tremendous postwar boom in advertising spending as well as the beginning of advertising's "Golden Age."

The 1960s and 1970s are especially important, and analyzed as a single period, because U.S. advertisers began naming competitors more frequently in the early-1960s and comparative advertising began in earnest at the outset of the 1970s. The 1960s to 1970 s are also important because they include the industry's much vaunted "Creative Revolution." The final three decades are analyzed as a single period for two reasons. First, by 1980, comparative advertising had become both accepted and widely practiced among mainstream advertisers. Second, the event that distinguishes this period from the one that precedes it literally occurred on a single day. On August 13, 1979, the FTC published a definitive restatement of its comparative advertising policy, declaring beyond question that trade association codes, media clearance policies, and advertising self-regulatory rules restricting comparative advertising would not be tolerated. This event likely contributed substantially to what appears to be the more widespread use of explicit comparative advertising among mainstream advertisers since then.

The method employed for this history lacks the appraisals of validity and reliability that quantitative content analysis possesses. In fact, the debate among historians over qualitative versus quantitative methods has often been quite contentious. ${ }^{52}$ It is, however, consistent with the methods of empirical historical research. Defined by historian David Fischer, an empirical historian is one "who asks an open-ended question about past events and answers it with selected facts that are arranged in the form of an explanatory paradigm." 53 As Smith elaborates, "The explanatory paradigm, of course, takes different forms - narrative, statistical explanation — but always consists of a reasoned, systematic examination of surviving recorded happenings, written in a spirit of critical inquiry seeking the whole truth." 54

\section{The 1900s to I920s}

Richard Pollay found that while it was not uncommon for advertisers to mention competitive standing in a general way during this period (i.e., implied comparative advertising), magazine advertisers rarely mentioned a competitor by name, with only $2 \%$ and $1 \%$ of ads in the 1900 s and 1910 s, and none in the 1920 s. ${ }^{55}$ Thus, it is not surprising to find that most advertisers at the turn of the last century held predominantly negative views toward comparative advertising, or what they often referred to as "knocking" or "unselling," as in the unselling of a competitor's merchandise rather than the selling of one's own.

The mention of a competitor was often associated with the frequently dishonest and professionally embarrassing "buncombe, bombast, and ballyhoo" advertising of the 
mid- to late-1800s. The views of the majority of advertisers during this period are summarized well by the author of a piece in Printers' Ink: "Hasn't the day passed in advertisements or elsewhere for attacks upon competitors' goods, whether direct or indirect?"56 Such views were predominant well into the 1920s, and most sources suggest that the use of comparative advertising remained infrequent: "Mention of competitors' names in advertising is sufficiently unusual to make those announcements noteworthy." ${ }^{57}$ Another Printers' Ink author admonished advertisers: "Consider for example that Eleventh Commandment of the advertising man: 'Thou shalt not knock thy competitor's goods." "'58

However, and despite the mainly negative views toward comparative advertising, sources confirmed it was not totally absent from the advertising of the period, and that it was often quite negative in tone. As Printers' Ink observed,

The garden variety of "knocking argument" is in bad odor everywhere- holding the nose when a competitor's name is mentioned - and though it is still in fairly general use by gyp concerns and guerrilla salesmen, it is proscribed by the "regulars" in all lines. ${ }^{59}$

San Francisco ad agency president Emil Brisacher also suggested that use of the tactic was becoming quite prevalent toward the end of the 1920s, even before the Wall Street Crash of November 1929, and that many continued to view it as unseemly. As Brisacher wrote, "It is really amazing to see how widespread this epithet-throwing contest has become. It is indulged in by so many advertisers generally thought to have spotless advertising reputations." 60

\section{Direct Effects}

Cognitive outcomes. Advertisers and industry observers wrote little about the effectiveness of comparative advertising during the first three decades of the twentieth century, consistent with a dearth of favorable views toward the tactic. However, during the mid- to late-1920s, they began to discuss its likely effects with greater frequency. Among the first beliefs to emerge was that comparative advertising directly affects the cognitive outcomes of attention and awareness. Referring to frequent discussions of the subject of "knocking" copy in the journal's pages, a Printers' Ink contributor observed the following: "The majority of these articles advanced the claim that negative advertising is a dangerous copy tool. Apparently, however, many copy writers believe that negative copy is 'interrupting' rather than alarming." 61

Another view to emerge was the belief that while comparative ads might create attention and awareness for the advertiser, they would benefit the competitor as well. As suggested by Printers' Ink in an editorial devoted to an ad that mentioned and complimented the advertiser's competitor,

Taking space in an advertisement to compliment a competitor on his advertising is an occurrence rare enough to take time out for a moment's reflection. . . . One danger which a compliment shares with a knock is that of informing the ignorant of the existence of the competitor. ${ }^{62}$ 
A comparative campaign that received considerable attention during the late-1920s was George Washington Hill's infamous "Reach for a Lucky instead of a Sweet" campaign (see Figure 1). As the editor of the Confectioners Journal, and vocal critic of the campaign and its supposed attack on the candy and confections industry, reported, "Mr. Hill, of American Tobacco, has told me, and I am certain that he believes it, that such attacks increase the consumption of the product attacked." 63

Only a single observer during this period argued that comparative campaigns, such as the "Reach for a Lucky" campaign, would be informative. As he proposed,

Such advertising brings out values in products that have never been generally known. This type of sales effort helps to make the public the real arbiter of what it shall buy; and, if properly weighed, tends to raise the level of intelligence upon which demand and consumption are based. ${ }^{64}$

As one might expect, given the lack of enthusiasm for comparative advertising, the majority of advertisers' views regarding its believability were negative. At the outset of the century, this view was captured well in a Printers' Ink reprint from the Southern Drug Journal:

If you must talk about your competitor, it is better for you to speak well of him than ill. . . If you try to "run him down" people will not only not believe what you say, but will think that he is taking your trade away from you by offering some superior inducements. ${ }^{65}$

Printers' Ink summarized this view again at the end of the period, strongly suggesting that the lack of believability was linked to comparative advertising that knocked, or directly criticized, competitors: "A knock has doubtful merit. The general effect, where a knock does not actually antagonize, is to make the prospect suspicious."66

Other sources linked their views regarding comparative advertising's lack of believability to two comparative tactics that garnered substantial discussion and frequent criticism throughout this period - those of implying or explicitly claiming that all the advertiser's competitors were dishonest in their advertising or that everyone else's products were inferior. A Printers' Ink author summarized this view: "Isn't the public suspicious of sweeping claims of superiority and allegations that no one except the advertiser himself should be credited with common honesty?" ${ }^{67}$ Another Printers ' Ink contributor expressed the identical belief some seventeen years later:

Here's another advertiser, who starts off with the headline, "Why Gamble with ?" and goes on to imply that that is precisely what anybody is doing who buys any other product than his own. Speaking as one who doesn't know much about that particular article, I announce that I don't believe it; and what is more, I don't believe the men who really do know a lot about it, believe it either. ${ }^{68}$

Conversely, an industry observer offered a more favorable observation regarding the believability of a sweeping comparative claim of superiority, but specifically one combined with a money-back guarantee (see Figure 2). As he concluded, 


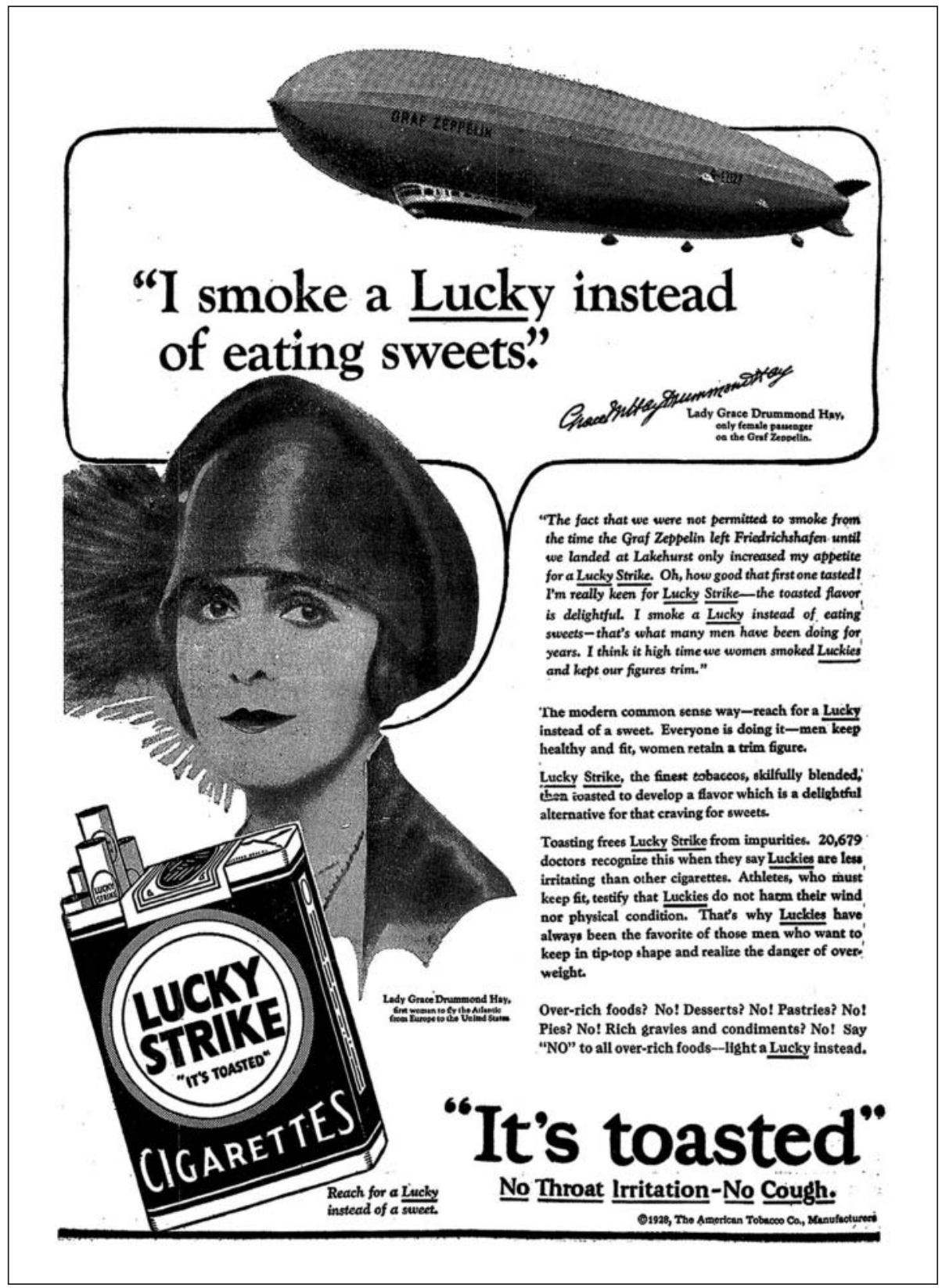

Figure I. "I smoke a Lucky instead of eating sweets."

Source: The New York Times, October 23, 1928, 22. Lucky Strike is a registered trademark of Reynolds Innovations Inc. Corporation. 


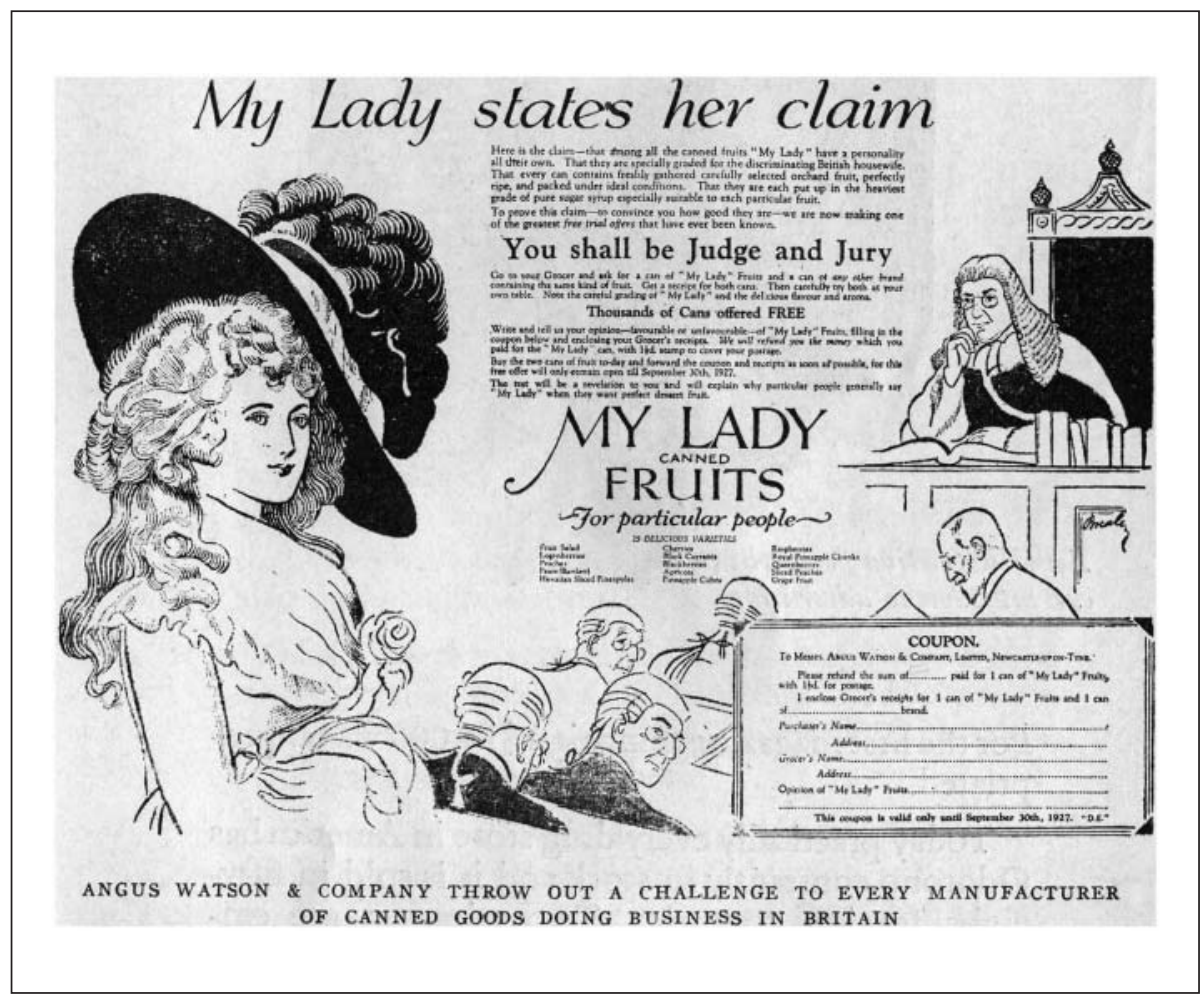

Figure 2. "My lady states her claim."

Source: Printers' Ink, October 6, 1927, 10.

The only inference possible to be drawn is the one which the advertiser obviously expects that newspaper readers will draw-namely that unless Angus Watson believed its product certain to beat all other brands, it would be foolish to make this offer. ${ }^{69}$

In addition to concerns about the believability of comparative advertising with regard to advertisers and their products, the comments of a Printers' Ink contributor acknowledged the possibility that comparative claims could produce negative consequences for all the competitors in the category as well as advertising as an institution. As he wrote,

If Advertiser A makes a certain statement of a positive sort and Advertiser B comes along with an equally strong statement, then both can't be telling the truth. Advertising is placed, therefore, under a shadow, in a sense. When an advertiser states in his advertising that "most other products of this type" have grievous faults, sometimes positively serious, to what extent does he damage both his worthy competitors and the cause of advertising in general? ${ }^{70}$ 
Affective outcomes. Although sources during this period had little to say about affective outcomes, those that did speculate about whether comparative ads encourage liking for sponsors or the ads themselves overwhelmingly agreed that comparative advertising would likely cause negative responses. As Printers' Ink concluded in its description of a comparative ad, "It certainly looks like a case of 'sour grapes,' whether it is or not, when a concern devotes an entire ad to talk about competitors." ${ }^{\prime 1}$ Another contributor captured the beliefs of many when he wrote the following:

But in nine cases out of ten, a salesman hurts his cause by being drawn into an argument as to whether a competitor's line is as good as his own. It puts him at the disadvantage of being on the defensive..$^{72}$

San Francisco adman Emil Brisacher declared some twenty years later, "Comparisons are always odious — but in advertising space they are costly — they lose sales and they lessen the prestige of the advertiser who makes them." "73

Conversely, a small minority proposed that comparative ads could reflect positively on their sponsors, but each of these views was also associated with the belief that this was only true if the advertising's tone were positive. At the outset of the century, this belief was captured well by Printers' Ink: "If you speak well of him [the competitor] it will indicate that you have so much confidence in your own goods and methods that you are not afraid of a little competition." "T4 The identical belief was expressed in a discussion of the comparative ad shown in Figure 3. As the author explained,

Printers' Ink has hitherto called attention to advertisements that contained friendly references to competitors, and attacks on competitors by name have occasionally been seen on both sides of the Atlantic. To be able to name a competitor in the way which the Dunlop company adopts is assuredly a sign of strength. ${ }^{75}$

On the other hand, a single source during this period mentioned the possibility that a comparative ad might encourage negative attitudes toward the sponsored brand and favorable ones toward the comparison brand by way of backlash. As he proposed, "Isn't it human nature to take the part of the underdog and to resent a holier-than-thou attitude?"76

Conative outcomes. During this period, the majority of advertisers and industry observers agreed that the conative effects of comparative advertising and the profitability resulting from them would be poor. One Printers' Ink writer seemed to speak for many when he wrote the following: "There is no need to refrain from attacking a competitor, directly or indirectly, on ethical grounds. It is enough if you once get it clearly in your head that it doesn't pay you." 77 As another pointed out with regard to George Washington Hill's apparent attack on the sweets industry and other advertisers who followed his example, 


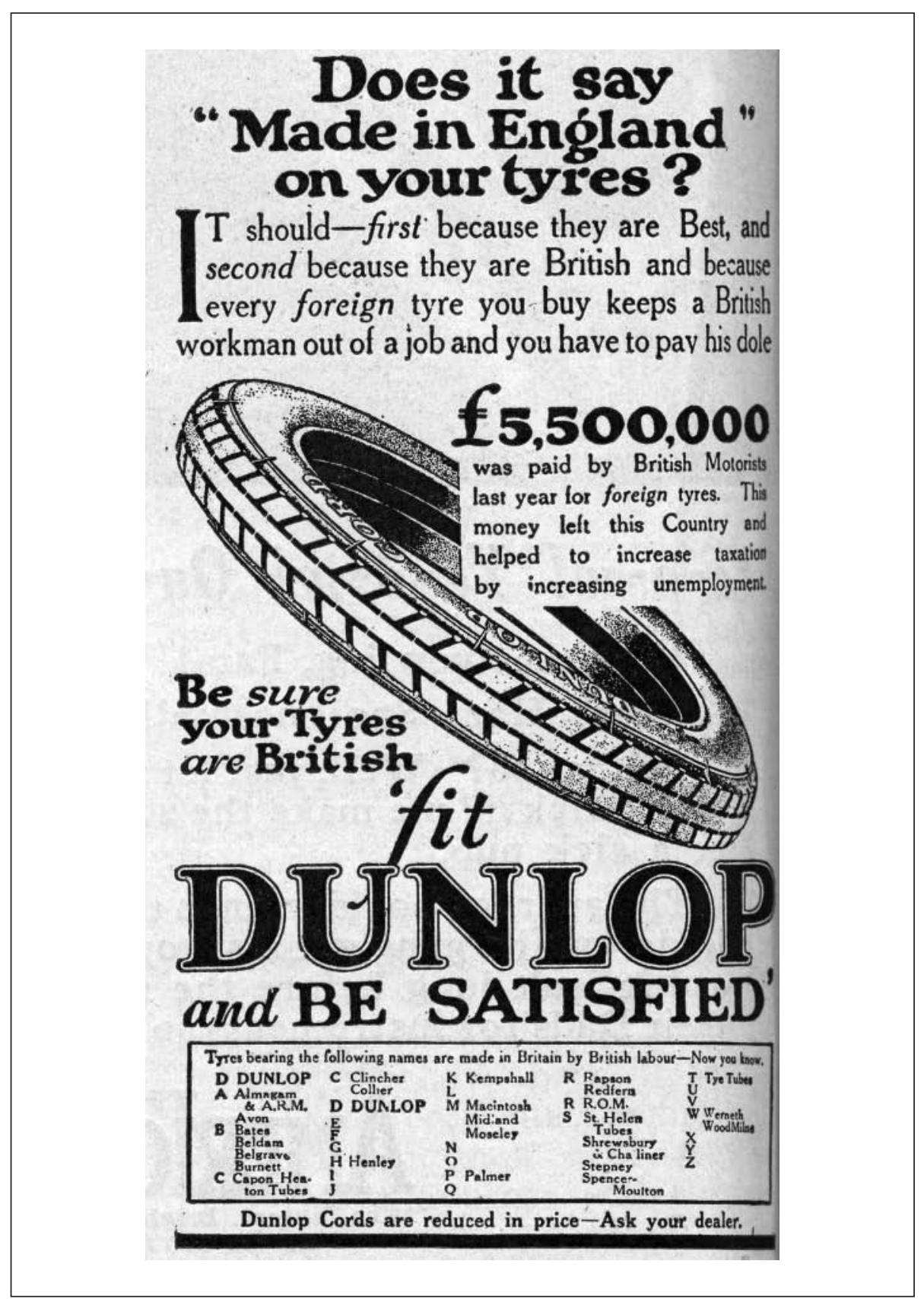

Figure 3. "Does it say 'Made in England' on your tyres?"

Source: Printers' Ink, September 13, 1923, 8. Dunlop is a registered trademark of DNA (Housemarks) Limited. 
Somewhere, some day, will come a point where everybody will realize that if all the money all these industries spend on their mock battles could be quietly invested in the unexciting process of simple direct selling of better goods at lower prices everybody would make more money. ${ }^{78}$

However, this was not the only view to find expression during this period, and specifically with regard to Hill's Reach for a Lucky campaign. The majority of the sources that discussed the campaign and its sales effects, including, especially, Hill himself, pointed to the tremendous increase in both sales of and market share for Luckies that occurred during the campaign. As critic of the campaign Eugene Pharo explained, "The American Tobacco Company has brought forward only one reason for adopting offensive advertising tactics. It has been that such tactics have increased the sale of its product." 79 Many historical and contemporary sources do, in fact, affirm the success of Hill and his Luckies brand during this period. ${ }^{80}$

Some contributors to the minority belief that comparative advertising could encourage sales directly also acknowledged the possibility that it would sell the competitor's product. A Printers' Ink author captured this view, when he wrote the following: "'It's clever stuff and good advertising, but it will sell the other fellow's line as well as it will sell your own,' is a popular phrase, not without some foundation of truth." 81 As George Washington Hill told critic Eugene Pharo, regarding his Reach for a Lucky campaign, "Without its being at all intentional on our part, the calling of attention to the sweets industries, by means of our pocketbook, has, paradoxically, resulted in an enormously increased consumption of sweets." 82

The belief that comparative advertising could lead to problems for entire industries found expression during this period. With regard to an extraordinarily vicious advertising war between Calumet baking powder and other brands marketed by a "trust," which included the equally popular Royal brand (see Figure 4, for an example), a Printers' Ink author noted,

Can one be blamed if the suspicion gets around, and gathers force with the passage of years, that all baking powders are bad, and that the less one uses any of them the better it will be for his health. ... What can such a condition be laid to except this persistent campaign of attack and counterattack? ${ }^{83}$

The mutually damaging consequences of this war were still being discussed nearly twenty years later in the pages of Printers' Ink:

Lots of people still alive and well can vividly recall the days of some years ago when they were repeatedly warned to beware of "benzoate of soda." Some folks even ceased to eat, for a while, fearing all their food was poisoned. ${ }^{84}$

\section{Situational Factors}

There were few explanations for what situational factors might contribute to the effectiveness of comparative advertising during the first three decades of the twentieth 


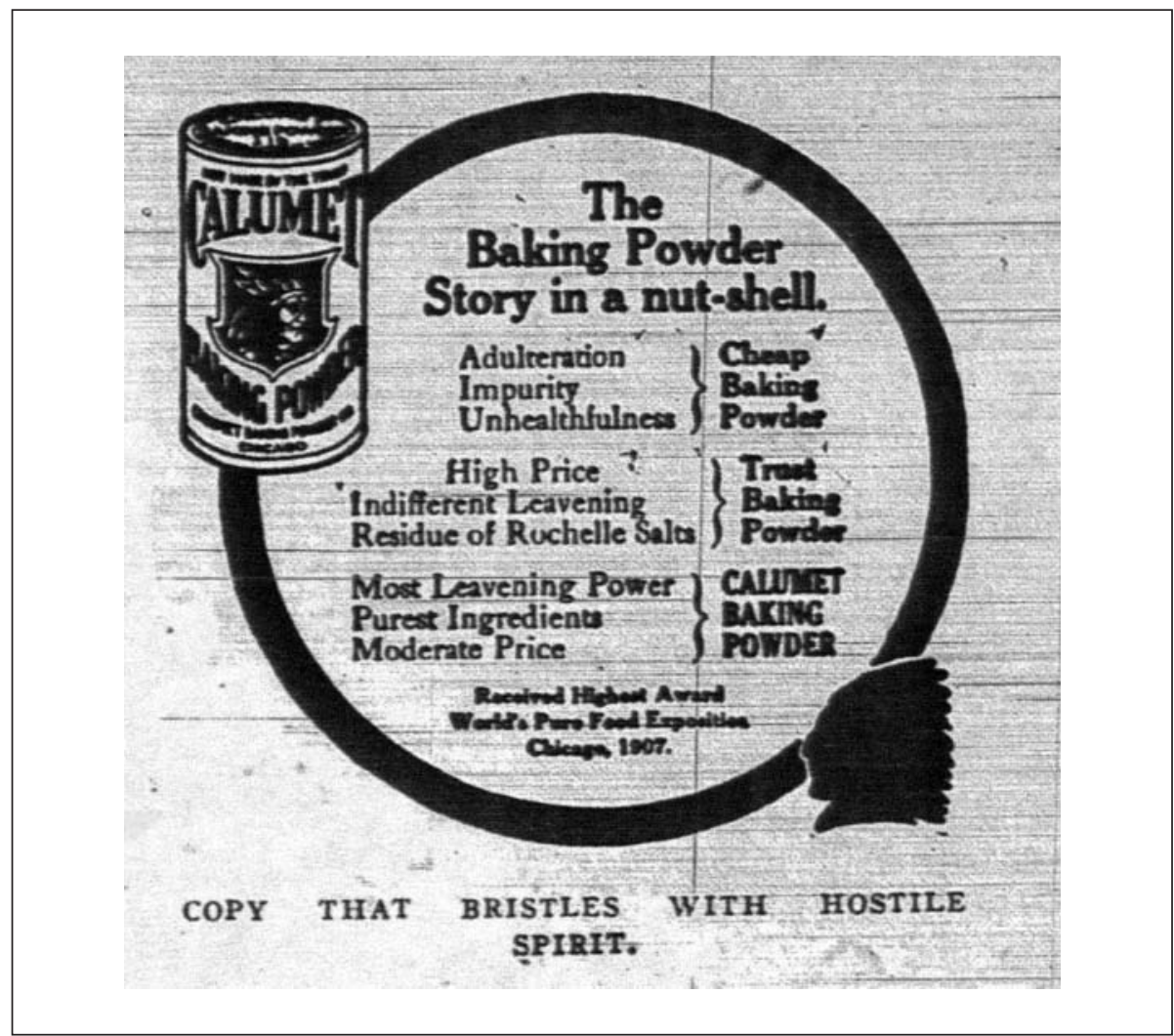

Figure 4. "The Baking Powder Story in a nut-shell."

Source: Printers' Ink, June 9, 1910, 23. Calumet is a registered trademark of Kraft Foods Global Brands LLC.

century, probably because so few advertisers had anything favorable to say about it. The suggestions that do appear are offered in a mainly cynical fashion and reflect the tendency of the period for comparative advertisers to create implied comparative ads that claimed superiority over all their competitors. As summarized by Printers'Ink,

Really, though there is only one method. You teach readers to view the other fellow with alarm. Nobody ever points a finger directly at him-Oh, dear, no! But a broad-minded, altruistic concern for the welfare of mankind leads you to expose some of the dark deceptions of your industry. ${ }^{85}$

Only one reference was made during this period as to what might contribute to the effectiveness of a comparative ad and claim. One of the few advertisers to advocate the approach, in an open forum on the topic, clearly expressed the view that wellsubstantiated comparative claims made about a product of superior quality would be believable and effective. As he declared, "Gentlemen, what better and more convincing 
campaign arguments can I possibly assemble than that I build my product with the greatest possible care, out of the best materials, and that my competitors do not?"86 Conversely, the view that comparative knocks directed toward one or more competitors would fail to communicate a salient consumer benefit or be persuasive was strongly implied by this critic:

You don't see Westinghouse or General Electric or the leading machine tool advertisers, or any of the other really successful industrial people wasting any time or attention on invidious comparisons with the other fellow's goods, whether he is named or otherwise identified, or not. That isn't merely a question of ethics, or of taste; it isn't even due to the fact that they know the products of their real competitors are good products, too - although they do know that. It is just simply due to the fact that they know they have a job to do - to sell their own stuff. ${ }^{87}$

A view that would contribute to substantial conflict over comparative advertising during the 1960s and 1970s emerged for the first time during this period. This was the belief that any reference to competitors, even indirectly, should be considered synonymous with disparagement. Included in Joseph Appel's "Ten Commandments of Advertising" speech at the 1911 Associated Advertising Clubs of America (AACA) convention were the following relevant admonitions: "Thou shalt not covet, nor imitate, nor run down thy neighbor's business; thou shalt not covet, nor imitate, nor run down thy neighbor's name, nor fame, nor his wares, nor his trade-mark, nor anything that is thy neighbor's." ${ }^{88}$ One of modern advertising's most influential early practitioners, Appel, at the time, was advertising manager for John Wanamaker's department stores and president of the AACA's (forerunner of today's American Advertising Federation) retail advertisers' division.

George Washington Hill's explanation at the end of the period for the candy and confectioner industry's angry response to his Reach for a Lucky campaign also illustrates the view that merely mentioning competitors was synonymous with disparagement. "They call it 'unfair' and 'disparaging,' and they tell us that in mentioning sweets in our advertising we are doing an 'unethical' thing," Hill told Sales Management and Advertisers' Weekly. "They tell us it isn't right to speak disparagingly of others in one's advertising." $" 89$

\section{The 1930s to I950s}

Richard Pollay found that the use of implied comparative ads was a common tactic during this period, at $22 \%, 26 \%$, and $37 \%$ of his sample of magazine ads from the $1930 \mathrm{~s}, 1940 \mathrm{~s}$, and 1950s, respectively. ${ }^{90}$ Direct comparisons with identified competitors were used rarely in magazine ads of this period. However, prior historical research on comparative advertising and competition in advertising ${ }^{91}$ strongly suggests that many advertisers began ignoring Claude Hopkins's admonition- "Rule 1 in all salesmanship courses I have studied is: Never attack a competitor" - at the outset of the Great Depression. ${ }^{92}$

Responding to a request for examples of "fighting copy" or advertising that "makes direct or indirect statements regarding the merit of the advertiser's type of product as compared with other types that compete for the same market," Printers' Ink replied, 
A history of advertising would tell more war-stories than ever were swapped at a G.A.R. [Grand Army of the Republic, a U.S. civil war fraternal organization] encampment. In advertising space there have been wars over soap, wars over shoes, wars over automobiles, wars over tires, wars over gasoline, wars over most of the products that manufacturers produce and sell..$^{93}$

The term comparative advertising, in fact, appeared in the literature for the first time at the beginning of this period, as opposed to knocking, competitive advertising, or unselling. ${ }^{94}$

The period also produced what is widely considered to be a watershed example, both then and now-adman J. Sterling Getchell's "Look at All Three" for Plymouth. Author Julian L. Watkins devoted a chapter to this ad in his book, The One Hundred Greatest Advertisements: Who Wrote Them and What They Did. ${ }^{95}$ President of agency Cunningham \& Walsh Inc. Anthony Chevins referred to the ad as "what may be the grand-daddy of all specific comparative ads." 96 A follow-up ad published a few weeks after the original is shown in Figure 5 and clearly suggests its effectiveness.

\section{Direct Effects}

Cognitive outcomes. The belief that comparative advertising successfully attracts attention was mentioned frequently during this period. This view was summarized, and endorsed somewhat, by advertising pioneer Claude Hopkins:

My friend had Irish parents, while mine were Scotch. So, while we agree on the love of advertising, we do not always agree on policies. Jim rather loves a fight. . . . Jim says, "Do something out of the ordinary. Stir people up. A single prize fight brought more revenue than Romeo and Juliet since the day it was written." I follow him to some extent. ${ }^{97}$

Referring to comparative advertising by Ford auto dealers, Printers' Ink observed, "The advertising is being talked about, which means the Ford is being talked about, and that is something that Mr. Ford always encourages." 98 The description of a historically significant episode and comparative campaign some twenty-five years later also shows that it was believed to have created significant attention and recall, and Printers' Ink cited research to prove it. Appliance manufacturer Westinghouse's "Sand Test" was reported to have "turned up by accident" but was initially ignored by Westinghouse ad agency McCann-Erickson because it was deemed "too daring." 99

One of the first product demonstrations ever televised live, the sand test was conducted by actress and Westinghouse spokeswoman Betty Furness under the oversight of the New York Federation of Women's Clubs. It aired on September 24, 1957, during a broadcast of network CBS's "Studio One." Two cups of sand were added to the loads in a Westinghouse washer and those of three unidentified competitors (brands "X," "Y," and "Z"). At the end of the program, a white-glove inspection revealed that only the Westinghouse held no residual sand. Figures 6 and 7 show still images from the groundbreaking commercial and a print execution from the campaign, the latter featuring a Marine Corps sergeant, who performed the white-glove test. Printers' Ink 


\section{$\boldsymbol{H}$ 缼 ThANK, YOU, FOLKS} .... I thank you for comparing all three cars in the lowest-priced field"

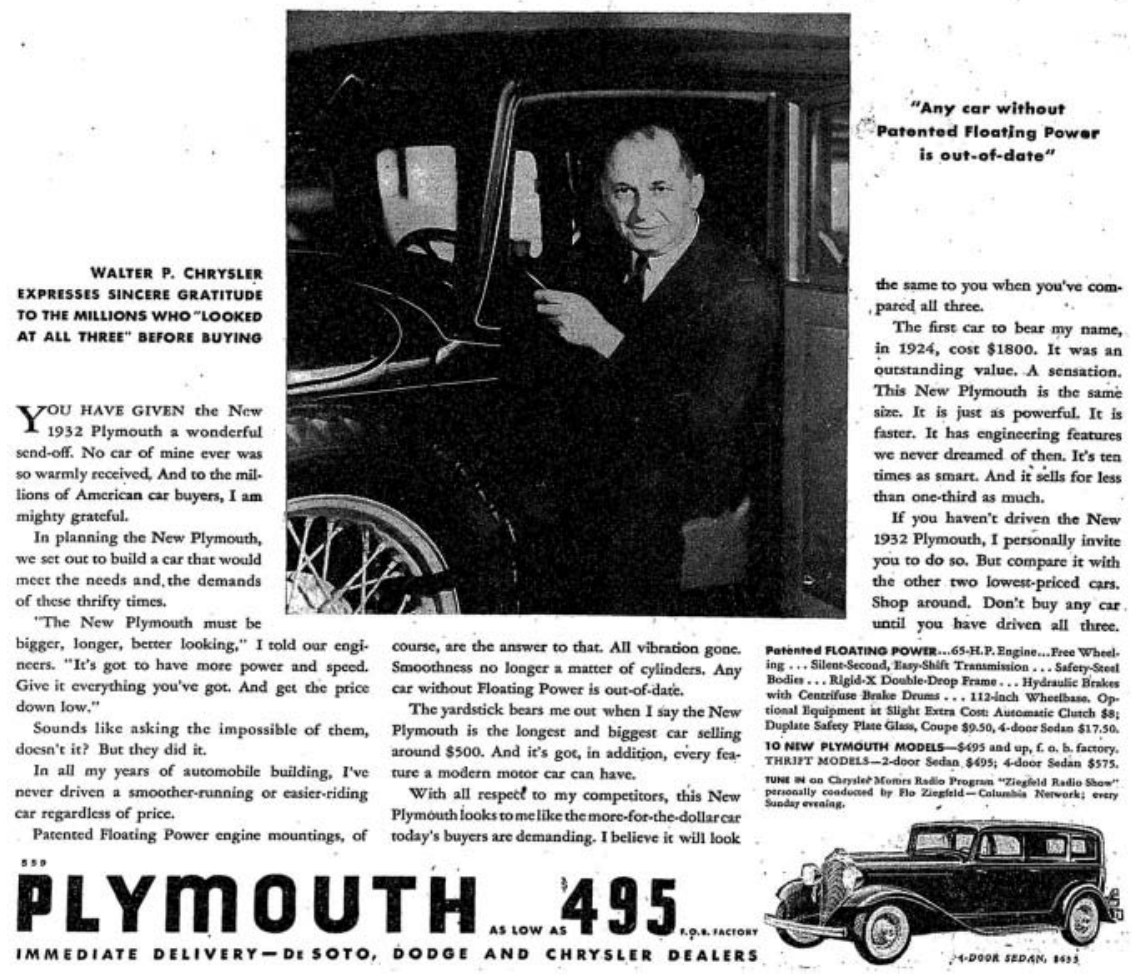

Figure 5. "Thank you, folks!"

Source: The Washington Post, April 24, 1932, 8. Plymouth is a registered trademark of Chrysler Group LLC.

associate editor Sarah Lee Gerrish reported that a second version of the sand testbroadcast live three weeks later because many viewers wrote to CBS, complaining that the first test must have been "rigged"-generated significant attention and recall: "Gallup-Robinson reported that it had an $88 \%$ recall response. No previous laundryequipment commercial rated by G-R had ever scored higher than 40\%."100 

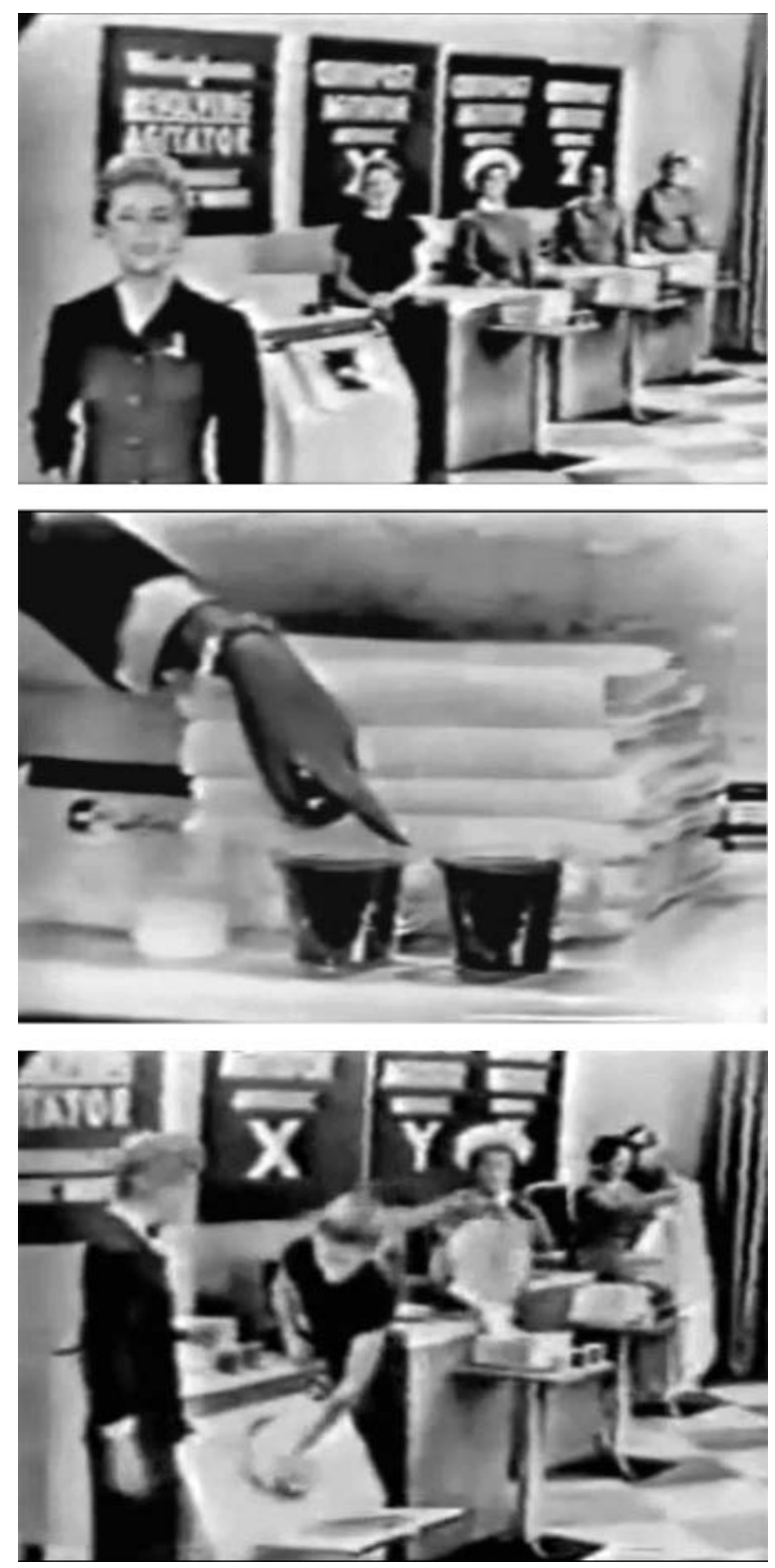

Figure 6. Westinghouse "Sand Test" (television).

Source: http://www.dailymotion.com. Westinghouse is a registered trademark of Westinghouse Electric Corporation. 


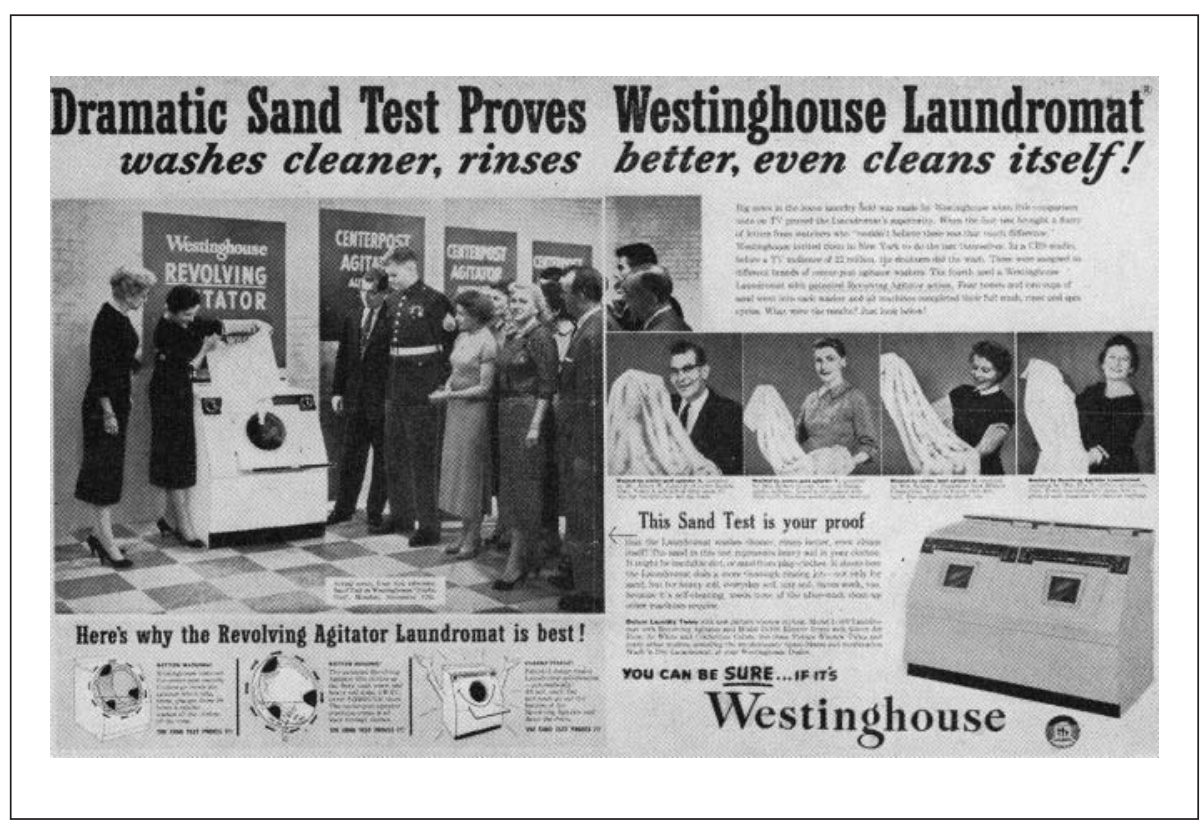

Figure 7. Westinghouse "Sand Test" (print).

Source: Printers' Ink, March 29, 1957, 57.

Some contributors on the topic of attention, while acknowledging that comparative advertising would likely encourage it, also questioned its value. As Claude Hopkins wrote in his critique of an attack on George Washington Hill by R. J. Reynolds on behalf of the company's Camel brand,

We agree that we must get attention. But we don't go out on the street and turn somersaults. We don't engage in a brawl. We don't wear a fool's cap, a great coat and red shoes. That is not the attention we want. ${ }^{101}$

Paul Hollister, publicity director for R. H. Macy \& Company, described his belief that the excessively belligerent comparative advertising of the early-1930s was motivated by the Depression-era desperation. Hollister also argued that the kind of attention comparative ads encouraged would contribute little to any legitimate advertising outcomes:

And in the past few years, those elders and betters of ours, the national advertisers, have been reaching for wider and heavier custard pies to throw at each other; they have filled the air with so much acrimony that they've come almost to believing themselves that they hate each other; they have wholly lost sight of the fact that the consumer - their consumer and oursfrankly doesn't give a whoop. . . . The public is well-bred; it may stop to watch a fight, but it will then go on about its business. ${ }^{102}$ 
The belief that comparative advertising creates awareness for the comparison product or service continued during this period and was held by a majority. One advertising agency executive made this point when describing a client who did not respond to comparative attacks with his own because he believed he was benefiting from them. As he wrote,

His first reaction was to make answer. But after gathering information on which to base his retort he came to the conclusion that to use it would be to repeat the error. His product, as he saw the situation, was being advertised by competitors. ${ }^{103}$

And as Aesop Glim—Printers' Ink columnist George Laflin Miller-warned comparative advertisers some seventeen years later, "In a left-handed way, you are inviting some of your prospects ... to look into your competitor's proposition." 104

At the outset of this period, many sources began expressing the belief that comparative advertising could be informative. In reference to an ongoing comparative advertising war among replacement tire manufacturers and merchandisers, Advertising \& Selling summarized this view:

It is probably true that Mr. Average Tire-Buyer is more interested — especially in this year of hard times - in price comparisons than he is in the word-sparring of the contestants. Consequently, this advertising may be selling him more tires simply because it is telling him more forcibly than ever before at how low a price tires can be bought. ${ }^{105}$

Responding to criticisms in the pages of Printers' Ink that its advertising implied that the advertising of other cigarette brands was false and misleading, The American Tobacco Co. took the position that such advertising performed an informative consumer service. In a letter to Eldridge Peterson, editor of Printers' Ink, American Tobacco president Paul M. Hahn argued the following:

In our opinion, an advertiser in a competitive business who makes statements of questionable validity in his advertising does, and should expect, to expose those statements to criticism by his competitors in the market place in which they are competing for public favor. We think that such criticism is healthy and in the interest of good advertising. ${ }^{106}$

Numerous sources during this period, however, expressed the concern that comparative advertising would cause not informed consumers but confused ones. This belief was summarized well by Charles Luckman, vice president and general manager of the Pepsodent Company:

We never attack the claims made for other brands because we don't believe a competitive fight benefits anyone. Only the executives of the companies involved understand what the fight is all about. The consumers not only don't understand but aren't interested. ${ }^{107}$

Trade journal Advertising \& Selling linked the problem with confusion, in a frontpage editorial, to the almost inevitable fact that comparative ads must present what appear to be conflicting claims: "Publication copy censors are throwing up their hands at the enormity of today's task of reconciling competing claims." 108 
Believability. The majority of advertisers and industry observers argued that comparative advertising was not believable, but this belief was consistently linked with a comparative advertising trend that occurred during this period, which also sparked a great deal of criticism - that of attacking competitors' advertising rather than the poor quality or other limitations of their products. The emergence of this trend was explained especially well by a Printers' Ink author, who linked the aggressive comparative advertising of the early Depression once again with bombast and ballyhoo and, equally important, challenged its ethicality. He lamented the trend in the following way:

Advertising began to overtake merit as a competitive factor. Copy became louder and, regrettably, funnier. The bass drums and tin horns of the Barnum era were heard in most unlikely quarters. Logically, the next step would have been open attack upon competitive products. But this was, by common consent, unethical. What to do? All those acres of bellowing type were neutralizing each other. Something had to be done about it.... So that's your solution, is it? Don't knock the other fellow's goods- knock his advertising! ${ }^{109}$

Advertising \& Selling criticized the trend with almost identical comments and likewise compared it with the professionally embarrassing advertising of the mid- to late1800s. "Once before advertising got a bit too intimate with Buncombe. Recall the Patent Medicine Era? . . . Running Buncombe a close second as a confidence-sapper is the current wave of advertising that knocks competitors." 110 As William B. Wisdom, advertising manager for the Union Indemnity Company, critically observed, "It is economically unsound to knock your competitor's advertising. . . . . What does it profit a man who convinces the whole world that his competitor's advertising is poor, if the public has forgotten that he has a product for sale?"111

A single source, advertising agency president S. O. Landry, expressed a favorable belief in the tactic of attacking a competitor's advertising. As he argued,

I believe in an advertiser expressing his personality and if he can do so by fighting the claims of his competitors skillfully and well, then more power to him. ... I do not see any reason to get alarmed because one manufacturer knocks the advertising of another. ${ }^{112}$

Sources during this period offered three significant insights into advertisers' beliefs regarding comparative advertising's believability. First, some linked the issue of believability with the presence of directly conflicting claims about competing products. As Advertising \& Selling editorialized,

If war will sell more goods than peace, why don't we all pitch at our nearest competitor? At first thought, it would seem that such ill nature displayed to public view might regale the consumer but would leave him in such a bewildered state of mind as not to know whom to believe-if anybody. ${ }^{113}$

In reference to an ongoing comparative advertising war among Ford, Chevrolet, and Plymouth automobile dealers, Printers' Ink concluded the following: "After reading the contradictory facts and figures, many a prospective automobile buyer must 
have decided to follow Ed Wynn's advice and buy a horse."114 Another Printers' Ink author stated the problem even more directly: "But when one party says one thing and the other states what seems to be a directly conflicting fact, the likely conclusion of the consumer is that one of the two is a liar-probably both."115

Writing metaphorically about an advertising "feud" between two paint companies, NBC network radio sales promotion manager Joseph A. Ecclestine summarized this view and strongly suggested that it continued throughout the period:

Asserting that you are the leader in your field is probably good for your ego-if your ego is the kind that requires such assertion. But I find it hard to overlook the fact that I'm not interested in your ego - only in mine. And that the next man is even less interested than I am. I also find myself suspecting that neither Hatfield nor McCoy is a leader in anything, but money or noise. ${ }^{116}$

A second theme having to do with the problem of believability was expressed by a broad majority of advertisers and industry observers, and this was the belief that comparative advertising threatened the believability of advertising for all the competitors in an industry or product category. A Printers' Ink author early in the period spoke for many with the following observation: "For you can't discredit the other fellow's advertising without discrediting your own. Old John J. Public's reaction is simple, obvious and reasonable. 'So I mustn't believe A's advertising, eh? Well, why should I believe B's, C's, or Z's?'”117 Advertising agency president Marsh K. Powers stated the problem even more directly:

The advertiser who is tempted to employ copy which slurs advertising should first ask himself this question - "If I warn readers that advertisers are prevaricators, why should they believe my statements, when, by the very act of using advertising, I class myself with the falsifiers and public enemies whom I criticize?"118

Media managers and publishers, often caught in the untenable position of arbitrating comparative advertising wars and facing the threat of lost business from angry advertisers, shared the concern about the long-term damage to entire product categories and industries. One publisher anonymously bemoaned the problem in the pages of Printers' Ink:

But far more important than either the publisher or the advertiser individually, is the adverse influence these copy discussions have on all advertising; the effect they have on undermining women's (and men's) confidence in the whole industry of which the participants are but a part. ${ }^{119}$

A third point of view, also shared by a significant majority, was that comparative advertising threatened the veracity of not just advertising in specific industries and product categories, but all advertising. Again, however, the belief was almost always associated directly with the period's tendency for advertisers to attack the truthfulness of competitors' advertising. As advertising man William Wisdom opined, comparing the damage caused by comparative advertising to that of the period's paid-testimonial scandal, 
Viewed from a purely ethical standpoint, such statements, claims and exposures as we read today shake the faithful public's faith in all advertising. The extravagant use of testimonials has dealt advertising one body blow. There is no use in aggravating the situation by an internecine struggle between advertisers. ${ }^{120}$

Edward L. Greene, general manager of the National Better Business Bureau (NBBB), also concisely summarized the beliefs of many with the following warning: "Can business complain of a lack of consumer confidence if it endorses and uses advertising which is a public record of competitive criticism - deliberately designed to shake public confidence in competitive business?"121 R. H. Macy \& Company executive Paul Hollister offered a similar criticism: "I believe that the public's confidence in all advertising is diluted, weakened, by the outrageous competitive wars that are being printed in national newspaper advertising." 122 This view is also apparent in statements from the Dallas Advertising League (DAL) nearly twenty years later. Concerned by what its members called an "attack by implication on the integrity of all advertising" in comparative advertising for Lucky Strikes, the group adopted a resolution calling on The American Tobacco Co. to discontinue the campaign. ${ }^{123}$

Many publishers and media managers shared the prevalent belief that comparative advertising was responsible for damage to the believability of advertising as an institution. Comments by Frank Braucher, vice president of The Crowell Publishing Company (publisher of widely read Collier's Weekly), help explain the concerns of the period's media executives. As he wrote,

Right now we are in the era of what is called "1931 Advertising." If 1931 advertising means what it appears to mean, it is highly competitive, high explosive advertising. The kind of advertising which it seems to me if carried to its logical conclusion will destroy the effectiveness of advertising media. It will destroy something that the advertiser needs, the agent must have and the publisher cannot under his present set-up exist without, namely the believability of advertising. ${ }^{124}$

A comparative advertising war among replacement auto tire manufacturers and merchandisers confirms that many newspaper and magazine executives were struggling to sustain the believability of advertising and the credibility of their publications using what advertisers of the day derisively referred to as "censorship." At the time, both Montgomery Ward \& Co. and Sears, Roebuck \& Co. often compared their private label tires with those of branded competitors, by name, taking advantage of the fact that they had complete control over the content of their own catalogs.

As president of the only major tire company that did not manufacture tires for the catalogers, Harvey Firestone counterattacked with newspaper ads calling for a "showdown" on the "misleading" claims of the "mail order houses" (see Figure 8). Despite not directly naming his mail-order foes, however, some newspapers refused Firestone's ads. As Business Week reported at the time, "Mr. Firestone has had considerable difficulty in having his comparative advertising published. Some publishers accepted it 'because others did,' some carried it under protest. The Chicago Tribune and the New York Daily News refused it." 25 


\section{Let's have a SHOWDOWN} on this matter of

\section{TIRE COMPARISONS}

$\mathbf{V T}_{\mathrm{ITH}}$ all the conflicting elaims pablished about tires, it is obvieus that misleading statements are being made. The oaly coneluaion that you as a tire bayer can draw is that either we, as Firestone Desiers, are misrepresenting Firestone products, oe that a cerrain mail order howe is not lelling the

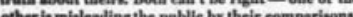
cher io malea.ling the publie by heir comparisons.

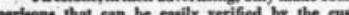

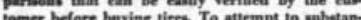

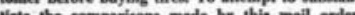
viste the comparisom and enploy experts

employ experts. The very reasea that the comparions made

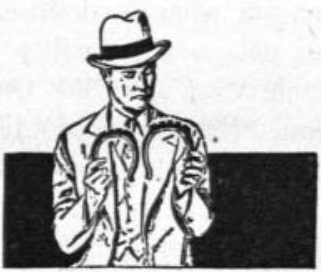

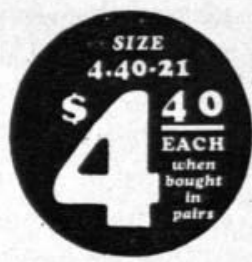

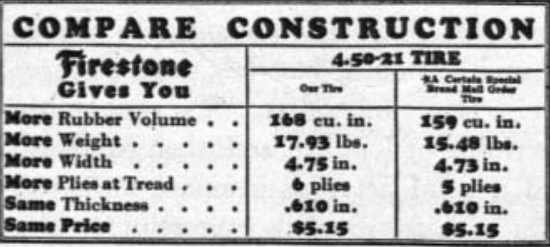

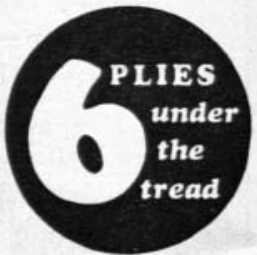

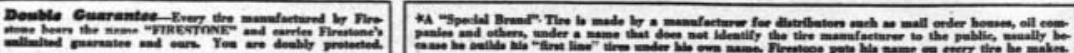

\section{COMPARE PRICES}

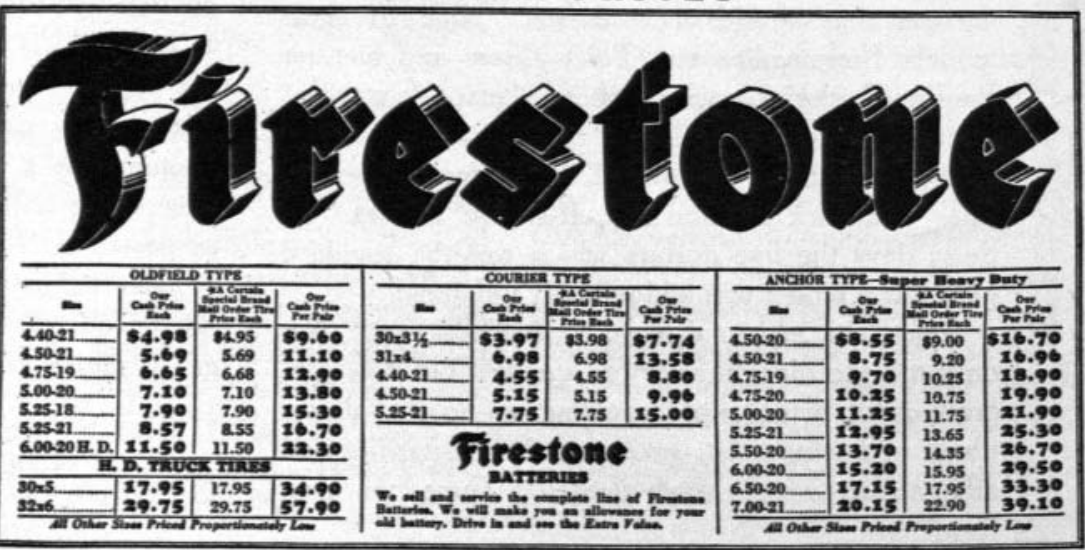

Figure 8. "Let's have a showdown."

Source: Advertising \& Selling, June 10, 1931, 21. Firestone is a registered trademark of Bridgestone Brands, LLC. 
Affective outcomes. A majority during this period expressed the belief that comparative advertising encouraged negative attitudes toward the ads themselves. Ralph Starr Butler, vice president of the General Foods Corporation and author of the first marketing textbook, captured this belief when he wrote the following:

Leaving out entirely the question of business ethics, this sort of competitive advertising will not pay ... Prolongation of it and more accessions to the ranks of its users may easily result in public disgust with advertising as a business tool. ${ }^{126}$

Butler also warned that continued use of the tactic could encourage the period's many calls to bring advertising under further regulatory control by the federal government. Claude Hopkins also warned that comparative ads would encourage dislike:

Nobody has grown more weary of the waste, the ineffectiveness, the palaver in cigarette advertising. But I believe that people are sick of wars, political and commercial. And I cannot imagine the throwing up of hats at an avalanche of brick-bats. ${ }^{127}$

The statements of some advertisers and industry observers offer helpful insights into what it was about comparative advertising that they believed contributed to negative consumer attitudes toward it. Numerous sources throughout the latter half of this period pointed to two related causes for negative attitudes - the perception that comparative advertising is excessively competitive and, consequently, in poor taste. As one Printers' Ink author noted, "Internal wars in advertising come and go but all the time a greater Taboo has arisen - the public's Taboo on bad taste in advertising." 128 This view was summarized perfectly by Printers' Ink columnist Aesop Glim: "Next, you must recognize that some of your prospects have a certain peculiar sense of taste that makes them reject all competitive selling." 129

Advertising attorney Morton J. Simon similarly captured this view in an Advertising Agency piece about the legal implications of what he referred to as "acrimonious advertising warfare" and disparagement: "Someone has said: 'I hate the man who builds his name, On the ruins of another's fame." "130 J. Walter Thompson executive Joseph Stone also linked dislike of comparative advertising to its excessive competitiveness and called for advertisers to avoid it. As he argued,

The coming months may see all the old high-pressure methods dusted off. They may see slants that not only hurt advertisers but undermine the standing of their whole industry. But those companies who move forward and those industries which raise their standards of advertising while others are raising a rumpus will find themselves ahead. But whatever we do, let's drop that tired bromide- - "competitive."131

Another interesting and important facet of the negative attitudes theme to emerge from the data has to do with the attitudes of channel members toward comparative manufacturer advertising. Comparative advertisers who also relied on distributors and retailers discovered the same problem George Washington Hill had in 1928. In some cases, channel members sold both the comparative advertiser's product and 
the competitor's. One advertiser described this problem with channel members, telling Printers' Ink what he decided to do about it. As he reported,

Some of them actually asked us to stop our national advertising. They said it was hurting their business as a whole more than it was enlarging it in our lines. Accordingly, in the second year of our campaign, we threw out all comparison and began to confine ourselves to direct statement of what our material would do. Complaints from distributors, retailers and outside sources naturally came to an end. ${ }^{132}$

A majority during this period also expressed the view that comparative advertising causes negative attitudes toward the advertiser's brand. And as during the previous period, some identified the cause of these negative attitudes as backlash. As Printers' Ink warned, "Rather often, 'fighting copy' back-fires. . . . Too often it besmirches the name and the long-pull reputation of him who uses it." 133 And as Aesop Glim similarly declared, "Competitive copy admits that you have some competition and that you are afraid of that competition; otherwise, you wouldn't be mentioning it."134

The belief that comparative advertising would specifically cause a backlash of negative attitudes toward comparative advertisers and their products or brands among the users of the comparison product was also mentioned for the first time during this period. Printers' Ink Monthly summarized this view:

Frequently it is difficult for a seller of quality merchandise to say all he knows he should say about his product without being tempted to make disparaging remarks about competition. But he realizes that his own case may be weakened if he yields to the temptation. He may succeed only in starting an unprofitable argument. And if his prospective customer has already bought, or even decided to buy an alternative product, he will be inclined to resent any sales talk that may prove to him that his judgment was wrong. Such is human nature. ${ }^{135}$

Aesop Glim stated this point of view even more directly: "If we imply that our prospect is a fool to be using some competitor's wares when he could be enjoying the unique benefits of our wares, we have undoubtedly overplayed our hand."136

Conative outcomes. Only a few sources during this period mentioned the effectiveness of comparative advertising for directly achieving sales or other behavioral outcomes. As mentioned earlier, many tobacco industry observers confirmed the sales effectiveness of the Reach for a Lucky campaign. As Printers' Ink reported, “That competing interests have sometimes opposed the publicity methods of American Tobacco merely reflects the effectiveness of the campaigns." 137 Referring to Westinghouse's sand test campaign, Jack D. Lee, manager of Westinghouse's laundry-equipment division, similarly praised the sales effectiveness of his advertising: "There's no doubt the sand test has produced more direct sales for us than anything we've ever tried."138

On the other hand, Kenyon \& Eckhardt executive William Green refuted the sales effectiveness of comparative advertising with his colorful description of a discussion of the topic between a sales manager and advertising manager: 
And every other week a certain sales manager was tearing out his hair at the latest competitive ad. "Ye gods," he'd yell on these occasions to his advertising men. "We gotta get an ad out quick to refute this. These guys are going to ruin us with their claims." . . But one day he'd (the advertising man) had enough. "Do you think," he asked, "that this competitive stuff is serious?" The sales manager did. "How are sales?" the adman asked. "Holding up pretty well." "I'll tell you something," the adman ventured, with an unusual show of bravado. "If your prospects paid $10 \%$ as much attention to those competitive claims as you do, you'd really be in a bad way. Right?" There was a labored silence. "Let's see that new layout you just brought over," said the sales manager. "And I hope it calls attention to our equipment rather than our competitor's." 139

\section{Situational Factors}

Nature of the claim. During this period, many critics of comparative advertising linked its undesirability to the likelihood that such advertising would fail to mention a salient claim on behalf of the advertiser. Most associated it with the period's tendency for advertisers to attack each other's advertising. Adman William Wisdom summarized this view in the following way:

In drawing attention to his competitor's advertising he is keeping the competitive product before their eyes and omitting to tell them how good his product is and what makes it good. ... If you and I go out to shoot rabbits and start shooting at each other, we are not going to get many rabbits. ${ }^{140}$

Aesop Glim also argued the importance of a salient benefit:

Quite obviously, the only effective comparisons will be those which are somehow constructive and helpful to our prospect. The comparisons must tell him something he didn't know - give him information by which he can benefit — and do it in a manner which earns belief. ${ }^{141}$

As Claude Hopkins wrote in his criticism of a counterattack on George Washington Hill by R. J. Reynolds on behalf of the Camel brand,

Certainly there is some genius who can bring cigarettes into a flattering limelight. Just as others have done on countless lines which have a hearthold in the home. Not by sheer force, not by attack. Not by any evidence of internal disagreements. But by a theme which leads on the tide of popular favor which cigarettes since the war have happily engendered. ${ }^{142}$

Other contributors confirmed that comparative advertising was appropriate and likely to be effective when the product possessed a true feature of superiority, often based on superior quality, and linked to its believability via substantiation. The American Tobacco Co. argued this point in the pages of Printers' Ink, while defending what was viewed by many to be an overly aggressive comparative campaign: "It's 
certainly human nature - and no breach of ethics - for one to say he is better than the other fellow, and why; especially when he feels he has conclusive proof and states it." 143 Westinghouse executive Jack D. Lee similarly praised the sand test campaign, linking it to the selling of product features and benefits: "There has been a lot of talk in the industry recently about the need to return to selling the product and to abandon price selling. We think the sand test is a prime example of selling the product. To those who criticize us and charge us with unfair tactics, we say, "You can't sell Heaven if you don't knock Hell."144

Others pointed to subtle shading of the truth as a contributing factor to what they perceived to be a frequent problem with the claims in comparative ads. As Printers' Ink editorialized,

Ironically enough, some of the most viciously offensive competitive copy is wholly true, judged by the strict letter of the law. But it often takes advantage of a technicality - accurately stated, too - in a way that puts the rival product under an undeserved and unfair handicap. This violation of advertising ethics is as bad as plain and unadulterated lying. ${ }^{145}$

Ads are more creative. Despite the prevalent and aggressive use of comparative advertising during the Depression and its frequent discussion, sources proposed only two tactical recommendations for the effective execution of comparative advertising. First, in Printers' Ink's description of a comparative advertising war between Chicago's Peoples Gas Light \& Coke Company and the Chicago Coal Merchants Association, the journal described the use of

an entirely new weapon of advertising combat - the reverse testimonial. The term is arbitrary_perhaps "non-testimonial" would be a good name. It designates a testimonial quotation of a consumer letter which proclaims, not eulogy of the advertiser's own products, but contempt of the competing one. ${ }^{146}$

Aesop Glim offered the period's only other tactical recommendation for executing a comparative ad. As he instructed,

In essence, you're going to say. "Ordinary widgets have these weaknesses." Say that, get completely through with all the details of that subject, before you go on to say, "By contrast, Schmaltz' Widgets are thus and thus." Don't say, "Schmaltz' Widgets are thus and sowhereas ordinary widgets have these weaknesses." You want your prospect to come to the end of your story with a strong, positive conviction regarding your wares. . . Work from the negative to the positive-never from the positive to the negative. ${ }^{147}$

An important theme to emerge from the data during this period in terms of a comparative ad's creativity is best defined as “opportunism." Moreover, often the advertising of competitors was the source of these opportunities. As the dispute over the comparative strength of all-steel versus wood-and-steel auto bodies heated up, for example, Chevrolet ran the ad shown in Figure 9, declaring that "if your elephant wants to ride on top, it's all right with a Chevrolet." A group of Houston, Texas, Ford 


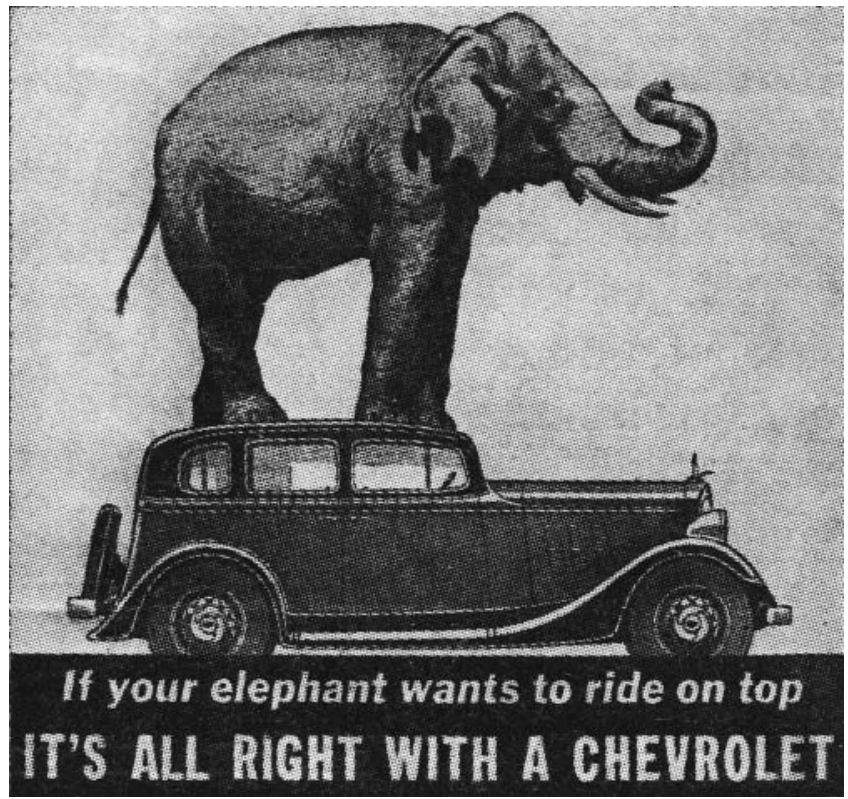

Figure 9. "If your elephant wants to ride on top." Source: Advertising \& Selling, September 14, 1933, 48. Chevrolet is a registered trademark of General Motors LLC.

dealers exploited the opportunity with the tongue-in-cheek response shown in Figure 10, offering a $\$ 500$ reward to anyone who would take an elephant for a ride on his or her Chevrolet. ${ }^{148}$

However, another almost concurrent episode demonstrated that opportunism is a knife that can cut both ways. Both Chevrolet and the Chrysler Corporation were quick to take comparative advertising advantage of Henry Ford's refusal to sign on to President Franklin D. Roosevelt's National Industrial Recovery Act (NRA) automobile code. The code mandated, among other things, specific levels of production, wages, hours of work, and prices. In reference to the NRA's distinctive Blue Eagle symbol, Ford is reported to have said, "Hell, that Roosevelt buzzard. I wouldn't put it on the car." 149 Two years later, the U.S. Supreme Court ruled that the entire NRA was unconstitutional.

Degree of negativity. The majority of sources during this period criticized excessively negative comparative advertising. Claude Hopkins summarized this belief with his criticism of R. J. Reynolds's attack on George Washington Hill. In a full-page, all-copy ad in national newspapers, R. J. Reynolds criticized Hill (referred to throughout the copy 

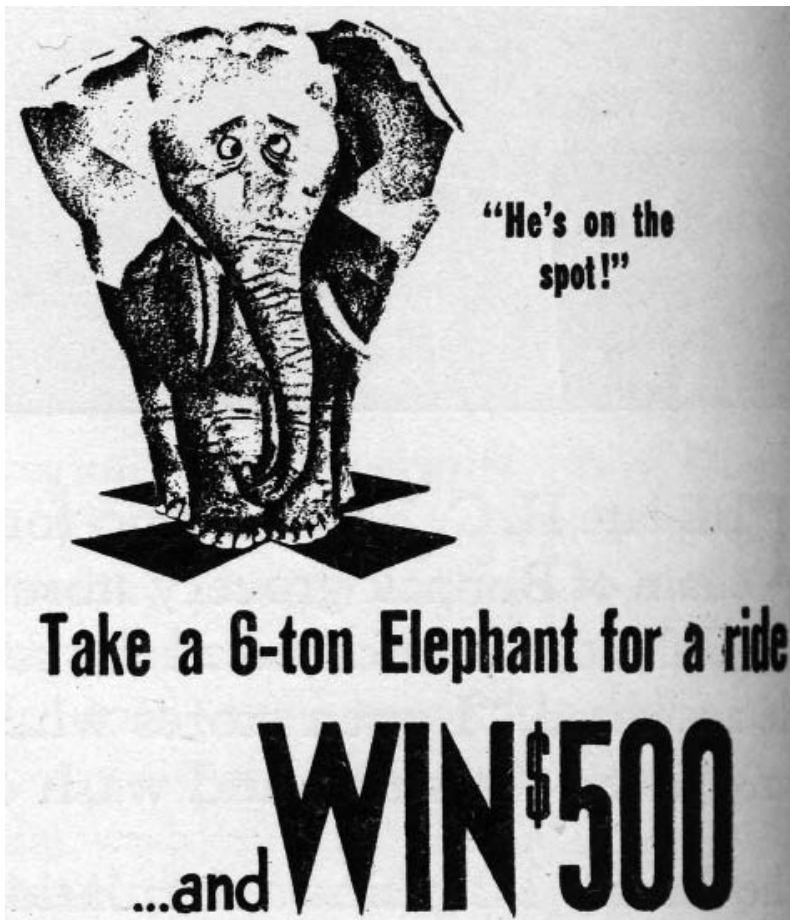

Manufacturers of a six eglinder car in a reeent newa. paper advertisement invile you to "take your elephant for a ride on top of their car."

who will take a atock modeh, put as elephast at is top and drive an wach an 100 feet, $\operatorname{wrmotT}$ is JURY TO THE CAR.

If you happen to have a litile 6-ten elephant in your home, put him on top of your ......... ear (if you have one) and let him enjoy a ride-li woa's hurt the car because they state clearly in thio adven. tisement.

$$
\begin{aligned}
& \text { "It is rigid enough, and strone } \\
& \text { enough to oupport } 6 \text { tons of elephant." }
\end{aligned}
$$

Thlo offer lo opes to ang orset of the dis gylater In Teas. The ear mint be a mpiler mol we withed extre braelag or otherwiles changed and the ovan if the ear must drtve.

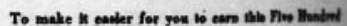

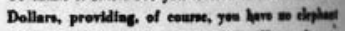
of your oms, wo are laformed that llokintoot ins "Nellie," the pride of Bernana Rark, wetdo onme

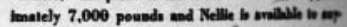

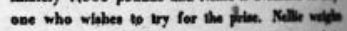

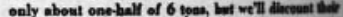
otatement 50\% and pey angese 8500.00 wh we

Now they wouldn't make this statement unles they had proven the fact-tried it out-and what has bees done once can be done again. The Houston Braseb Authorized Ford Dealers, knowing that elephasto sel. dom aet the thrill of riding alop in automoblle, are curious to see thlo unusual slabt and will pay Flve

Hundred Dollare to any owner of this six eylinder ear

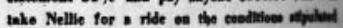
abore.

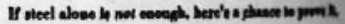

\section{HOUSTON BRANCH AUTHORIZED FORD DEALERS

Figure 10. "Take a 6-ton Elephant for a ride."

Source: Advertising \& Selling, September 14, 1933, 48. Ford is a registered trademark of Ford Motor Company. 
as "he") for making false statements in his advertising, and further publicized the fact that he had recently been ordered by the FTC to cease using false testimonials from nonsmokers, claiming that they kept slender by smoking Luckies. As Hopkins wrote,

Some methods strike a responsive chord which lead to overwhelming favor. Some arouse dislike. I hope that George Hill will not take up the gauntlet Camel has laid. I think that a shiver went over all of us when we read that page attack. ${ }^{150}$

At about the same time, some note of what many practitioners believed caused comparative ads to be viewed as excessively negative and problematic began to appear among the sources. American Association of Advertising Agencies (AAAA) president Joel Benton declared, in a speech to the feuding members of the National Tire Dealers' Association, that comparative ads should not include false statements about competitors' products, that they should not promote the advertiser's product by attributing faults to an entire industry that were true of only a few members, and that they should not attack a competitor's advertising. More important, however, was Benton's first admonition: "In the first place," he said, "no competing product should be named or referred to by name in any derogatory way." 151 Federal Advertising Agency president Robert Tinsman similarly implored his contemporaries: "Advertising is on trial, like it or not.... It must stop being offensively mean, and come clean, regardless of competitive attitudes. Let us resume the dignity that advertising almost won for itself after years of struggle." 152

The sole exception to appear in the literature of this period linked his favorable view of aggressively comparative advertising to the belief that it was competitively persuasive. Once again, it was adman S. O. Landry, who argued the following:

Business is a fight and advertising is a part of the fight. ... If the advertising agency, or the advertising man, tones down all his messages to the public; if he cuts out all the strong talk, deletes all the ideas and takes every thought out of it except the few platitudes and generalities that anybody can use, then I think his advertising is becoming weak. ${ }^{153}$

Perhaps as a consequence of the desperate and "viciously offensive" comparative advertising of the 1930s, some sources began to point out the importance of limiting the negativity or, better yet, avoiding it all together. Arguing that excessively negative comparative advertising wars often made advertisers look foolish, Printers' Ink proposed,

If advertisers must fight in print, and if they must incur the risk of being unconsciously comical, why in the name of common sense don't they obviate that risk by anticipating and disarming the chuckles with at least a glint of humor in the copy, itself?'154

Much later in the period, advertising executive and marketing textbook author Edward E. B. Weiss similarly referred to the importance of maintaining a positive 
tone, and avoiding the appearance of excessive negativity, with good sportsmanship. As he wrote,

Now it strikes me that the American public has given abundant evidence of our love of good sportsmanship. It was this national characteristic that helped make Plymouth's Look at All Three such an instantaneous success. Competitive rivalry, until then, had publicly displayed little sportsmanship. ${ }^{155}$

Trade journal Domestic Engineering elaborated on this preference in favor of positivity:

Whether it be the politician, smiling pleasantly and chucking babies under the chin, the salesman making his approach at the front door, or a merchandising message in print, the art of persuasion demands almost without exception that the thing which is offered be offered in pleasant associations. This is another way of saying that constructive selling is more effective than destructive selling. 156

Lord \& Thomas executive Robert L. Philippi similarly proposed,

When you run into a product which seems to have no exclusive, logical story (and the inclination is to resort to hog-calling) why not take a tip from radio? Use the advertising pages to entertain, instruct, or otherwise divert the reader-with a couple of sales messages and a reasonable amount of product identity thrown in?157

Significant insight into this theme is evident in Printer's Ink Monthly's praise of the humorous approach shown in Figure 11's comparative ad for a home heating company: "The sting was removed by means of jocular treatment in the text and cartoon illustrations that could hardly help leaving the reader in good humor."158

\section{The 1960s to 1970s}

Similar to earlier decades, Richard Pollay found that the use of implied comparisons of competitive standing remained about the same in magazine advertising during the 1960s and 1970s. However, while the frequency of use of explicit comparative ads remained small, it nearly doubled during these two decades to $3 \%$ and $4 \%$, respectively. ${ }^{159}$ Other sources, moreover, establish beyond question that the use of explicit comparative advertising soared during this period, as did Printers' Ink in a "Commentary" piece, published in 1966. As the journal reported, "Some admen call it 'disparagement,' others object that this word is neither adequate nor accurate. Whatever it is it's spreading like soot and it seems to have caught the conscience of the advertising industry with its definitions down." 160

The early-1960s also saw a comparative advertising campaign and ensuing war that many believe established the modern era of comparative advertising-Avis Inc. versus Hertz Corporation. ${ }^{161}$ The groundbreaking Avis "We Try Harder" campaignwhich continued as a central theme of Avis advertising until 2012 - placed 10th on 


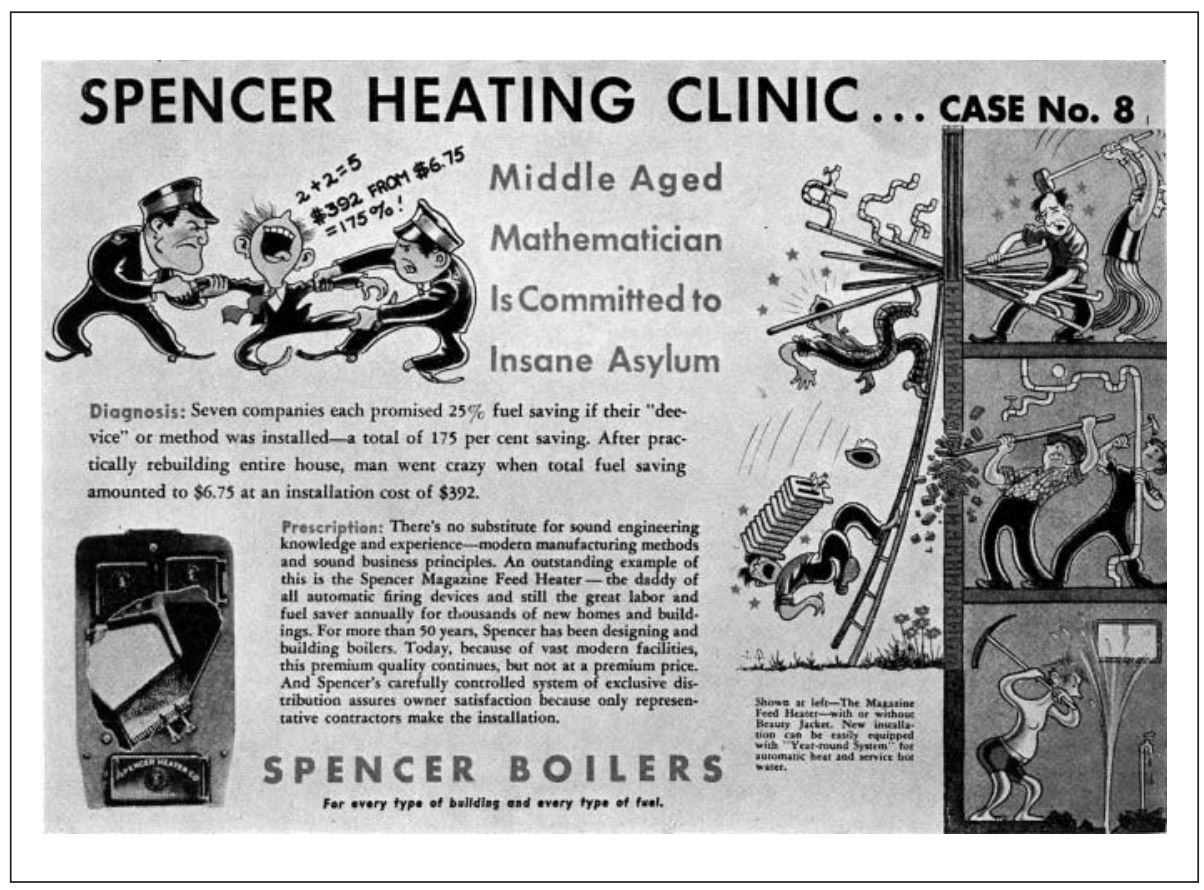

Figure I I. "Spencer Heating Clinic."

Source: Printers' Ink Monthly, November, 194I, 22.

Ad Age's list of the top 100 campaigns of the twentieth century. ${ }^{162}$ Although Hertz declined to counterattack for several years, and the company's initial rejection of this strategy led to an advertising agency change, they ultimately did with the following copy: "For years, Avis has been telling you Hertz is No. 1. Now we're going to tell you "why.",

Throughout the mid-1960s and early-1970s, national advertisers were increasingly naming names. Indeed, Advertising Age columnist Sidney A. Diamond declared toward the end of this period that "Brand X now is just a historical curiosity."163 Much of the discussion in the trade literature about comparative advertising throughout the 1970 s focused on the television networks and their affiliates. The reason is that the networks' policies had previously prohibited comparative ads, with the exception of NBC, which changed its clearance policy in 1965 and began accepting "substantiated comparative ads." In fact, the effectiveness of the networks' clearance policies, combined with the National Association of Broadcasters (NAB) Television Code, likely explains why many have thought comparative advertising was "illegal" in the United States. The entire network spectrum opened up, however, in late-1971 and early-1972 when the FTC persuaded networks $\mathrm{ABC}$ and $\mathrm{CBS}$ to give comparative advertising a one-year trial. 
The FTC's campaign to encourage comparative advertising - inspired by the period's political, economic, and regulatory philosophy of deregulation, ${ }^{164}$ and based on the belief that it would lead to more informative and less misleading advertising - led to a flood of comparative ads in the broadcast media. It also brought the federal agency into direct confrontation with the advertising industry. Although advertisers clearly wanted to identify competitors, they also hoped to maintain greater requirements for substantiation for what they often viewed to be questionably valid comparisons and, especially, limits on disparagement.

The FTC's investigation and subsequent campaign of litigation in support of comparative advertising was extensive. The agency proposed new rules to keep professional groups and state agencies from restricting competitive advertising for drugs, funeral services, and eyeglasses. It also called for the elimination of strictures on disparagement established by associations in industries as varied as liquor, beer, toys, air conditioners, soaps, seat belts, and savings and loans. More important, the FTC's campaign targeted both the Council of Better Business Bureaus' (CBBB) rule that advertisers could not refer to a competitor by name when reporting comparative test data and the NAB's ban on comparative superiority claims in toy advertising. ${ }^{165}$

Despite the advertising industry's and the networks' hopes and efforts to retain control over comparative advertising by way of their own self-regulatory bodies (e.g., the National Advertising Division of the CBBB), industry association codes, and media clearance policies, they were ultimately forced to acquiesce to the power of the FTC. This turbulent period for those involved in the regulatory battle over comparative advertising ended on August 13, 1979, when the FTC published a restatement of its comparative advertising policy. The agency's intent was to make it clear once and for all that industry codes prohibiting disparagement would be "subject to challenge" and that codes requiring a higher standard of substantiation for comparative ads and claims were "inappropriate and should be revised."166

\section{Direct Effects}

Cognitive outcomes. During this period, advertisers overwhelmingly agreed that comparative advertising attracts attention and creates awareness. The marketer of a new brand of antacid that identified competitors Alka-Seltzer and Bromo Seltzer in its ads made it clear the attention value was due to the still-unusual nature of identifying a competitor. As Brioschi company president Marco Brizzolara told Sales Management, "Actually saying 'Alka-Seltzer' in the new ad has shock value - capturing the attention of the consumer. And that is the whole secret of advertising." 167 This belief is also evident in a piece about the Cola Wars. As an Advertising Age author reported, "Privately, Pepsi officials say they never liked knocking Coke, but when they learned it gave them some recognition they had failed to attract by other techniques, they felt obligated to use comparative advertising." 168

Advertisers during this period, in the main, also expressed the belief that comparative advertising could be informative. William D. Tyler-who held major creative posts at agencies Young \& Rubicam, Dancer Fitzgerald Sample, Leo Burnett agency, 
and Benton \& Bowles - summarized this view: "It is not only a powerful selling tool, it can provide consumers with valuable buying information, something our critics say there is precious little of in advertising today." 169 One of comparative advertising's most devoted advocates during this period, Stanley Tannenbaum, chairman of agency Kenyon \& Eckhardt, Inc., also seemed to speak for many when he wrote,

It makes the consumer more conscious of his responsibility to himself to compare before he buys.... I say that comparative advertising — naming names in a case like this —is performing a consumer service and doing what advertising should do: provide useful information and promote better product development. ${ }^{170}$

However, the belief that comparative advertising creates awareness for the comparison product or service was also prevalent during this period. As several import and domestic automakers made the increasingly popular Volkswagen Beetle the target of their comparative ads, an unidentified executive at agency Doyle Dane Bernbach clearly captured this point of view in his comments to Advertising Age: "Every time somebody uses Volkswagen to make a comparison, it's space we don't have to pay for." 171 Wayne K. Nelson, head of McNeil Laboratories' consumer products unit, and in reference to the controversial comparative price introduction of Bristol-Myers's Datril pain reliever, told Advertising Age that "the ads have had the effect of acquainting consumers with Tylenol as well as Datril." 172 However, it is also important to note that the Datril versus Tylenol episode was unique because Tylenol, despite holding $10 \%$ of the analgesic market at the time, had never been advertised directly to consumers. As one source proposed, with regard to the campaign, "Not only was a price comparison on national television highly unusual, but the naming of a competitor that had never been advertised to the general public was even more startling."173

Similarly, Ogilvy \& Mather (O\&M) chairman Andrew Kershaw, unquestionably the industry's single most vocal critic of comparative advertising during this period, summarized this view, which he based on a widely cited proprietary O\&M study:

Comparative television advertising does not offer any advantage to the package goods advertiser. It does not increase brand identification. It makes consumers more aware of competitors. It results in lower belief in claims. It results in increased miscommunication and confusion. ${ }^{174}$

Despite the surging use of comparative advertising during this period, or possibly because of it, many advertisers and media executives agreed with Kershaw that it frequently caused confusion. As the television networks struggled to manage the flood of comparative ads in the 1970s, CBS's director of commercial clearance, Jack Hinton, succinctly stated this belief: "CBS feels that comparative advertising is not always making for a better informed consumer, but is more often creating a confused consumer." 175 The concerns of the U.S. Food and Drug Administration (FDA), stated in a letter to the chairman of analgesic marketer Sterling Drugs, also captured this view and suggested an explanation for it. The comparative advertising war between Tylenol marketer Johnson \& Johnson's McNeil Laboratories (e.g., "Why doctors recommend 
Tylenol more than all leading aspirin brands combined.") and Bayer Aspirin marketer Sterling Drugs (e.g., "Makers of Tylenol, shame on you!") became so vicious, the FDA told Sterling Drugs that commissioner Donald Kennedy believed the ads were "causing confusion that will ultimately result in erosion of public confidence in selfmedication products." 176

But this view was not the only one to find expression in this period. The belief that comparative advertising causes confusion was refuted by Tannenbaum, and based on the rationale that consumers are smart. As he argued,

So, for the dwindling minority who would have us believe - in their sincere but nonetheless mistaken conviction - that comparative advertising confuses the consumer and undermines his confidence in all advertising, may I quote David Ogilvy: "Never underestimate the intelligence of the consumer. She is your wife."177

Believability. The three dimensions of disbelief - that comparative ads themselves are not believable, that they cause consumers to question the believability of all advertising in a product category, and that they call into question the veracity of advertising as an institution-were all evident during this period. Although there were clearly a growing number of comparative advertising advocates, by far the majority who expressed their beliefs in print argued that the ads were not believable. Father of motivation research Ernest Dichter, in a speech to the members of the Chicago Chapter of the American Marketing Association, argued that comparative advertising was not believable for the same reason many of his contemporaries did during the prior period - the problem with conflicting claims. Dichter, however, also linked the problem with believability to increasingly exaggerated competitive claims in ongoing advertising wars. As Dichter explained,

You cannot advertise for 40 or 50 years, and conduct comparisons, without arousing suspicion in the consumer and bringing about a reaction comparable to a plague on both your houses. The more confusing and vicious the mutual attacks become, the more the respondent comes to the conclusion that he had better rely on his own judgment and not on what he is being told in the ad. ${ }^{178}$

Even the period's most vocal comparative advertising advocate, Kenyon \& Eckhardt's Tannenbaum, was forced to admit there might occasionally be a problem with believability. As he wrote, "Even when true and valid, if the comparison is drastically inconsistent with consumer beliefs, we risk the loss of credibility." 179

However, a small minority agreed with Tannenbaum that comparative advertising encourages believability. After describing the industry "laws, codes and customs" that had previously and successfully discouraged explicit comparative advertising, Printers' Ink observed, in a lengthy article published in 1966, that these assumptions "failed to anticipate a new middle-ground ethic which holds that name-naming within limits is not only proper, but realistic and refreshing." 180 Moreover, the journal cited Murray Valenstein, copresident of agency Leber Katz Paccione, regarding 
a comparative campaign he was responsible for on behalf of Hudson's Bay scotch. As he explained,

What we've done ... is to recreate the same situation which faces the customer when he walks into a package store - the various competing brands lined up on the shelf. . . People have become sophisticated beyond "Brand X."181

The point of view that comparative advertising causes disbelief for the advertising of all competitors in a product or service category was prevalent during this period. As many advertisers did during the previous period, the majority linked this problem with disbelief to comparative advertising that challenged the believability of one or more competitors' ads. Critical of a Sears Roebuck and Co. campaign that warned consumers not to be "bamboozled" by the prices in their competitors' advertising, Printers' Ink conjectured,

The question does arise whether this creates the impression that all manufacturers' suggested prices are either artificially high or phony. . . What's more, by declaring itself the saint among the sinners, doesn't Sears sow doubt as to the probability or possibility of its own regular prices being inflated? ${ }^{182}$

Influential advertising man Fairfax Cone-a protégé of advertising pioneer Albert Lasker and cofounder of agency Foote, Cone and Belding - also came out publicly against his contemporaries' more frequent use of comparative advertising. Moreover, he was especially critical of the exaggerated claims that so often seemed to characterize it. In a speech to the Chicago Chapter of the Public Relations Society of America, Cone warned,

The misuse and abuse of advertising is bad for all business. For one thing, it is only a matter of time, if exaggerated competitive claims continue to be hurled by scores of rivals in business, before none will have any effect at all on any but the small unthinking part of our public. ${ }^{183}$

Many of those involved with the advertising industry's self-regulatory groups, media executives, and advertisers, in the main, agreed that comparative advertising damaged the institutional veracity of advertising. Here again, some critics linked their concerns to advertising that included comparative claims of questionable validity. William H. Tankersley, then president of the CBBB, told the Economic Club of Chicago that not only had six years of comparative advertising on network television produced few consumer benefits, but also "the plethora of such ads has further damaged the credibility of advertising with equal negative effect on the mores of civilized business behavior." 184 Furthermore, he made it clear that ongoing advertising wars and the potential for increasingly misleading claims were major causes of the problem. As he explained to Advertising Age,

Allowing advertisers injured by unfair comparisons to respond through "counter advertising," as he said one ex-FTC commissioner has suggested, is an example of "jungle morality, paying lip service to competition, but placing an impossible burden on both consumers and business." 185 
Kenneth B. Wilson, president of the NBBB, also captured the view of those who criticized comparative campaigns that escalated into conflicting claims of questionable validity. As he argued, 'Exaggeration by one 'knocking' advertiser leads to further exaggeration by his competitors and eventually to outright misrepresentation. In the ensuing welter of conflicting claims, reader confidence in all advertising is damaged."'186

The next year, the release of a 1966 AAAA policy statement condemning comparative advertising that "untruthfully or unfairly depicts or disparages competitive products or services" received front-page attention in Advertising Age. ${ }^{187}$ The journal reported that the AAAA statement was a result of months of pleas for comparative advertising reform from the NAB's code authority, the NBBB, the Advertising Federation of America, and several other industry groups. As the journal reported, "All of these have asked for a curb on advertising that belittles competition in order to protect the believability of all advertising." The belief that comparative advertising caused damage to advertising's institutional veracity, however, was, perhaps, summarized most clearly by O\&M executive Jack Roberts: "By quietly accepting creeping comparatives, and by being very, very good at making comparisons, we may not only be damaging the credibility of all advertising, but may very well be assisting consumers in making a misinformed choice." 188

Affective outcomes. During this period, unlike the previous ones, the majority of comments about negative attitudes toward comparative advertising are linked to the identification of competitors by name. One obvious explanation is that this was the dominant comparative advertising trend during this period and almost entirely related to FTC's campaign to encourage comparative television advertising.

Advertisers, media executives, and industry observers made numerous references to the belief that comparative advertising causes negative attitudes toward the ads themselves. As Sales Management editorialized,

Granting such points, many advertising people still feel that name-naming, however tasteful, should be ruled out of the game completely. ... Once accepted, the trend is almost certain to deteriorate into a free-for-all which will invite public contempt and possible governmental intervention. ${ }^{189}$

Of name-naming as an advertising tactic, Jack Gilbert, president of agency Gilbert \& Felix, similarly argued, "It may be a proper approach . . . but it's skating on very thin ice. Personally, I don’t believe we should expose ourselves to criticism in this manner."190

NBBB president Kenneth B. Wilson also seemed to speak for many: "The bad manners shown by name-calling advertisers is received with resentment or revulsion by many thoughtful citizens to whom they would sell their wares."191 Jack Hinton, CBS-TV's director of commercial clearance, also argued, in reference to the simple identification of a competitor by name: "We don't like it, most advertisers don't like it, and our mail indicates consumers don't like it."192 Even advocate Tannenbaum 
acknowledged that comparative advertising almost always "incurs a degree of negative reaction." 193

On the other hand, one advertiser specifically sought to find out how consumers felt about comparative advertising and subsequently left behind a revealing historical artifact. When cigar maker Tueros ran a comparative ad offering free cigars and featuring the names of two of its competitors in the headline, they gave away thousands of cigars. But the company also received a handful of complaints from cigar smokers "who told us they didn't think it was right or proper or cricket to mention the names of our competition in our ad." 194 The company then ran an ad asking readers to tell them whether they thought it was "cricket or not" to mention competitors in their ads. As the subsequent ad shown in Figure 12 shows, some $91.4 \%$ of those who responded were unoffended by the comparative tactic.

Indeed, sources during this period seemed about split over whether comparative ads necessarily encourage negative attitudes toward either the ads themselves or their sponsors. An agency executive with forty years experience, writing anonymously in Printers' Ink because "his agency does not see eye to eye with him" on what he had to say, spoke for many in his observation that comparative ads were not always disliked and praised the Avis We Try Harder campaign as an example. As he argued, "Avis' theme, 'We try harder because we're number two,' injected an effective, hard-hitting note into car-rental advertising." 195 An unidentified industry leader also summarized this belief in his comments about a widely discussed American Motors campaign that named the automaker's Big Three rivals: "I think if I were an American Motors dealer I'd like those ads. If I were a Chevrolet dealer, I'm not so sure. There's no evidence the public dislikes them." 196

The belief that comparative ads predominantly cause negative attitudes was not unanimous at the television networks, either. In 1976, a representative of ABC's Department of Broadcasting Standards \& Practices told Tannenbaum that "During the past year, we have not received an unusual amount of complaints from either advertisers or viewers. In fact, the amount decreased below previous years. The number of viewer complaints (1973 through 1976) has been negligible." 197 A representative for NBC's Office of Advertising Standards similarly told Tannenbaum, "Sensitivity to comparison commercials lies with the 'attacked' rather than with the consumer. There's no more question of good taste with comparison commercials than for those of any other type." 198

However, the view that comparative advertising would likely encourage negative attitudes toward all the competitors in a product category was also mentioned by several sources during this period. In almost every instance, however, sources linked this belief to comparative ads that also stretched the truth, made unfair comparisons, or disparaged competitors. Morris A. Kaplan, president of mattress manufacturer Sealy Inc., summarized the views of many of these sources in a speech to the New York Ad Club. Critical of "stacked-deck advertising" in which "a lower-price product is compared on irrelevant grounds with a nationally advertised product," he concluded with the statement that "Advertising that denigrates competition ... damages all brand names." 199 Andrew Kershaw similarly captured the views of those concerned about increasingly questionable and potentially unfair claims: 


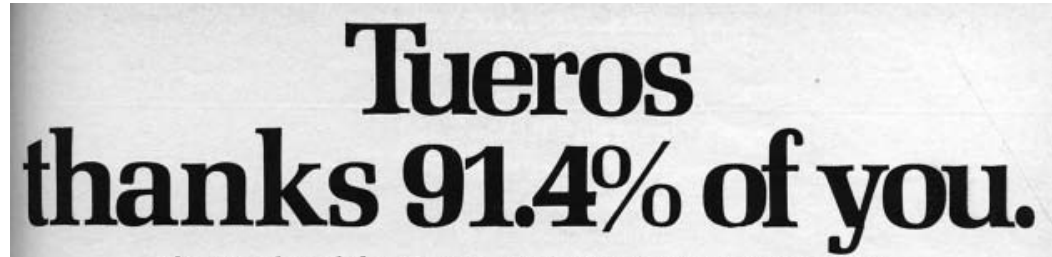

The results of the Tueros Cigar Smoker's Survey are in. And 9 out of 10 men thought it was cricket to use the names of our competitors - A\& C, Garcia y Vega and Gold Label-in our Tueros advertising. Tueros thanks everyone who wrote in

(including the $8.6 \%$ who disagreed).

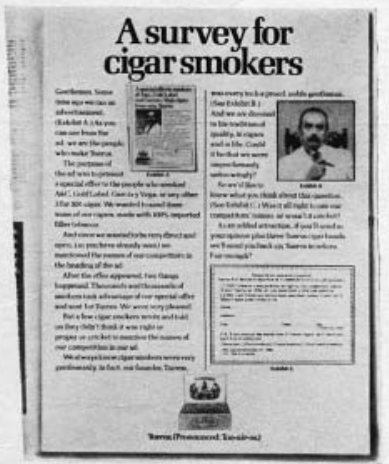

It all started when we made a special offer to the people who smoked our competitors' brands. We wanted them to try our Tueros cigar, made with $100 \%$ imported filler tobacco, and judge Tueros for themselves.

While thousands of men wrote in and took advantage of our offer, we became concerned because some men wrote and complained that we were being unfair by using the actual names of our competition in the advertising.

So we conducted our Cigar Smoker's Survey. (See tbove ad.) And happily, 9 out of 10 thought what we tid was o.k.

Frankly, we were relieved. Tueros, you see, was a very proud man and would never have offended myone. And since we are carrying on his tradition If pride and quality, we certainly didn't want to be ingentlemanly unknowingly.

You may have missed the chance to answer our

survey, but we don't want you to miss the chance to try our cigars. So we're repeating the special offer we made to all smokers of A\&C. Garcia y Vega and Gold Label, or any other 3 for 50 c cigar.

Just send us three Tueros cigar bands and we'll send you back six Tueros in return. It's a nice way to discover for yourself the new cigar with a history. Two shapes: Fiesta, a trim corona, or Pico, a long slim panatela.
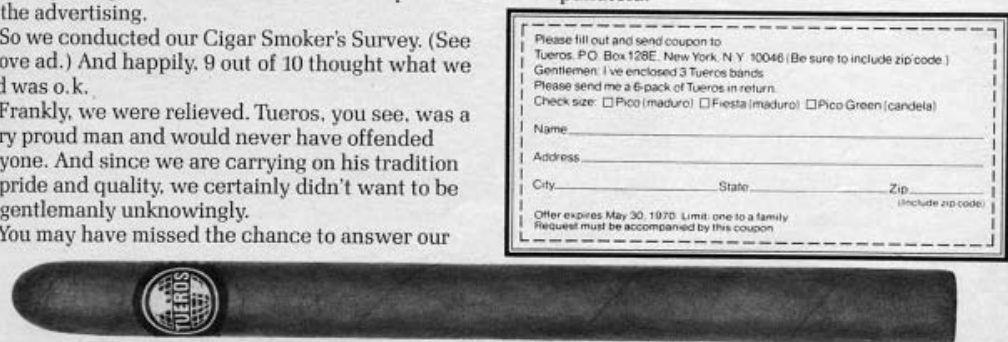

Tueros.(Pronounced:Too-air-os.)

Figure I 2. "Tueros ... thanks $91.4 \%$ of you."

Source: Advertising Age, March 30, 1970, 28. 
We have already seen that ferocious hostility erupts between corporations that used to be sensible, honorable competitors - all because of some stupidly provocative advertising. . . . Widely practiced comparative advertising could speed up the destruction of what remains of the free enterprise system, for in the end nobody would have any respect for business or advertising. ${ }^{200}$

The belief that comparative advertising would likely lead to negative attitudes among the users of the comparison brand was also mentioned by some sources during this period. One was Lawrence Light, vice president and director of research for agency Batten, Barton, Durstine \& Osborn (BBDO). Writing in the first issue of a BBDO "Research Newsletter," Light warned that "The American housewife . . can be alienated by what she feels to be an unfair attack on one of her favorite products."201 Even Tannenbaum acknowledged that comparative ads often encouraged a backlash from users of the comparison brand. Despite the many advantages he attributed to the tactic, he told Advertising Age that "the comparative commercial does, however, incur a degree of negative reaction since it challenges the brand user's judgment."202

Conative outcomes. The belief that comparative advertising could successfully create sales occurred simultaneously during this period with the widely held belief that it might often cause negative attitudes toward the advertiser, possibly the brand, and the product or service category overall. As Printers' Ink reported in 1966, "The old axiom - confidently revived during the past year-that knocking the other fellow doesn't pay has been replaced by an uneasy suspicion that it is paying, and handsomely." ${ }^{203}$ Moreover, while Tannenbaum claimed to have "seen comparative advertising literally turn around market share overnight," 204 other sources likewise pointed to market share gains resulting from successful comparative campaigns on behalf of Schick's Flexamatic shaver, ${ }^{205}$ Datril pain reliever, ${ }^{206}$ and Sno-Bowl bathroom cleaner. ${ }^{207}$

Only a few sources during this period mentioned the belief that comparative advertising might also boost the sales of the competitor. Referring to the Avis We Try Harder campaign, Sales Management editorially proposed the following:

Hertz absorbed the Avis blitz for quite some time and then came out with a campaign of its own, stating the whole thing was little more than a mosquito bite, and, in fact, saying that the Avis barbs actually helped Hertz business. Perhaps the whole controversy will end with that ironic discovery. ${ }^{208}$

On the other hand, even the ultimate sales effectiveness of another of the most widely discussed comparative campaigns of the twentieth century, the "Pepsi Challenge" of the 1970s, was called into question. Launched in 1975, Pepsi challenged Coca-Cola on the basis of personal taste preference and specifically tasked the campaign with improving Pepsi's share in markets where it was unquestionably an underdog. Writing about the campaign in 1977, an Advertising Age author reported, 
Ironically, Coca-Cola's sales continued to grow in markets where challenge advertising ran. Although Pepsi gained a few share points in its early Texas test markets, it was so far behind that those few points were insignificant in closing the gap between the two colas. In New York, the country's biggest soft drink market, Coca-Cola even gained a few points after the challenge began running. ${ }^{209}$

\section{Situational Factors}

Comparative advertisers and market share. Surprisingly, the well-established contemporary belief and empirically supported conclusion that comparative advertising works most effectively for smaller advertisers was not mentioned until the 1960s. However, it was discussed quite extensively in the literature during and after this period. As an Advertising Age author reported in the mid-1970s, "Many proponents of the name-calling technique believe it is best applied to a small, relatively unknown brand going after the big brand in its category. BBDO has written that advice into its own published comparative advertising thinking." 210 What emerged during this period are two clear comparative strategies for smaller versus larger advertisers, which have previously been defined in the academic research literature as "Riding the Coattails" and "Twisting the Tiger's Tail." ${ }^{11}$ Advertisers and industry observers offered numerous insights into the tactical advantages and disadvantages they attributed to both.

The Riding the Coattails approach involves the identification of a larger, typically dominant competitor for mainly associational purposes (i.e., an intent to communicate how the products are similar rather than different). A U.S. court of appeals decision in 1968, which affirmed a California perfume distributor's right to use competitor Chanel's registered trademark "Chanel No. 5" in ads for his own products, legitimized this form of name-naming and likely encouraged the subsequent comparative product "knock-off" phenomenon of the late-1970s and 1980s.

This coattail-riding trend occurred despite early industry views that it was definitely unethical and should be illegal. An editorial in Printers' Ink described the tactic and placed it within a context created by the period's acrimonious debate over identifying competitors by name. As the journal proposed,

Almost overlooked in the public debate is the possibility that name-naming may be used in some instances not to knock the competition, but to build it up and a lesser brand along with it. In this case, the advertiser's motive would be to imply that Brand $\mathrm{X}$ was competing on equal terms with the market leaders hoping some of their reputation would rub off. ${ }^{212}$

Some sources simply pointed to the attention advantage resulting from associating the advertised product or service with a more prominent competitor. As one marketer proposed, referring to a comparative campaign used to introduce a new brand of antacid and that mentioned competitor Alka-Seltzer, "But when you're trying to break into a market that is very highly competitive, this is a dramatic way to do so." 213 Others, however, argued that there were informational advantages resulting from riding on an established competitor's coattails. An article in Brand Week cited a marketing executive responsible for Tums antacid, who summarized this advantage: 
A previous campaign identifying Tums as being stronger "than the leading antacid product" was not as effective as the one that names Rolaids. The new ads, he says, "have greatly increased consumer perception and made people aware that the product is not candy or chewing gum." 214

As a spokesperson for a major marketer with a product that had been the target of a comparative ad similarly told Advertising Age, "Comparative advertising gives a small company a chance to compete with the big guys; it doesn't have to wait five years for the word to get around." 215

However, many sources during this period criticized the identification of any competitors, even if it were just for the purposes of coattail riding. An anonymous editorial in Printers' Ink summarized this view:

Some advertisers, well aware of this tactic, are nevertheless uncertain what should be done about it. It does come under the heading of "identification," but it is closer to flattery than belittlement, and it is likely to be unaffected by any rules designed to curb disparagement. ${ }^{216}$

A statement by the AAAA also demonstrates how widely held this view was:

While the board of directors of the American Assn. of Advertising Agencies believes wholeheartedly in competition in advertising, it does not believe in advertising which untruthfully or unfairly depicts or disparages competitive products or services. Nor does it believe in advertising that uses another product's trademark or brand name in an effort to trade on the reputation which the competitive brand has built through advertising and public acceptance. It believes that such use of competitor's brand names, packages, and trademarks without express permission of such competitors should be discouraged. ${ }^{217}$

Jean J. Boddewyn - who reported the findings of an international study of comparative advertising in a book published in 1978 (with coinvestigator Katherin Marton $)^{218}$ _reported that this view was widely held throughout the world. As he wrote in 1978, "To claim that one's product is as good as a competitive one-even when lauding the latter - is usually considered in non-Anglo-Saxon countries as undesirable 'parasitic' behavior that exploits someone else's property." 219 Indeed, comparative advertising remained almost entirely illegal in the European Community for another two decades, until Directive 97/55/EC (European Parliament and Council of the European Union) established that it should be permitted as long as, among other requirements, it was not anticompetitive, unfair, or misleading.

The Twisting the Tiger's Tail approach involves identifying a larger competitor for mainly differentiative purposes, usually to claim that the smaller competitor's product or service is superior. Advertisers who wrote favorably of this tactic attributed some of the same advantages to it as to the Riding the Coattails approach: advertisers achieved greater attention to their ads and also benefitted from their competitors' larger advertising budgets. As advertising agency partner Marvin Cantz told Advertising Age, in reference to a comparative ad for automaker Renault that both mentioned import leader Volkswagen and claimed superiority over the Beetle, "We 
need this approach because we don't have Volkswagen's budget." 220 As an executive with Whitehall Laboratories similarly told Advertising Age, in reference to advertising for antacid Bisodol that mentioned competitor Tums, "We are one of the smallest brands on the market, with one of the smallest ad budgets, and we needed to make the most impact with our money."221

Surprisingly, the now prevalent and empirically supported belief that comparative advertising should be especially effective for new products and brands was not mentioned until 1975. Adman and Advertising Age columnist William D. Tyler offered a revealing report:

When I gave my talk on successful new product introductions last year, I commented on the surprising (to me) lack of use of the "comparative approach," since that was already a growing vogue in American advertising. By comparative advertising, I mean ads that use direct confrontation, calling the competitor by name, using side-by-side comparisons to prove superior performance. ... Well, my talk this year is full of such examples. At least a dozen successes depend on this technique in their advertising. You can bet that there will be many more in the years to come unless the newcomers abuse the privilege. 222

Finally, some definite views of whether a larger competitor should respond emerged during this period. Sources predominantly held the view that it was a bad idea, and almost all of them linked their belief to the differences in size between comparative advertisers and their larger competitors. Agency BBDO, for instance, argued the following:

Research predicts that if the named competitor retaliates, the "underdog" will benefit for two reasons: (1) People interpret the response as a sign that the first attack may be true, and (2) the "association rule" holds. This rule states that when a high-status object is associated with a low-status object, the high-status object loses a little and the low-status object gains from the association. ${ }^{223}$

The president of a pet food company, and frequent target of comparative advertising, similarly told Tannenbaum, "Allen Products historically has been reluctant to name competitive brands in its own advertising. This is basically because we have $40 \%$ of the premium canned dog food dollar volume and feel that a name-calling contest would not be in our best interest."'224

Toward the end of this period, a discussion among the members of "BrainReserve," a think tank of top marketing and advertising creative professionals, revealed that some continued to question the effectiveness and appropriateness of comparative advertising and whether a larger advertiser should respond to comparative attack. Shirley Polykoff, creator of the landmark "Does She or Doesn't She?" campaign for Clairol hair coloring, for example, tellingly referred to comparative ads as "offensive" and "a last resort." As Bert Neufeld, a former creative director at agency Wells, Rich, Greene Inc., told Business Week, "They're all right for the little guy trying to get ahead . . . but if a big guy answers back, he loses points." ${ }^{225}$ The organization's founder and CEO, Faith Popcorn, also agreed, condemning comparative ads as "the lazy way to advertise." Think tank member Stuart Pittman, however, disagreed, arguing that 
comparative ads "parallel the consumer's experience at home where he or she . . makes comparisons" and that "Americans like a street-fighter approach."

Nature of the claim. During this period, advertisers often mentioned the importance of a comparative ad's claim and their overwhelming faith in the appropriateness and effectiveness of one or more valid features of superiority. Sherman L. Smith, advertising manager for stapler manufacturer Stanley Bostitch, referring to his comparative advertising war with packing tape manufacturer $3 \mathrm{M}$, summarized this view: "When we compare stapling with other methods of fastening, our comparisons will be oriented to specific and documented instances rather than to general, broad and unsupported claims. ${ }^{226}$ Frustrated over refusals by radio stations to run his comparative ads for client Renault, San Francisco adman Marvin Crantz expressed the same faith in claims based on valid features of superiority: "If you have the slightest doubt, make us prove it," Crantz told the radio stations. "The facts we state in our comparison prove our bold challenge." 227

Facing similar difficulties with reluctant radio stations on behalf of a group of regional Oldsmobile dealers, San Francisco ad agency partner Martin Rockey described the identical belief: "The most effective approach seemed to be a nose-tonose confrontation: 'This is our car-it has this, and costs this much. This is their car - it has this, and costs this much. Take your choice." ${ }^{228}$ A Whitehall Laboratories executive made the point even more directly in his reference to a Bisodol comparative ad that named competitor Tums: "We had some very definite superiority claims to make and felt justified in producing a comparative commercial." 229 One of the architects of the comparative Datril launch campaign, ad agency Ted Bates \& Co. creative supervisor Raymond Barker, told Advertising Age that "if an advertiser has an advantage over a competitor, he is probably wasting ad dollars if he is not telling the consumer what his benefit is in specific direct comparison to his competitors." 230

Obviously, Kenyon \& Eckhardt's Tannenbaum agreed with this view. As he explained, "We employ the comparison technique only in significant product attributes areas where we have demonstrable superiority and where the major competitive brand is perceived more positively than our brand." ${ }^{231}$ However, and based on agency research conducted over a period of seven years, Tannenbaum added a caveat, suggesting the risk associated with the potential for a counterattack: "Whatever advantages we might reap by comparison, we could lose, if the brand leader were able to counterargue in a more meaningful consumer-interest area where he enjoyed superiority." Advertising Age columnist, creative executive, and book author Arthur J. Bellaire, who wrote for years under the pseudonym "Mr. TV Byor," described a similar belief in the value of product demonstrations. Describing a Sno-Bowl bathroom cleaner comparative launch campaign, he wrote,

Here is a side-by-side comparative demonstration of three leading bathroom bowl cleaners on a rust-stained test panel, visually proving that Sno-Bowl outperforms the leading liquid and dry cleaners in terms of ease and cleaning ability. With a story like this, it's hardly surprising that Sno-Bowl's sales, distribution and market share goals have been exceeded since the national rollout last June. ${ }^{232}$ 
Referring to a comparative campaign on behalf of Coca-Cola's Tab brand that demonstrated its fewer calories in a visual way, Coca-Cola executive Donald Keough, a veteran of the Cola Wars, called it "legitimate comparative advertising, where clearcut objective factors, accurately measurable are involved." This kind of advertising can serve "as a source of consumer information supporting rational purchasing decisions." $" 233$

Media executives and advertisers also agreed, in the main, that a comparative claim would be more effective if it were based on a feature or benefit that was especially salient to the consumer. However, almost all these views about salient points of difference were associated with what some believed to be the period's problem with coattail riding and the exaggeration of minor differences in ongoing advertising wars. $\mathrm{ABC}$ executive and "censor" Alfred Schneider captured these views perfectly: "Comparisons do serve a purpose from the standpoint of the viewer if they abide by the key code guideline, and are based on something significant and meaningful to the over-all performance of the product." 234 But, as he also warned, "Too often singular, unrelated, minor differences are being used to upgrade a product's image in comparison to its named competitor, which only leads to challenges as to the appropriateness of this type of advertising." After predicting that there would likely be much more comparative advertising in the near future "unless the newcomers abuse the privilege," adman William Tyler defined such abuse as "comparisons that mislead by implying that a product advantage in one feature means over-all superiority. Or stretch a point. Or lie a little. Or make their point in such a way as to denigrate a competitor."235

Coca-Cola executive Donald Keough seemed to speak for many when he pointed to comparisons based on "highly subjective areas" as a problem with comparative advertising claims. Likening some of the Cola War battles to his experience in the coffee product category, where consumption had declined considerably, Keough tellingly revealed to Advertising Age,

Some coffee marketers forgot about advertising designed to reverse the trend. Instead they thought it would be smart to turn inside and begin feeding upon each other. They stopped selling universally appealing taste, aroma, flavor and enjoyment and started picking each other apart before the wondering eyes of the public. The results are well known. In 1960, coffee was far and away the nation's favorite beverage. In 1976 coffee is just another liquid commodity struggling to hold on to third place. ${ }^{236}$

Included in this thematic concern about comparative advertising that failed to emphasize a salient benefit was the old problem of advertising that focused on a competitor's advertising. Copywriters Archie Anderson and Mitchell Koss, of ad agency Ross Roy Inc., stated this view in reference to the ongoing advertising wars between brands Avis and Hertz, and Tylenol and Bayer. As they argued,

Competition, though hardly the most elemental source of advertising is fine. The problem starts when the competition is between the products' advertising, rather than the products themselves. ... The danger is in defining your product by its relationship to its competition and that's intellectual suicide. It's incestuous, because it grows out of its concern with the competition rather than its potential for the consumer. ${ }^{237}$ 
Degree of negativity. Somewhat surprisingly, especially given what seems to have been a substantial increase in the use of comparative advertising during this period, there were few recommendations regarding its proper execution beyond the nature of the claim. However, one of the most important themes to appear in the 1960s, along with the decline of "Brand X" and the increasing frequency of naming names, was the extent to which many advertisers viewed the tactic as representing a high degree of negativity and being synonymous with disparagement.

As the use of comparative advertising became more frequent during the 1960s, both advertisers and industry observers made scores of references to their belief that simply identifying a competitor was synonymous with disparagement. An anonymous ad agency executive captured this view:

There was once a sort of gentlemen's agreement, an unwritten code among advertisers, that competitors' names were not to be mentioned in ads, and that advertising would sell its products on its own merits and not by disparaging competitive products. . . . But this unwritten code is withering, and across-the-board comparisons are becoming respectable. ${ }^{238}$

Printers' Ink attempted an explanation for the growing use of comparative advertising during the 1960s and, subsequently, provided a helpful historical explanation for why many advertisers believed that naming a competitor constituted disparagement. As the journal observed,

Since the brass-knuckle days of the early 1900's that [the typical advertiser's] conscience has always assumed that (1) name-naming and name-calling were synonymous, (2) no established advertiser would do either and (3) the problem was permanently hedged in anyway by law, code and custom. ${ }^{239}$

Many sources argued, as they did in previous periods, that naming names was excessively competitive and simply in bad taste. An anonymous author in Sales Management summarized this view: "Traditionally, it was considered bad taste, or even against the best interest of advertising, to name a competitor in your ads." 240

Two episodes during this period also offer some insight into what many advertisers of the period considered excessively negative-excessive competitiveness and bad taste. In the first episode, publishers of the Encyclopedia Britannica complained that rival Collier's had unfairly disparaged their encyclopedia in a magazine ad with the headline, "How can all three [encyclopedias] be most used?" The ad's copy claimed one could simply "watch the students" to answer the question. While the copy did not mention competitors by name, two of them, Britannica and Americana, were clearly identifiable in the visual. Britannica objected to their product being depicted without permission and to Collier's implication that its books are "used more," and also sent letters of complaint to all the magazines that had published the ad. One Grolier Inc. executive, publisher of Americana, tellingly noted that the company would take no further action because "Our feeling was that because of its negative nature the ad probably caused more hard feelings against Collier's than it made sales." ${ }^{241}$ Another Grolier executive pointedly referred to the ad as "in bad taste." 
The second episode occurred when McCall's magazine ran an ad announcing its publishers would no longer charge extra for color printing. The publishers of competitor Editor \& Publisher opportunistically rushed to publish ads in the New York Herald Tribune and The New York Times, provocatively recommending that "previous color advertisers in McCall's 'should ask for a rebate." "242 Herbert R. Mayes, president of McCall Corp., complained to both papers, calling the "knock" both "irresponsible" and "erroneous." The subsequent apology, which the Times published as a full page, confirms the paper's agreement regarding the "overly competitive nature" of the ad (see Figure 13).

\section{The I980s to $2010 \mathrm{~s}$}

Many advertisers and industry observers throughout this final period confirm that the use of comparative advertising had become ubiquitous. Citing David Kerr, director advertising-marketing planning for automaker Renault, an Advertising Age author reported in 1985, "Mr. Kerr said up to the past few years the issue of comparative 'drew a lot of crossfire. Now it's an accepted form.'"243 By the early-1990s, the television networks had reduced their clearance staffs, but the number of comparative ads continued to grow. As one industry observer noted in 1990, "Comparative adscommercials that attack or mock competing products by name - have grown substantially over the last few years, especially in competitive categories such as telecommunications, beverages and automobiles." 244 Referring to "TV's early days" when most comparisons were made with "Brand X," Advertising Age revealingly pointed out the following: "That had its limitations, to be sure, but it didn't violate this old marketing adage: 'Never mention a rival brand in your own ads.' If there's a rule for marketers today, it isn't 'never name a rival."'245

Another Advertising Age contributor strongly suggested that the frequent use of comparative advertising continued into the twenty-first century. As she reported,

Perhaps it's the tight economy and the idea that the way to grow in a recession is at the expense of your rivals; maybe the presidential candidates have set the tone for television advertising; or it could be the influence of those masterful and highly effective Mac vs. PC spots. Whatever the reasons, comparative ads - some of them pretty aggressive - are all the rage. ${ }^{246}$

Yet both advertisers and industry observers also strongly suggested that the tactic continued to be viewed as both controversial and risky, referencing many of the same concerns their predecessors did during earlier periods. Numerous sources, for instance, lamented the negativity and aggressiveness of this period's comparative advertising. Political communication consultant Roger Ailes, famous for helping craft the controversial "Willie Horton" attack ad for the 1988 presidential campaign of George H. W. Bush (with political communication consultant Larry McCarthy), told Advertising Age, "The product advertising world has taken over most of the negative advertising. Political advertising looks mild by comparison." 247 As the author of the piece tellingly 


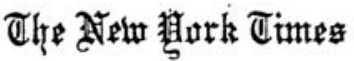

Tintes Square

MONROE GREEN

OUgINESS MANABLA

April 3, 1962

\author{
Mr. Herbert R. Mayes \\ President \\ McCall Corporation \\ 230 Park Avenue \\ New York, N. Y. \\ Dear Mr. Mayes:
}

This is in reply to your letter of this morning.

Because of the overly competitive nature of today's "Editor \& Publisher" advertisement and because of 1ts reflection on McCall's Magazine, it should not have been accepted by The Times.

Very, truly yours,

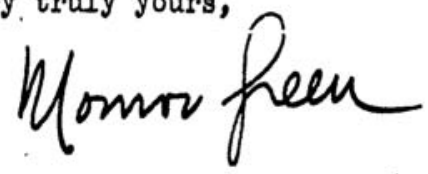

Figure 13. "The New York Times."

Source: The New York Times, April 4, 1962, 85. The New York Times is a registered trademark of The New York Times Company.

concluded, "Even though top marketing executives frequently disavow the suitability or effectiveness of negative advertising, the deployment of this potent but risky weapon is definitely proliferating in American business." 248

Others also suggest this period's comparative advertising was especially aggressive and that many advertisers continued to view it as somewhat unseemly, as this Advertising Age writer did: 
For all the brand-slamming you'll see in just a night of watching prime-time television, it's not easy finding a marketer outside of the political arena who'll confess to using negative advertising as a marketing tool. Asked if they practice that craft, they inevitably demur, and assure you that only political advertising practitioners do so. ${ }^{249}$

The aggressiveness and frequency of use of comparative advertising during this period helps explain why problems with lawsuits caused by it turned up in seventh place on a list of the top ten advertising legal issues for $2005 .{ }^{250}$ Indeed, as advertising wars among major competitors in product and service categories as varied as hot dogs, sports drinks, sunscreens, ready-to-eat soups, and cell phone services have demonstrated, one of the greatest risks involved in comparative advertising continues to be the likelihood of a lawsuit, and increasingly during this period, countersuits. ${ }^{251}$

\section{Direct Effects}

Cognitive outcomes. The belief that comparative advertising greatly enhances attention and awareness was overwhelming during this period. Referring to a bout of comparative advertising among business magazine publishers, Marianne Caponnetto, an associate media director at agency Needham, Harper \& Steers, told Advertising Age, "To go and knock your competitor is not always a positive way to do things, but it is often a way to get noticed." 252 The author of a piece in Advertising Age about a controversial Burger King comparative campaign cited statistics:

Burger King's awareness soared 15.7 percentage points in October to $24.1 \%$ of all responses to a question asking consumers to identify the fast-food advertising that first came to mind. McDonald's still led the category with $35.6 \%$ of all responses, but that was down 10 points from September and McDonald's lowest score to date. ${ }^{253}$

J. C. Perkins, general manager of Chevrolet at the time, was the subject of an interview about a comparative campaign for Chevrolet trucks. Asked whether he believed he had left himself open to the old criticism that the campaign was helping create awareness for the competitor, Perkins replied, "There is that possibility. But the truth is, and we have considerable data to back it up, the awareness for Chevrolet trucks has just leapfrogged. As a result, we believe in this advertising wave we've been on." 254

Moreover, toward the end of the period, some advertisers began mentioning a connection that had not emerged previously - they proposed that the initiation of a lawsuit often enhanced the awareness created by a comparative campaign. After McDonald's filed suit against Burger King five days before the company launched a comparative campaign in 1984, Burger King executive Kyle T. Craig told Advertising Age, "McDonald's did us a favor for which I will be forever grateful. . . . It created such tremendous consumer awareness that when the campaign broke it created even higher awareness and impact than we had ever dreamed." 255 And as an Advertising Age author similarly reported some twenty years later, 
Marketing experts were quick to criticize AT\&T for taking legal action against Verizon's "Map for That" ads. While AT\&T wanted the ads pulled, what the lawsuit was more likely to do is bring attention to the ads, and AT\&T's weakness: its iPhone-taxed 3G network. A few weeks later and it looks like those experts were right. After having disappeared from the Viral Video Chart, Verizon's "Map for That" ad is back on it, in the No. 7 spot with almost 500,000 views. ${ }^{256}$

Although, as in other periods, a majority held the view that comparative advertising may capture attention, some continued to argue that it was the wrong kind of attention. Referring to the contentious and much-criticized comparative ad shown in Figure 14 for magazine Business Week, which depicts The Wall Street Journal stuffed in a wastebasket, Young \& Rubicam executive Joseph Ostrow argued that the ad might be engaging but would fail to be effective. As he told Advertising Age, "That sort of thing is not a way of doing battle that I think makes sense. . . It doesn't cause you to read the ad. It just catches your attention momentarily and then you move on." 257 Bruce Kushnick, president of New Networks Inc., a market research firm, similarly observed, "Watching the commercials where AT\&T and MCI square off is the same as looking at a car wreck-you slow down to see the mess. But you don't really pay attention to what's going on."258

The belief that comparative advertising could be informative was also widely held during this period. Also in reference to the Business Week ad in Figure 14, media director Marianne Caponnetto told Advertising Age, "It reminds us of the different strengths of the magazines." ${ }^{259}$ Describing a comparative campaign for automotive brand Pontiac, Michael Wright, Pontiac's advertising and consumer marketing manager at the time, also summarized this view: "I think people see what we're doing as informational and not necessarily an attack on anybody's choice of vehicles."260 McCann-Erickson executive David Ramsey, responsible for General Motors advertising at the time, similarly argued, "Buyers are looking for more product information, comparisons. I like it when it is done fairly; when it is an honest-to-goodness free-forall. Where it is done right, it is extremely helpful. It makes good reading."261

Moreover, advertisers offered increasingly specific insights into why they believed comparative advertising was often informative. Some linked this outcome to a proliferation of similar products and brands. This belief was summarized well by Advertising Age columnist Sid Bernstein:

I have always considered the technique a useful one, definitely serving the interests of consumers, because comparing Product A with Brand B is essential in almost every buying decision-especially in an economy with endless numbers of look-alike, taste-alike, costalike and perform-alike products. ${ }^{262}$

Others who argued in favor of the informativeness of comparative ads suggested that they were the most effective tactic for communicating a feature of similarity or difference. An example of the former occurred with a re-launch of the soft drink Pepsi Max in the United States in 2010. PepsiCo marketing executive Lauren Hobart, for 


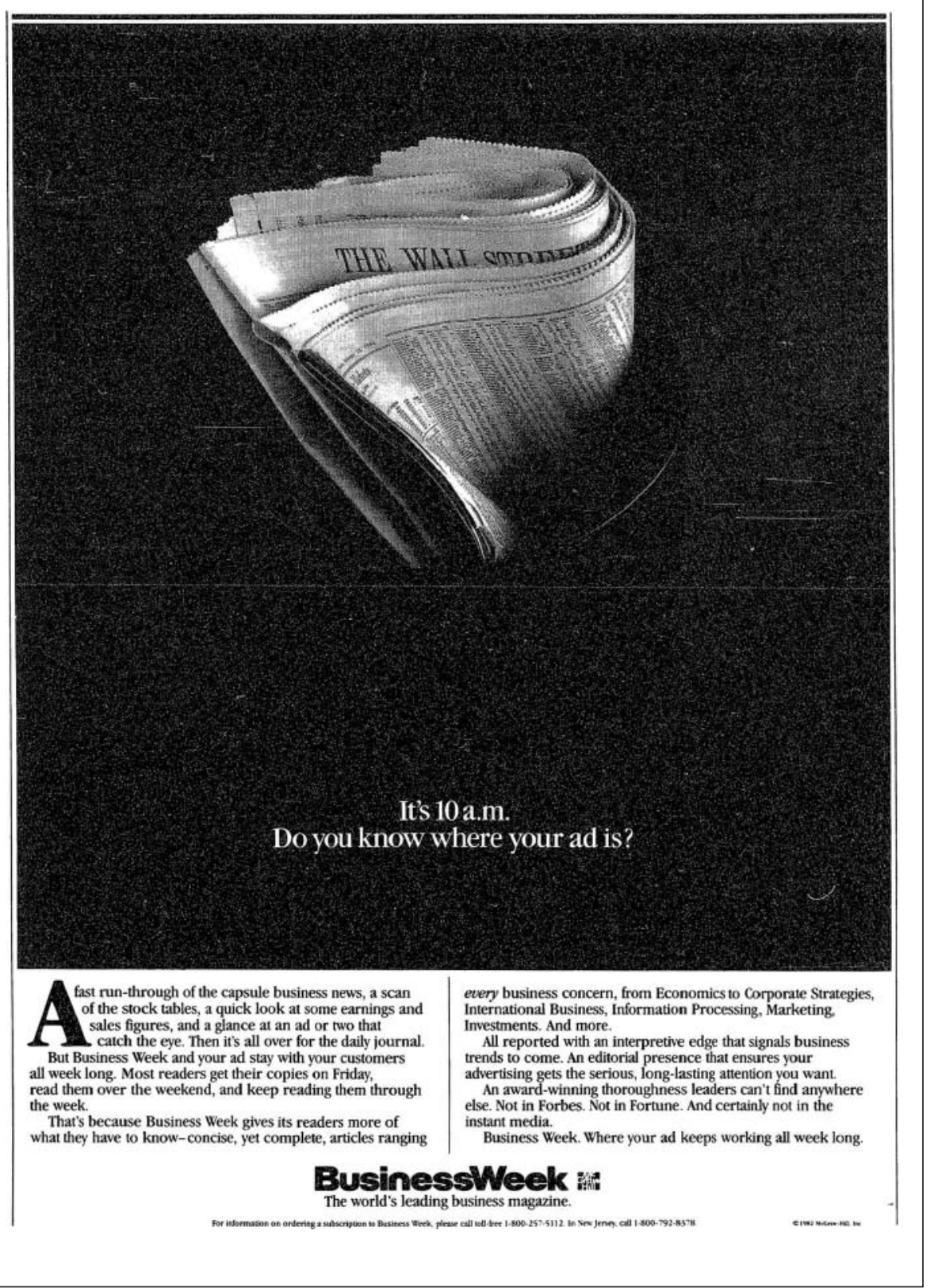

Figure I4. "It's 10 a.m."

Source: The New York Times, March 8, 1982, DI2. Business Week is a registered trademark of Bloomberg L. P. 
example, told Advertising Age that the company revived comparative advertising from the mid-1990s to compare Coke Zero with Pepsi Max because "Not having diet on the can, the challenge is on us to communicate that it also has zero calories." ${ }^{263}$ Conversely, referring to the decision to switch from a noncomparative campaign for beverage Sierra Mist Natural to a more aggressive one, comparing the soda with Sprite ("If you're not fond of fake, try Sierra Mist Natural"), PepsiCo marketing executive Kristina Mangelsdorf told Advertising Age, "We found that they were not hard-hitting enough on the real point of difference in the product. People didn't understand why it was different from other lemon-lime sodas." 264

As during earlier periods, a majority of advertisers acknowledged that explicit comparative ads often create attention and awareness for the competitor as well. Many, however, also offered additional insights into when creating awareness for a competitor would likely become especially problematic. Advertising Age's Sid Bernstein pointed to an overemphasis on competitors as a principal problem:

A more serious objection, from the standpoint of the advertiser, is the fact that comparisons cannot be made without mentioning the competitor; and there is at least an occasional advertiser who wonders if it is worth his while to spend any part of his promotional budget advertising his competitors. . . . Most of us can recall at least one personal selling situation in which too much talk about the competition has benefited the competitor at the expense of the talker. ${ }^{265}$

Moreover, in 2012, one source cited statistical proof. Immediately after General Motors ran an ad during the 2012 Super Bowl, in which Chevy Silverado owners lamented the loss of a friend, who failed to survive an apocalypse because he drove a Ford, a marketing analyst at Kelley Blue Book (KBB) confirmed that the Ford truck area on KBB's website received more hits than the area devoted to Chevy. ${ }^{266}$

Others argued that creating problematic awareness for a competitor was more likely to occur if consumers lacked awareness about the comparison product or brand. Adman Herschell Gordon Lewis explained this view, in reference to the use of comparisons in direct-response advertising. As he wrote, "In years past, 'cold list' soliciting seldom gave us confidence in any assumption that our target-readers understood our comparative claims against competitors. We were likely to open Pandora's box giving free exposure to a rival." ${ }^{267}$

Advertisers during this period made scores of references to the problem of comparative advertising confusion. An Advertising Age author summarized this view very early in the period and in reference to the frequently discussed war among electric shaver advertisers:

It has been suggested that the ad battle among the electrics over shaving closeness has confused and disgusted consumers with the whole category. The market leader, Norelco, which stuck to its strategy against wet shaving systems actually increased its share during and after the Remington-Schick dogfight. ${ }^{268}$ 
Ad agency president Murray Raphel argued the same point, with this reference to an early comparative ad for pain reliever Excedrin: "The commercial mentioned a competitor and said why Excedrin was better. The only problem: Half the viewers remembered the competitor brand by name instead of Excedrin." 269 This view was summarized perfectly, however, in an Advertising Age opinion piece in 1999: "There have been great, informative campaigns built on this tactic, yet look where it's taken us lately: a rampant trend in household products marketing toward not-very-informative, confusing ads that make a mockery of the potential benefit of comparisons." 270

Sources during this period also offered increasingly specific reasons for why and when consumers would be likely to be confused by a comparative ad or campaign: (1) They were unfamiliar with the target of the comparison, ${ }^{271}$ (2) the target of the comparison was a dissimilar product (e.g., a comparative Super Bowl ad that pitted Diet Coke against the sugared Pepsi flagship brand), ${ }^{272}$ (3) the ad lacked sufficient identification for the sponsoring brand, ${ }^{273}$ (4) the decades-old problem with directly conflicting claims in an ongoing advertising war, ${ }^{274}$ (5) consumers lacked knowledge to effectively counterargue with comparative claims based on often insufficient factual information (e.g., comparative ads for prescription drugs), ${ }^{275}$ and (6) ads, themselves, were too dense with information. ${ }^{276}$

Several sources pointed to a specific example of the problem of lack of brand identification in 2009. In the commercial, Verizon Communications Inc. targeted Apple's iPhone with comparative ads for its new Android device, summarizing all the iPhone's limitations with a series of "iDon'ts" (see Figure 15). Problems with the ad and its brand identification were described by Karl Barnhart, managing director and partner at CoreBrand, a brand strategy and communications firm: "There's no summary about the product, and you don't know who the brand is. . . It's clever, but you have no idea what this is for." 277

However, this was not the only point of view to find expression with regard to confusion. Describing a comparative ad for First Jersey National Bank, the author of an article in Bank Advertising News explained that the campaign was actually created to eliminate confusion between the bank and similarly named but more widely known First Jersey Securities. As the author explained,

The rules of marketing positioning say don't focus ads on the competition because they only serve to make the other folks better known.... That ad, designed to eliminate confusion over the names, clearly refers to First Jersey Securities, which has run a national campaign on television and has been the subject of in-depth articles. ${ }^{278}$

Believability. Perhaps because the use of comparative advertising had become so widespread by this time, few sources directly addressed the believability of comparative ads. All those that did pointed to the inherent skepticism and likely counterargument created by the tactic, and moreover linked it to the believability of the claim itself. Direct-response advertising man Herschell Gordon Lewis captured this view perfectly: 


\section{iDon't run widgets.}

\section{iDon't take pictures in the dark.}

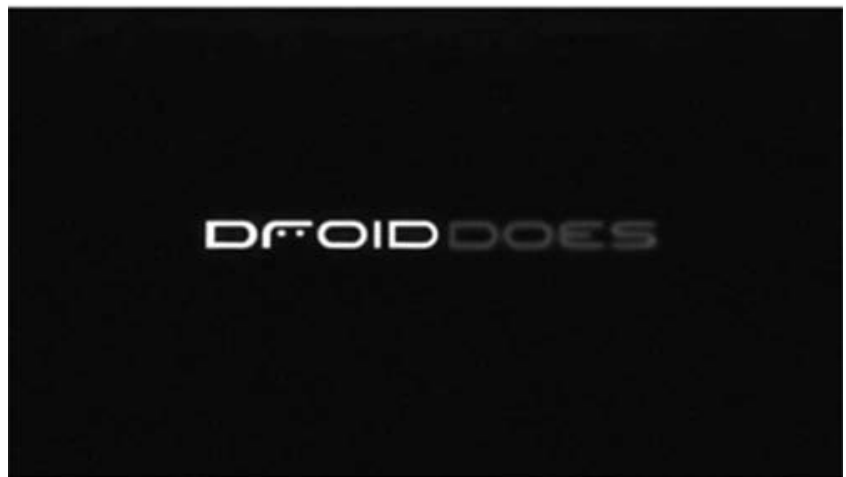

Figure I5. Verizon's 'iDon't.”

Source: www.youtube.com. Droid is a registered trademark of Lucasfilm Ltd., used under license by Motorola, Inc. 
What we say about ourselves is self-digesting; what we say about others starts a battle, not only with competitors, who may not respond . . . but also with the reader, who does respond in ratio to two factors: 1) the amount of implicit skepticism, and 2) validation of our claim. ${ }^{279}$

Quoting Allen Adamson, managing director of agency Landor Associates, two Brandweek authors summarized this view twenty years later: "the approach is 'not necessarily the best way to market a product' for various reasons. One is consumer skepticism - viewers of such ads tend to conclude that the test is rigged somehow to show a positive result." ${ }^{280}$ In reference to a Diet Pepsi ad showing entertainer Ray Charles taking a sip of Diet Coke and then apparently realizing it wasn't Diet Pepsi, Al Ries, branding expert and coauthor of Positioning: The Battle for Your Mind, similarly argued,

It's difficult for the ordinary person to tell the difference between Diet Pepsi and Diet Coke, and to pretend that Ray Charles can tell is ridiculous.... The consumer thinks he can tell the difference because he's been paid a million to tell the difference.... It's totally unbelievable. ${ }^{281}$

Affective outcomes. Similar to their contemporaries during earlier periods, advertisers questioned the likability of comparative ads, although the theme was not as prevalent. Moreover, and unlike the previous period, the mere identification of a competitor was never referenced as a cause of negative attitudes toward comparative ads. The belief that comparative ads cause negative attitudes was mentioned frequently by observers of a trend toward their use in the health care industry. Dick McDonald, a management officer at Milwaukee-based agency BVK/McDonald, a marketing and communications firm, told a writer for magazine Modern Healthcare: "I think negative advertising generates insecurity. You are raising issues that people don't want, especially in healthcare." 282

Others linked negative attitudes to a frequently used tactic of the period, especially among auto marketers - across-class comparisons of a car model to a more expensive or prestigious "faux" competitor (i.e., a variation of the Twisting the Tiger's Tail tactic). Citing an auto industry survey conducted by consultancy CNW Marketing Research on the effectiveness of comparative television commercials comparing Nissan's Altima to Mercedes-Benz and BMW models, CNW executive Art Spinella told Advertising Age, "People were offended with the comparison of Altima to Mercedes-Benz. . . . Prospects of both sexes and all ages fairly frequently said comparing the two cars was like comparing apples to oranges." 283 The piece also cited John Slaven, founder of consultancy Slaven Marketing Services and a former auto-marketer ad director and agency executive: "When you reach too far, I think you destroy your credibility."

The belief that comparative ads often reflect negatively on the sponsor was a frequently discussed theme. Advertising agency president Adam Hanft told Advertising Age, in reference to an ongoing advertising war between long-distance carriers AT\&T and MCI, "Our research shows consumers don't want to be a pawn in the fight. 
They feel the companies are not interested in them and only want to make a sale."284 Although Chevrolet's J. C. Perkins affirmed his commitment to the comparative campaign mentioned earlier, he tellingly told Advertising Age, "But if we had our choice, I would tell you we would always take the high road and deal with brand image." 285 The findings of an AdweekMedia/Harris Poll of consumers conducted in 2009 confirmed the potential for backlash:

Only $4 \%$ said they think less of the brand that's attacked. Thirteen percent said they think less of both brands. Thirty-nine percent said they think less of the brand making the attack. And 44\% said it doesn't change their opinion of either brand. ${ }^{286}$

However, this was not the only point of view with regard to negative attitudes toward comparative ads or their sponsors. Eric Swartz, president of The Byline Group advertising agency, pointed to, once again, the Avis We Try Harder campaign as a successful example:

Consumers are impressed by a healthy dose of humility. Those companies claiming to have made it to the pinnacle don't appear lean and hungry; they're fat and happy. Companies that strive to achieve have pluck - and our undying admiration. Witness one of the most effective taglines in history: DDB's "We try harder" for Avis. ${ }^{287}$

This belief was also reflected in comments by Massimo d'Amore, CEO of PepsiCo Beverages America, in reference to 2011's version of the Cola Wars:

Hyper-competition is always good to sell more soda. Consumers love the cola wars. Since we launched the Max campaign, Max is growing triple digits and Coke Zero is still growing, so everybody wins when we get into the cola wars. ${ }^{288}$

The belief that comparative advertising causes especially negative attitudes among the users of the comparison brand was also prevalent during this period. Atlantic City ad agency president Murray Raphel summarized the view with this succinct warning: "You embarrass the customer. No one likes to be told he made a mistake."289 John Goodchild, chief operations officer of ad agency Weightman Group, also spoke for many with this observation:

Even the lowest brand has fans who resent being ridiculed by a rival's advertising. . . But it's just plain dumb to trash a brand in a mean-spirited fashion and offend the millions who know it and love it. ${ }^{290}$

In 1996, Anheuser-Busch (A-B) executives tellingly admitted to Advertising Age that their comparative campaign criticizing craft brewers, such as the Boston Beer Company, for the questionable quality of their beer "garnered a stronger response from A-B consumers than from the non-A-B consumers they were targeting." 291

Sources during this period offered additional insights into when backlash against the sponsor of a comparative ad might be more likely to occur. Conceding that 
comparative advertising could be an effective short-term tactic, O\&M executive vice president Graham Phillips told members of the AAAA that consumers did not object to 'their product's' [sic] being knocked in comparisons, except where the product involved is a high-ticket item such as a car, where broader, emotional feelings were invested in the consumer's purchase." ${ }^{292}$ Some twenty years later, and in reference to the escalating comparative war between cell phone carriers Verizon and AT\&T, Jeremy Toeman, a partner with marketing consultancy Stage Two Consulting, similarly told Advertising Age,

While people may prefer one brand of soup or drink to another, there's a lot more at stake with mobile carriers. . . . [and] when consumers are seeing the carriers attack each other, there's enough to get them to rally at a personal level. ${ }^{293}$

Despite the prevalent use of comparative advertising during this period, the belief that the tactic could lead to damage to all the competitors in a product category was frequently mentioned and shared by a majority. However, in each of these cases, sources referenced ongoing advertising wars as the cause of the problem. Rena Bartos, a senior vice president for agency J. Walter Thompson, summarized the views of many in her reference to what turned out to be Coca-Cola's short-lived decision to withdraw from this period's Cola Wars: "such strategies 'erode confidence in both brands in the mind of the public and that both companies would ultimately carry the soft-drink market into a commodity category."'294 McDonald's Corp. president Michael Quinlan similarly admonished his competitors, in reference to the period's ongoing Burger Wars: "If you've got good [product], flaunt it, but don't tear down someone else. It's not good for the industry as a whole, and I think we ought to stop."295 This view was captured best, however, by this veteran of the Spaghetti Sauce Wars: "At a certain point [Unilever] realized, hey, the category has declined every year for several years . . . and between [Unilever and Campbell], we're spending \$60 million a year to convince consumers that our spaghetti sauce is really crappy."296

The belief that comparative advertising could lead to damage to advertising's credibility as an institution was also evident during this period, although certainly not as prevalent as during earlier periods. However, this view was almost entirely linked to either potentially misleading comparisons that led to lawsuits or especially negative attack advertising. This point of view was effectively summarized by Ira Herbert, president of Coca-Cola's North American soft-drink sector, who went public in late1990 to complain about the many questionable comparative claims that he thought were slipping past television network clearance staffs. As he told Advertising Age,

There's a flaw in the system, and that allows - either purposely or by accident-for an advertiser to take advantage of the system, which could affect the credibility of advertising. ... I am primarily concerned about the legitimacy of advertising and that if this is allowed to continue it is potentially a very serious situation. ${ }^{297}$

John Bissell, a managing partner of Gundersen Partners, a search/management consulting firm in the marketing field, comparing comparative product advertising with 
political attack ads, similarly observed, "Attack ads, whether for politicians or brands, are a blight on our national and business landscapes that all reasonable marketing professionals should strive to end." 298 And as an Adweek author strikingly opined with regard to the increasingly vicious war between pain relievers Tylenol and Advil,

But the main educational benefit of the Tylenol-Advil war has been to teach the public that you can't believe anything you hear, that the world is unsafe, and that drug companies, behaving like cynical cutthroats, are no better than, well, politicians. ${ }^{299}$

The importance and occasional influence of channel members and other internal audiences was also a prevalent theme during this period. In a few cases, comparative manufacturer advertising created problems for dealers and merchandisers who sold both the sponsored and comparison products. What was also prevalent during this period, however, was a widely expressed belief that both channel members and internal audiences tended to favor aggressive comparative advertising campaigns. Mike Rawlings, president and CEO of DDB Needham Worldwide Dallas Group, perfectly captured this view:

It can be a huge power marketing tool that rallies and energizes an entire organization. . . . Send that smart comparative ad for your stain-resistant carpet to your international sales force. Throw them a party with themed favors. Just don't put the ad on the air. ${ }^{300}$

Referring to a Burger King campaign that reignited the Burger Wars, a franchisee told Advertising Age, "This campaign is long overdue. . . All of us believe our products are superior, and the research proves that consumers believe it, too." ${ }^{301}$ Moreover, and much as they did in the 1920 s, auto dealers frequently and loudly complained when manufacturer advertising was not aggressively comparative enough and even launched their own comparative campaigns to address the problem. ${ }^{302}$

Conative outcomes. Two prevalent themes were clearly evident among advertisers' and industry observers' statements and reports regarding comparative advertising's direct effects on behavioral outcomes during this period. First, sources made scores of references to the effectiveness of comparative campaigns for directly causing sales. The many examples began, appropriately enough, with an Advertising Age author's historical reference to the previous period's most famous comparative campaign, Avis's We Try Harder. As she reported, "The campaign provoked quite a bit of criticism, but by year's end Avis reported a profit $-\mathrm{a} \$ 1,200,000$ net - for the first time in 15 years." ${ }^{303}$

Sources throughout this period attributed direct increases in sales to comparative campaigns on behalf of numerous products, including Taylor California wines ${ }^{304}$; Coors Extra Gold beer ${ }^{305}$; Prego spaghetti sauce ${ }^{306}$; Chrysler automobiles ${ }^{307}$; Royal Crown (RC) Cola ${ }^{308}$; Pontiac automobiles ${ }^{309}$; Anheuser-Busch Natural Light beer ${ }^{310}$; Miller Lite beer ${ }^{311}$; Apple computers ${ }^{312}$; Ford trucks ${ }^{313}$; Ford Edge, Fusion, and Expedition automobiles and SUVs ${ }^{314}$; DiGiorno frozen pizza ${ }^{315}$; Miller High Life beer ${ }^{316}$; Campbell's Select Harvest soups ${ }^{317}$; Domino's sandwiches ${ }^{318}$; Dish Network ${ }^{319}$; 
and Sony Playstation PSP. ${ }^{320}$ Moreover, in almost every instance, sources cited industry sales and/or market share statistics as evidence of the effectiveness of the campaigns.

Although advertisers and industry observers offered only a few explanations for the effectiveness of these comparative campaigns, some explanatory themes are evident. Among the campaigns are two comparative tastes tests, three tactical switches from previously noncomparative to comparative campaigns, two strategic emphases on comparative value, and two new product launches.

A second conative outcome sources frequently mentioned during this period was the use of comparative advertising to initiate brand trial. In 1991, Coors Brewing conducted a sixteen-market taste-test and purportedly found that $58 \%$ of beer drinkers preferred Coors Extra Gold to Budweiser. In his description of comparative advertising that featured this finding, Coors Extra Gold brand manager Gary Skovsted told Advertising Age, "We're confident that the results of this survey will convince premium beer drinkers - specifically Bud drinkers - to try Extra Gold." 321 This point of view was similarly referenced by Paul Gordon, advertising and marketing manager for film marketer Konica, regarding his comparative campaign targeting competitor Kodak: "We have to initiate trial." 322 Trial was also stated as the objective for comparative advertising for Taco Bell's Gordita (which was compared with Burger King's Whopper) ${ }^{323}$ and Minute Maid Orange Juice. ${ }^{324}$

The beliefs that comparative advertising would fail to encourage sales, however, or even lead to damage to the sales of all competitors in a product category, were also prevalent during this period. But in almost every case, they were associated with ongoing advertising wars. For instance, while Procter \& Gamble's (P\&G) Scope was referring to Warner-Lambert's Listerine as the brand that gives consumers "medicine breath," and Listerine was derisively describing Scope as "the leading soda pop mouthwash," a P\&G executive was acknowledging that category sales had noticeably declined. ${ }^{325}$ Referring to comparative advertising that targeted prescription drugs Seldane and Alegra on behalf of Claritin, ad agency executive Lorraine Pastore tellingly told Advertising Age that they would not respond: "That would damage the category as a whole; it's not a strategy we would be comfortable with." ${ }^{326}$ This point of view was also explained especially well by Microsoft's vice president of systems strategy Jonathan Lazarus, in his reference to comparative advertising among software marketers: "So if I suddenly paint a competitor's products as complicated, I'm overall feeding those arguments that things will be tough to deal with." 327

Perhaps this period's most revealing episode occurred in 1993, however. Likening an aggressive comparative advertising war among personal computer marketers to the period's Long-Distance Wars, ${ }^{328}$ computer maker Compaq's director of marketing communications Jim Garrity felt strongly enough about the futility of the industry's bout of comparative advertising to run the ad shown in Figure 16. Although the ad does not directly name competitor Dell, it does make the case directly to consumers that "Mudslinging, be it at a political candidate or a computer company, serves little purpose other than to muddy the waters."

A similar episode occurred some fifteen years later. After what was an apparently successful launch of Select Harvest soups in 2008 with a comparative campaign 


\section{Aggressive AdVERTISING}

\section{VS. \\ Aggressive EngINEERING}

\section{WHO Wins?}

\footnotetext{
If you've opened up this newspaper lately, you may have noticed that one of our competitors has been spending a great deal of money on advertising that attacks Compaq rather directly.

And while we certainly appreciate being singled out as the benchmark of comparison for the entire personal computer and server industry, we can also appreciate the fact that mudslinging, be it at a political candidate or a computer company, serves little purpose other than to muddy the waters.

What consumers desire is credible, reliable information. Not innuendo.
}

To that end, Compaq would like to make a commitment to you.

A commitment to continue designing

and building the very best computing products for your needs, pricing them competitively and then servicing them better than anyone in the business.

And a commitment to spend our advertising dollars bringing you rational, logical, meaningful reasons why our personal computers and servers are the best overall value for the money.

Bar none.

With the right information, you can make the right decisions. Simple as that.

\section{COMPAQ}

Figure 16. "Aggressive advertising."

Source: The Wall Street Journal, May 19, 1993, 7. Compaq is a registered trademark of Compaq Trademark B. V.

(see Figure 17 for an especially aggressive example), the war between Campbell Soup and General Mills grew even more negative. In late-2009, The New York Times reported that sales in the wet-soup product category had declined for four consecutive 


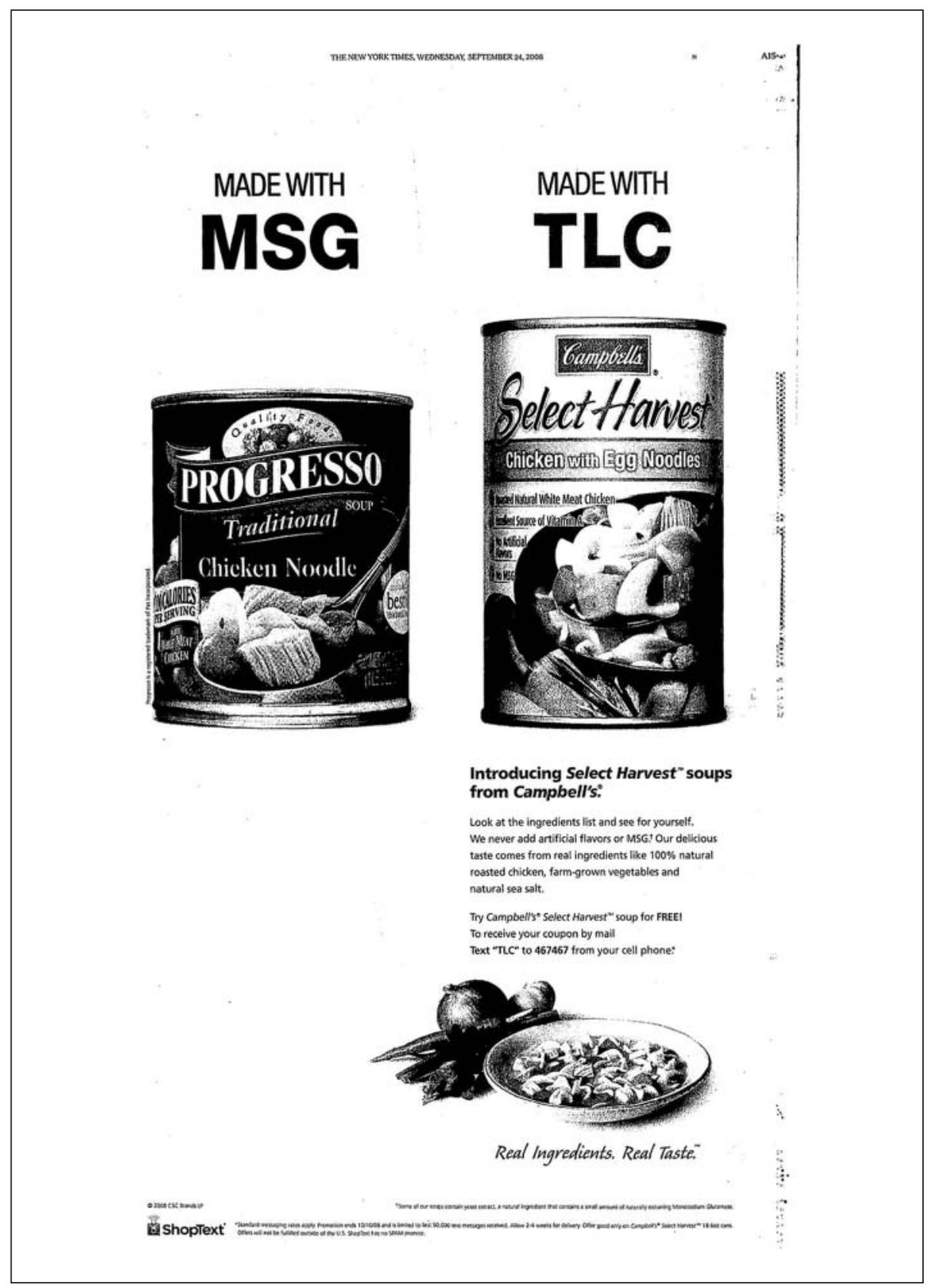

Figure I7. "Made with MSG."

Source: The New York Times, September 24, 2008, A I5. Select Harvest is a registered trademark of CSC Brands, Inc.

Note: MSG = monosodium glutamate . 
quarters. Quoting James P. Othmer, author of Adland: Searching for the Meaning of Life on a Branded Planet, the Times offered the following explanation: "They're navel-gazing and they're not thinking about what consumers want to hear-they're just talking at conference tables about how to strike back or how their integrity has been affected. . . They get caught up in each other's messages." ${ }^{329}$

\section{Situational Factors}

Comparative advertisers and market share. Numerous sources during this final period mentioned their belief that comparative advertising works most effectively for smaller competitors, whether it was a new product launch, Riding the Coattails, Twisting the Tiger's Tail, or a combination of these tactics. Such comparative campaigns were frequently referred to as "David versus Goliath" confrontations. ${ }^{330}$ An Adweek contributor clearly revealed the longevity of this belief: "Letting loose, drawing blood or simply kicking dirt on the competition has long been a tactic for advertising underdogs in their quest for greater consumer awareness." 331

Bob Hirsch, a senior executive vice president with agency FCB/Leber Katz, credited one of the period's most widely discussed comparative campaigns for the successful launch of Prego spaghetti sauce. The campaign was also the focus of an unsuccessful three-year legal challenge by competitor Unilever/Van den Bergh Foods, marketer of the comparison brand, Ragu. As Hirsch told Advertising Age, regarding what was likely one of the most effective comparative campaigns of the twentieth century, "They had like a 50\% share of the category in the 1980 s and we had to find a way to show consumers we were better." 332 Figure 18 shows a key frame from one of the campaign's most memorable and widely discussed commercials, all of which consistently portrayed Ragu as thin and runny compared with thicker, slower-pouring Prego.

Sources during this period offered numerous insights into what they thought the advantages would be when using the Riding the Coattails tactic. One was simply to establish a product or brand as a legitimate member of a product or service category. Discussing a bout of comparative campaigns among business magazines Inc., Barron's, Dun's and Industry Week, a Forbes executive summarized this view:

This comparative advertising is not really new for us, but it is a change for some of the smaller publications.... To get a part of the action they have to become part of the field. It's how the women's books grew into a category. 333

Trade journal BtoB in 2003 similarly expressed this belief:

For the No. $2 \mathrm{~s}$ in a category, a comparative ad can be smart marketing. It allows the smaller player to place itself on the same pedestal as the market leader. Come decision-making time, the market leader and the challenger get mentioned in the same breath. ${ }^{334}$

Other sources also mentioned the effectiveness of comparative advertising when going up against competitors with significantly larger budgets. Kyle T. Craig, an executive vice president for Burger King, captured this view succinctly: "It can be an 


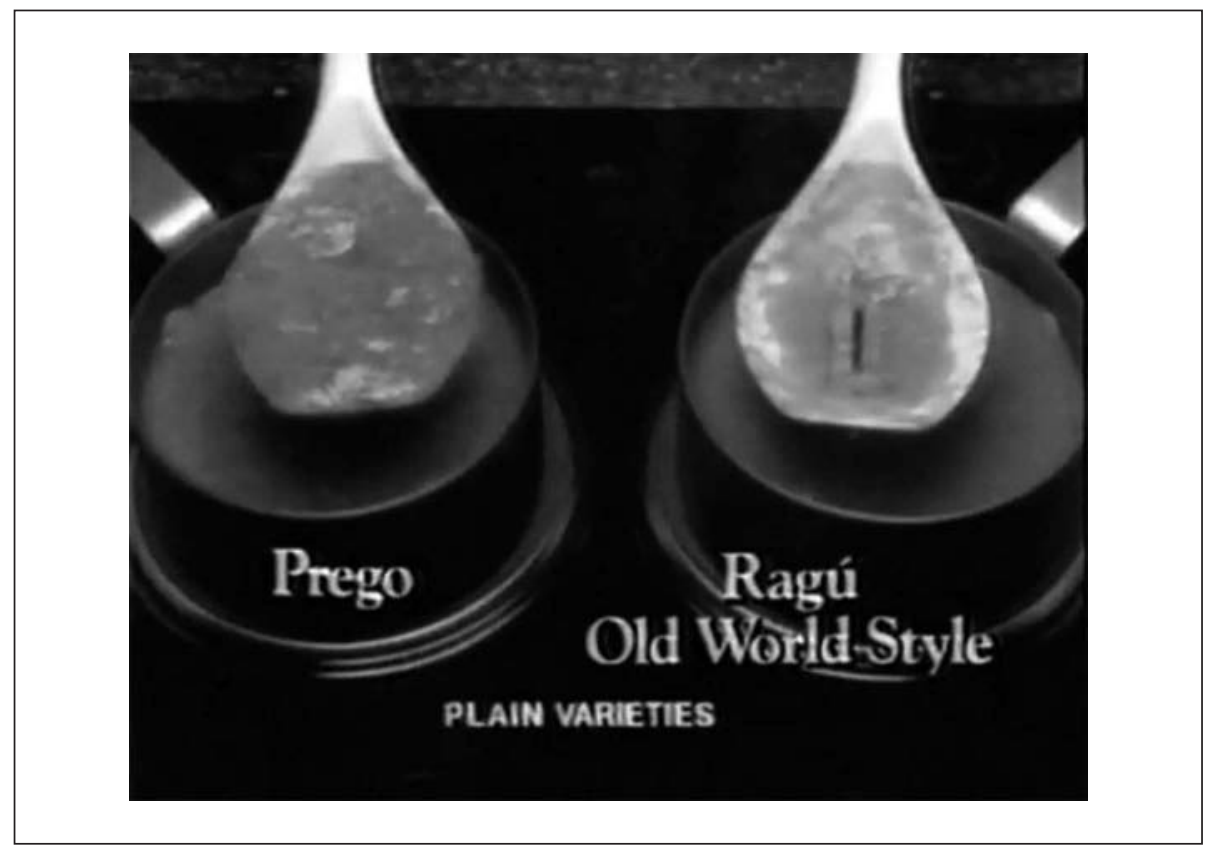

Figure 18. Prego.

Source: www.youtube.com. Prego is a registered trademark of CSC Brands, Inc.

extremely beneficial tactic, first, if your company is being tremendously outspent by the market leader." 335 Other advertisers mentioned simply comparing their products with larger competitors to take advantage of their popularity or because the competitor had established a product category. As Taco Bell's chief marketing officer Vada Hill told Advertising Age, in reference to a campaign comparing the company's Gordita Supreme to Burger King's Whopper via a taste-test,

We're not trying to say, "Don't eat burgers." Burger King was chosen for the taste test because "the Whopper is coming up as the product to beat" during focus groups and other marketing research.... We're really kind of putting their Whopper on a pedestal. ${ }^{336}$

Michelin Tire Corp., in 1994, similarly compared its new rain tire with Goodyear Tire \& Rubber Co.'s Aquatred because, as a vice president of brand marketing pointed out, "The (Aquatred) concept has such attention and notoriety brought to it, we felt that would be the most effective way to get our message across." 337

Arguably the most important and influential application of the Riding the Coattails approach occurred during this period — the product "knock-off" trend. Adman Herschell Gordon Lewis offered this insightful description of the marketing phenomenon: 
A sniff-alike perfume calls itself a "version" of Giorgio or Opium. An inexpensive watch used successfully as a premium has this descriptive line: "No, it isn't the $\$ 2,000$ museum watch-but your friends will think it is." This type of comparison is, really, coattail-riding. The comparison gains credibility through association (or deliberate) confusion with a similar item whose position is admittedly superior. ${ }^{338}$

By 1987, more than two dozen firms were marketing copycat fragrances, and the knock-off trend had spread to other product categories, including, especially, fashion and personal care products. Among perfume industry advertisers and observers, the belief was almost unanimous that - while the knock-offs captured some sales from the more expensive, upscale competitors they compared themselves with-they stole most of their sales from the mid-priced, mass-market brands that were not the target of their comparisons. Indeed, the knock-offs did not even sell in the same retail outlets as the high-end brands. As an Advertising Age author reported at the time, "Other market observers agree that mass fragrances, not class fragrances, are being hurt by knockoffs." 339 Even some fragrance industry executives, such as this one for upscale brand Oscar de la Renta, agreed, "Really, it has no effect on us at all. . . . Our customers don't shop at $\mathrm{K}$ mart [sic]." 340

Other upscale brands, such as Calvin Klein, however, resented the knock-offs and criticized these coattail riders for two reasons. One is that they viewed the exploitation of their brand names and registered trademarks as infringement. A second, which was explained by an attorney on behalf of Calvin Klein Cosmetics, was the concern that "a consumer who wants Obsession but first tries a copycat fragrance might never buy Obsession if the imitation is lower quality." 341 Calvin Klein sued, charging their principal foe, knock-off marketer Parfums de Coeur, with trademark infringement and with deception of consumers by implying that its brands were connected with Calvin Klein. Although the trademark-infringement claim failed, a federal district court judge did enjoin Parfums de Coeur to place a sticker on the packaging of its "Confess" brand, with the following disclaimer: "Designer IMPOSTERS-Designer Quality Fragrances, Not Designer Prices-PARFUMS DE COEUR." 342

The Twisting the Tiger's Tail approach, however, was mentioned far more frequently during this period, with many sources referencing the importance of making a claim of superiority in comparison with much larger competitors. This point of view was summarized well by Burger King executive Kyle T. Craig, who told Advertising Age that, for a comparative campaign to be effective, "there should be a clear and meaningful difference that can be exploited." 343 Twisting the Tiger's Tail was extremely prevalent in the automotive advertising of this period. Examples include Subaru comparing its models with Mercedes-Benz and Volvo, ${ }^{344}$ Ford comparing its Edge model with BMW and Lexus, ${ }^{345}$ and Chrysler comparing its LeBaron with BMW and Mercedes. ${ }^{346}$

Although there weren't many highly publicized examples of a tiger actually turning to bite, competitive retaliation was often mentioned as a risk. Moreover, a Snapple Fruit \& Juice Co. episode showed that it could happen. In 1989, Snapple ran a comparative ad in Atlanta, Georgia (hometown of Coca-Cola), showing a can of 
Coca-Cola Classic and declaring Snapple to be "The realer thing." Coca-Cola was not amused. The company not only accused Snapple of trademark infringement but also subpoenaed Snapple for proprietary company information in a completely unrelated legal case. As an Advertising Age author reported, "Snapple was ordered by an administrative law judge to show detailed documents — some dating as far back as 1975- of its business plans, including promotional expenses, expansion plans and other confidential information." ${ }^{347}$ Elaine Taylor-Gordon, president of Taylor-Gordon, Aarons, Snapple's ad agency, complained to Advertising Age: "We used some gentle humor and went for a little nibble, and they [Coca-Cola] are going for our throat." 348

Sources during this period also offered numerous insights into why the majority believed it would be a bad idea for larger advertisers to respond to comparative attacks by smaller competitors or ever mention them at all. Ford truck advertising manager Bill Glick, citing proprietary research, told Advertising Age: "We're told [in surveys] that when you're a leader, you should talk like a leader." 349 Wine marketing executive Peter Sealey also seemed to speak for many with this observation: "Comparative ads are good when you're new ... but when you're the standard, it just gives a lot of free publicity to your competitors." 350

Moreover, numerous advertisers specifically pointed to the danger of legitimizing a smaller competitor. The vice president-marketing for long-distance company MCI at the time, John Donoghue, claimed to be a direct beneficiary of this unintended outcome: "By naming us, AT\&T made this a two-horse race. . . . They are Goliath taking on David." ${ }^{351}$ As another source confirmed, regarding the same campaign,

AT\&T's inclusion of MCI in its advertising, even though it's negative, actually lends credibility and name-recognition to its rival. It is always a mistake for a market share leader to leave its pedestal, because doing so only builds awareness of lesser-known competitors. ${ }^{352}$

A marketing professor at Northeastern University also spoke for many toward the end of the period: "If I'm bigger than you and run advertising because I' $m$ better than you, a certain number of people who haven't heard of the upstart learn about them." 353

This was not the only point of view to find expression during this period, however, as to whether larger advertisers should ever mention smaller competitors in their advertising. Direct-response advertiser Herschell Gordon Lewis, with his application of what he called The Law of Comparative Advertising, offered this tactical advice: "If you're number two or smaller, attack a specific. If you're number one, ridicule generic opposition, don't single out or respond to one target." 354 On the other hand, some twenty years later, sources reported that cell phone provider Verizon was able to take advantage of consumer perceptions that second-place competitor AT\&T was actually the leader, and, as one source noted, able "to come out with its map campaign without it feeling like a bully." 355 As Karl Barnhart, managing partner of branding firm CoreBrand, further explained, "In this case, because AT\&T has the bigger brand, it didn't feel like bashing. It felt like Verizon was just being honest."

Another variation of the Twisting the Tiger's Tail tactic that emerged during this period is best described as the "Good Guy, Bad Guy" scenario. Employed by 
numerous typically small- to medium-sized banks, the Good Guy, Bad Guy scenario involved referring to larger competitors, some occasionally by name, as slow, impersonal, stodgy members of a "banking bureaucracy," unconcerned about customers and oblivious to their frustrations. ${ }^{356}$ Especially noteworthy about the campaigns was their sponsors' willingness to openly acknowledge the banking industry's frequently discussed problem with poor customer service. Quoting Robert Moss, president of Competitrack, a consulting company, Advertising Age reported, "It used to be that most banks wouldn't discuss service problems publicly for fear of insulting their employees.... But now, banks are acknowledging the fact that service levels are terrible. They're becoming more honest." 357

An important point of view emerged as to the credibility of comparative claims on behalf of smaller brands, whether it was the Riding the Coattails or the Twisting the Tiger's Tail approach. Some sources mentioned the concern that such claims would not be credible. Burger King's Kyle T. Craig captured this view perfectly: "Your company must be of legitimate size to have credibility with the consumer." 358 Some twenty years later, Wes Brown, a partner with marketing consultancy Iceology, similarly observed that automaker Ford was "risking a credibility problem by comparing the Edge with BMW and Lexus." ${ }^{359}$ Others, however, dismissed such concerns. ChryslerPlymouth advertising executive Mike Howe, with regard to advertising that compared Chrysler LeBaron to faux competitors BMW and Mercedes, captured this view:

We don't think these ads will necessarily change the minds of people who have the wherewithal to spend $\$ 35,000$ to $\$ 40,000$ for a Mercedes or BMW. But we believe we can intercept the consumer who aspires to those cars, but who doesn't have the money to buy them. ${ }^{360}$

Nature of the claim. As during previous periods, advertisers frequently referenced their belief that comparative advertising would most likely be effective if the product or service possessed a true feature of superiority. O\&M's executive vice president Graham Phillips summarized this point of view in a speech to the members of the AAAA: "Agencies and advertisers should consider comparative ads only when a brand has a clear and important functional performance advantage over a larger competitor that can be visually demonstrated or otherwise clearly explained in advertising." ${ }^{361}$ Citing the company's own proprietary research, Burger King spokesperson Joyce Meyers similarly explained to Advertising Age, "Consumers are saying, 'If you think you do something better, don't be afraid to say it." 362 This faith in a true feature of superiority was probably captured best in this statement near the end of the period, attributed to industry observer Roger Entner, a senior vice president with research company Nielsen Telecom, with regard to a Verizon attack on the iPhone: "This strategy can work quite well if you have a device that is truly better than the iPhone. ... As long as you can back it up. If not, you lose a lot of credibility." ${ }^{363}$

Also during this period, advertisers continued to express their belief that the feature or selling point that was the focus of a comparative claim needed to be salient to consumers. Joseph Ostrow, in his criticism of the Business Week ad shown in Figure 14, 
captured this view: "The kind of comparative ads that are useful are those dealing with issues of substance: Editorial quality, price, performance." ${ }^{364}$ In a lengthy piece devoted to this period's Analgesic Wars, an Advertising Age contributor described the undesirable consequences of failing to focus on salient features. As she wrote, "The risks in opting for comparative advertising of relatively insignificant points seem to be those of creating total cynicism among consumers toward advertising, rendering it ineffective as a promotional tool." 365

Related to the importance of salience, numerous advertisers acknowledged how easy it was for comparative advertising to distract them from a proper focus on it. Burger King executive Kyle T. Craig seemed to speak for many, in reference to one of his comparative campaigns: "It's very easy to get off track. You can get so caught up in competition that you forget the positioning."366 Adman Herschell Gordon Lewis, however, offered the most direct warning:

Be certain your comparison caters to the reader's question: "What's in it for me?" Ignoring that last caution means you're ignoring the reader. The biggest mistake marketers make when they compare their wares or services with a competitor's is forgetting (or worse, ignoring) why they're advertising in the first place. ${ }^{367}$

In reference to Figure 16's Compaq ad, advertising executive Mike Massaro, of agency Goldberg Moser O'Neill, similarly told Advertising Age, "It's like they're talking to their navel. . . . They're trying to make themselves feel good. . . . They're trying to make the argument about advertising as opposed to about products." 368 This point of view was also captured perfectly toward the very end of the period. As AT\&T's senior vice president-brand marketing and advertising Esther Lee admitted to Advertising Age, regarding the battle over 3G coverage between her company and Verizon, "It's dominated more our industry conversation than our consumer conversation. . . . It's time to get past the competitive conversation and talk about what's in it for the consumers." 369

Moreover, among the most widely held views, as it was during the previous period, was the believability of product demonstrations. O\&M's Graham Phillips summarized this belief: "Visual demonstrations of product superiority are viewed as objective and less prone to tampering . . . while taste preferences and 'statistical arguments' are discounted." 370 Although there were no other widely held majority views among the sources, some recommendations for improving the believability of comparative ads included the use of charts, graphs, and tables to illustrate comparisons, ${ }^{371}$ fact-based claims substantiated by independent sources, and two-sided versus one-sided arguments. ${ }^{372}$

Ads are more creative. This period revealed numerous examples of comparative advertising campaigns based on opportunism. By this time, three types of opportunities were clearly apparent among the findings: (1) the exploitation of an uncontrollable external event that affected a competitor in a negative way, (2) the discovery of a problem or limitation with a competitor's product or service, or (3) the exploitation of some purposeful change in a competitor's marketing strategy. One of the most 
famous comparative ads of all time-Pepsi's "The Other Guy Blinked"-is an obvious example of the third type. The ad ran in national newspapers on April 23, 1985, as Pepsi celebrated, and exploited, the opportunity created by its apparent victory in the Cola Wars, with Coco-Cola's announcement of a reformulation of their flagship soda (see Figure 19). This was not the final chapter in this story, however. When Coca-Cola introduced Coke II (a new name for the "New Coke" reformulation) seven years later, the company did so with taste-tests and comparative advertising that claimed the following: "Real cola taste, plus the sweetness of Pepsi."

During this period, one of the most widespread, and potentially destructive, instances of advertisers exploiting an external event with comparative advertising took place. As the savings and loan crisis of the late-1980s and early-1990s deepened, hundreds of savings and loan associations (S\&Ls) failed, and the federal government scrambled to draft bailout legislation. Numerous large, regional banks exploited the crisis with comparative advertising that questioned the financial solvency of their S\&L competitors. An author for Credit Union Management confirms how widespread this trend actually was: "If the financial industry had its say, the 11th Commandment would be 'Thou Shalt Not Criticize Each Other's Banks and S\&Ls in Public.' And that commandment would have been broken just about as often as the other 10 combined." $" 373$

In a memo to the CEOs of 200 banking institutions, federal banking regulator Michael Patriarca called on the banks to put a stop to the predatory comparative attacks. As he wrote,

Such ads, which are designed to undermine the public standing of other insured institutions, serve to increase the public's concerns.... I believe this is an embarrassing and self-defeating spectacle and the last thing the thrift industry needs in a time of record deposit outflows. ${ }^{374}$

Another federal regulator similarly criticized the trend, arguing that "cannibalistic advertising not only hurts thrifts but banks as well. It generally erodes depositor confidence, particularly in light of the difficulties." ${ }^{375}$ Indeed, the federal government viewed the problems caused by this opportunistic comparative advertising so seriously the House of Representatives Banking Committee proposed an amendment to the initial legislation enacted to bail out the S\&Ls, recommending that the Federal Deposit Insurance Corporation (FDIC) adopt regulations forbidding the use of advertising that disparaged other savings institutions.

A similar exploitation of problems with financial solvency took place among personal computer marketers during the early-1990s. As described in Advertising Age, "A few major computer marketers have already noticed and are promoting their own health-while casting aspersions on the competition." ${ }^{376}$ What makes this episode especially noteworthy, as well as somewhat ironic, is that among the PC makers running comparative ads implying some competitors were about to declare bankruptcy was Compaq Computer Corp., the advertiser responsible just a few months later for the ad shown in Figure 16, which declared the futility of such "mud-slinging" ads.

However, arguably the most striking historical example of comparative advertising that exploited an external event occurred in 1996. After a jury awarded Tylenol user 


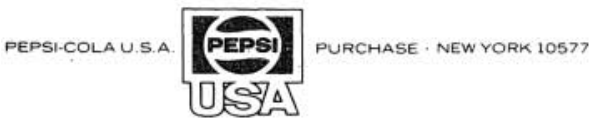

To all Pepsi Bottlers and Pepsi-Cola Company personnel:

It gives me great pleasure to offer each of you my heartiest congratulations.

After 87 years of going at it eyeball to eyeball, the other guy just blinked.

Coca-Cola is withdrawing their product from the marketplace, and is reformulating brand Coke to be "more like Pepsi." Too bad Ripley's not around... he could have had a field day with this one.

There is no question the long-term market success of Pepsi has forced this move.

Everyone knows when something is right it doesn't need changing.

Maybe they finally realized what most of us have known for years...Pepsi tastes better than Coke.

Well, people in trouble tend to do desperate things....and we'll have to keep our eye on them.

But for now, I say victory is sweet, and we have earned a celebration. We're going to declare a holiday on Friday.

Enjoy!

Best Regards,

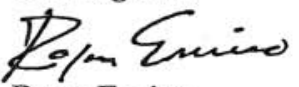

Roger Enrico

President, Chief Executive Officer

Pepsi-Cola U.S.A.

PEPSI. THE CHOICE OFA NEW GENERATION."

Figure 19. "To all Pepsi bottlers."

Source: The New York Times, April 23, 1985, D7. Pepsi is a registered trademark of PEPSICO Inc. 
Antonio Benedi $\$ 8.8$ million in a successful lawsuit against Johnson \& Johnson for the failure of his liver, he published a letter in his hometown newspaper, The Washington Times, criticizing the company. Seizing on the opportunity, Advil manufacturer American Home Products obtained Benedi's permission and republished the letter as a full-page ad in The New York Times.

Numerous other instances of comparative campaigns that creatively and opportunistically exploited the discovery of a problem or limitation on behalf of a competitor or a purposeful change in marketing strategy also occurred in the financial industry. During this period, banks repeatedly employed comparative campaigns that criticized competitors for charging higher fees, paying lower savings interest rates, closing branches, or merging with other banks. One such banking executive summarized his motives clearly: "We were taking advantage of a fairly short-lived opportunity." 377 Moreover, a Credit Union Management contributor confirmed that this exploitation was not limited to just the banks:

A group of Southern California credit unions is proud to let you know that they most emphatically do not invest in South American governments, junk bonds, Texas real estate or oil wells. And they are just as quick to let you know who does invest in all these economic no-nos: other financial institutions, specifically banks and S\&Ls. ${ }^{378}$

Comparative campaigns that exploited a limitation or weakness of a competitor, based on a competitor's marketing misstep, or failure to update or innovate its offerings, were employed in numerous other industries and product categories. Examples include a campaign for Buick Century that targeted an aging Ford Taurus, ${ }^{379}$ BMW claims that the Lexus ES300 was nothing more than a "dressed up Toyota Camry" because the automaker addressed declining profitability at the time by sharing parts between the two models, ${ }^{380}$ Anheuser-Busch's quality attack on Boston Beer Company for hiring regional brewers to brew Samuel Adams under contract, ${ }^{381}$ a Coca-Cola Vault soft-drink attack on Mountain Dew ("Don't Dew It") following an unpopular packaging redesign, ${ }^{382}$ comparative advertising on behalf of Ben \& Jerry's ice cream that criticized competitor Haagen-Dazs for reducing the size of its "pints" from sixteen to fourteen ounces, ${ }^{383}$ and Verizon's attack on AT\&T for its alleged spotty coverage and overtaxed network. ${ }^{384}$

An important creative trend to emerge during this period was the frequent discussion of and reliance on the creative tactics of satire and parody. Many advertisers during this period, for instance, employed satirical attacks on competitors' brand images. Some especially notable examples include a European Pepsi commercial in which rapper M. C. Hammer loses his ability to rap and is only able to croon the 1974 pop song "Feelings" after accidentally drinking a Coke (Coca-Cola tried to sue);385 a Joe Camel campaign with the theme "Never Boring," intended to portray the Marlboro cowboy as passé; 386 a 1994 campaign for RC Co.'s regional soda Kick that claimed Mountain Dew was "wimpy"; 387 a 1997 Procter \& Gamble campaign for Millstone coffee, portraying Starbuck Coffee Co. as a good place to buy t-shirts and novelties; 388 and a 2011 campaign in which Pepsi portrays Coca-Cola's iconic Santa Claus and polar bears disloyally preferring Pepsi. ${ }^{389}$ 
Many of the satirical comparative campaigns reflected an important trend identified during earlier periods - a strategic decision to respond directly to a competitor's advertising. Among these comparative campaigns and ads are several identifiable tactics: (1) using a competitor's actual ads in the advertiser's comparative ads; (2) portraying a competitor's employees in their recognizable uniforms, often consuming the comparative advertiser's product; and (3) parodying a competitor's brand name, slogan, or advertising theme. An example of the second tactic is a 2007 Pizza Hut commercial, showing Domino's and Papa John's delivery drivers-in uniform, and apparently on the job-eating pizza at the home of a Pizza Hut delivery driver. A stunning example of the third one occurred in 1994, when American Express hammered home its comparative claim of lower interest charges with this parody of competitor Visa's slogan: "Visa. It's everywhere you want to pay more interest charges." 390 A similar and notable example occurred a year earlier, after President Bill Clinton mentioned that his favorite candy bar was Baby Ruth. Nestlé ran an ad with the following copy: "When the new President said his favorite candy bar is Baby Ruth, nobody Snickered." 391

A sampling of other campaigns that parodied competitors' slogans, message strategies, and creative themes include a campaign for automaker Volvo that targeted BMW ("The ultimate driving machine, outdone by a Volvo") 392; GMC truck's 2002 response to Dodge Ram's "Mayor of Truckville" campaign ("If this is the mayor of Truckville, maybe it's time for a recount");393 a 2007 Microsoft ad that starts with a look-alike for actor John Hodgman, who plays the role of "PC" in Apple's successful "Mac vs. PC" comparative campaign ("Hello. I'm a PC. And I've been made into a stereotype") 394 ; a 2009 billboard featuring a photo of Buick LaCrosse with the headline "Another thing for Lexus to relentlessly pursue"395; Verizon's 2009 parody of Apple's "There's an App for That" with its own "There's a Map for That"396; and T-Mobile USA's 2011 parody of the "Mac vs. PC" campaign, featuring an attractive young woman repeatedly putting down the iPhone.

Only a few explanations for the use of satire in comparative advertising were offered by sources during this period. One, however, was the belief that it was fresh and innovative. This point of view was summarized well in the comments of Tom Pirko, an executive with beverage consultant Bevmark Inc., with regard to a RC Co. campaign that satirized Coca-Cola and Pepsi-Cola and its patrons: "People are tired of the same old messages." ${ }^{397}$ However, it was stated even more directly and insightfully by Ted Sann, chief creative officer with BBDO, who told Advertising Age that the beginning of the near-constant satirical give-and-take between Cola giants Pepsi and Coca-Cola could be traced to 1983, "when Pepsi was losing its edge in an advertising genre it had embraced. Lifestyle advertising was getting a little tired." 398

Degree of negativity. A majority of sources during this period expressed the belief that excessive negativity in comparative advertising was a bad idea. As Brock Luther, a Direct Marketing columnist, argued, "So how can you down your competition in a way that will pay off for you? You'll make your sales letters much more believable and, as a result, powerful if you go easy with the bad-mouthing." ${ }^{999}$ Referring to a spate of comparative advertising between Apple and Microsoft in 1992, agency 
BBDO/LA's Steve Hayden (a cocreator of Apple's watershed 1984 comparative commercial) tellingly told Advertising Age, "If the negative advertising is scary and manipulative, it's a disaster for a brand." ${ }^{400}$ Microsoft's vice president of systems strategy Jonathan Lazarus offered a similar point of view: "I don't think there's ever been a study that shows that negative advertising sells products." ${ }^{401}$ Bruce Cashbaugh, senior VP at Juhl Marketing Communications Inc., also seemed to speak for many: "When you throw dirt, you lose ground.... We don't think it's effective or desirable. If someone has to slam the competition, they probably don't have much to say for themselves." ${ }^{402}$

Moreover, Business Marketing helpfully summarized the findings of a 1992 poll of business-to-business marketing executives, conducted by Leo Shapiro \& Associates. The poll showed that in most industries, "negative advertising was seen as a bad tactic, ineffective, with little potential reward, and the chosen response to a competitor's negative ad would be promotion of good points or ignoring the attack." ${ }^{403}$ However, it is important to point out that the poll also showed that younger marketing executives held significantly more favorable views toward negative advertising, would be much more likely to respond with attack advertising of their own, and had more favorable beliefs that negative advertising would encourage sales.

The belief that excessive negativity would be ineffective was also summarized well in an Advertising Age editorial about the comparative war between Pizza Hut and Papa John's:

And so it goes. We can only imagine what the creative minds at Papa John's marketing department will come up with as an advertising rejoinder now that Pizza Hut has raised the level of nastiness a notch — unless someone rediscovers that advertising must leave behind a positive feeling about the advertiser's brand, not merely fire-bomb the opposition. Pizza Hut's latest tactic is what we see all too often in political campaign ads. ${ }^{404}$

Indeed, the concern that the comparative advertising of this period was beginning to resemble the much-criticized negativity of political attack advertising was a prevalent theme. This belief was summarized especially well by Steve Center, American Honda Motor Co.'s vice president of marketing operations: "Brand building is better than trying to undermine the competition. And, of course, no one wants automotive advertising to slip into the slimy muck that has swallowed so much of today's political advertising in the United States." 405

Sources during this period also offered some insights into what they believed constituted excessive negativity in comparative advertising. One theme was that comparative advertising would not be viewed as excessively negative if the claims it contained were true. This point of view was captured by Burger King president Jay Darling, when asked about McDonald's Corp. president Michael Quinlan's criticism that the ongoing Burger Wars were harmful for the fast food industry. As he told Advertising Age,

All we've done is talk about product. ... Our Chicken Tenders ads say they're real chicken cooked in vegetable shortening. I don't think that damages the industry, just as I don't think our "Broiling vs. frying" advertising damaged the industry. ${ }^{406}$ 
Another episode suggests that the perception of excessive negativity might depend on the product category. When Fuji Photo Film USA ran comparative advertising that merely implied competitor Kodak was "old-fashioned," and without even identifying Kodak by name, Advertising Age reported, "Industry experts agree the spot pushes the envelope in a field where ads usually feature warm and fuzzy images of children and families." 407

Another theme to emerge has to do with how to execute comparative advertising and avoid the consumer perception of excessive negativity. As direct-response advertiser Herschell Gordon Lewis advocated,

If you write exhortational copy for a living, comparative claims are just about the strongest weapon you can wield. . . . Best of all created with professional delicacy, a comparison can build buying desire without damning another product or company. 408

Referring to a comparative Pepsi ad that topped USA Today's Ad Meter for the 1994 Super Bowl, Pepsi executive Jeff Campbell told Advertising Age, "We have to be real careful with the competitive stuff . . . and not err on the side of being annoying."409 The same executive told two other Advertising Age contributors, regarding another comparative Pepsi campaign, "If you're too competitive it bums people out." 410 Agency president Adam Hanft proposed that the perception of excessive negativity could be avoided by not identifying a specific competitor. As he told Advertising Age, "Every commercial you do can be comparative. . . . The competition can be there in absentia." 411

Others pointed to the importance of tactical humor and, as some did in previous periods, maintaining a positive tone. As Ellen Koteff, the executive editor of Restaurant News, observed, with regard to the increasingly nasty comparative war between Pizza Hut and Papa John's,

I can't recall too many instances when mean-spirited comparative advertising scores points with me except, of course, when humor was involved. . . . Watching a playground fight is amusing for only so long, and after a while no one but the brawlers really cares or remembers who won. ${ }^{412}$

Dunkin Donuts chief branding officer Frances Allen also seemed to speak for many in her observation that "When you do comparison advertising it has to be fun and lighthearted." 413 Perhaps one of the most insightful observations, however, was offered by Apple's Steve Jobs, in response to a question about the "Mac vs. PC" campaign: "The art of those commercials is not to be mean, but for the guys to like each other." 414

Finally, the importance of a positive tone to avoid perceptions of excessive negativity was also mentioned by many sources. This theme was insightfully summarized by Domino's Pizza CEO David Brandon, in reference to a historically unique 2009 commercial, broadcast during a spring 2009 episode of "American Idol." During the commercial, Brandon used a 450-degree pizza oven to torch a letter he received from an attorney representing Subway Sandwiches Company, demanding he cease running comparative ads featuring the results of a national taste-test that found Domino's 
sandwiches preferred over Subway's. "So we poked a little fun, because we try not to take ourselves too seriously. However, we could never be mean or nasty." 415

\section{Discussion}

Many contemporary researchers on the topic of comparative advertising - such as Stanley Ulanoff, author of an early historical retrospective for the Marketing Science Institute ${ }^{416}$ - have reported that it is a relatively recent phenomenon, and point to the FTC's aggressive 1970s campaign to encourage it as a major transition point in its history. While the findings of this study show that the latter is no doubt a valid conclusion, they also confirm what other recent historical studies have reported, and that is that both implied and explicit comparative advertising played important roles in the history of advertising throughout the twentieth century.

The findings confirm that comparative advertising was often a source of debate and controversy during the first half-century of modern advertising's professional practice, and the flood of explicit comparative ads actually broke during the 1960s, a decade before the FTC's initiative. Although some of this history's primary and secondary sources consist of observations by industry pundits and trade journal editorials, the findings show that many of the twentieth century's most influential business executives, advertising professionals, and industry opinion leaders participated in the ongoing debate over comparative advertising's appropriateness, effectiveness, and ethicality. The full extent to which this debate occupied the advertising industry, and how deeply these issues reflected core principles of advertising practice, had not been reported in the literature prior to these findings.

There seems little doubt that the evolution of professional thought regarding the functions and attributes of effective advertising during the past 100 years had some influence on advertisers' views toward comparative advertising. Some historians suggest most advertisers at the turn of the last century favored a descriptive and emphatically rational approach due in part to embarrassment over the frequently dishonest "bombast and ballyhoo" and patent medicine advertising of the nineteenth century. ${ }^{417}$ This concern was quite evident among the early findings of this study. The announcement advertising of the late-nineteenth century eventually gave way to the belief advertising should persuade, and the informative school of thought, or what is often called the "hard sell," coexisted with the emotional and transformational "soft sell" throughout the twentieth century. ${ }^{418}$ Again, among this study's early findings were the obvious concerns that comparative advertising would not sell because advertisers believed it did not sufficiently inform or that it often failed to be persuasive.

Yet this study's findings offer substantially deeper insights beyond the influence of just professional, economic, or cultural context. The findings also highlight the goals and outcomes advertisers believed comparative advertising would be most effective for achieving and why. Moreover, while contemporary surveys of advertising professionals have shown that their beliefs regarding situational factors or moderators of comparative advertising effectiveness were quite consistent with the findings of scholarly research, the present findings also show that their beliefs regarding their effects on 
advertising process outcomes are more consistent than some prior research had suggested. ${ }^{419}$

For instance, advertisers clearly believed just as strongly in the last period as in the first that comparative ads encourage high levels of attention and recall. Returning to Table 1's model, scholarly researchers have concluded overwhelmingly that comparative advertising, versus noncomparative advertising, has significantly greater effects on such related cognitive outcomes as ad attention, ad interest, message recall, and message processing.

Related to this finding, it is important to note that some advertisers clearly believed comparative advertising was effective early on because of its novelty but that this would likely decrease over time. Some contemporary researchers, such as Donald Jackson and his colleagues - who predicted more than thirty years ago that the "novelty" of explicit comparisons would eventually wear out - have argued the same. ${ }^{420}$ However, this study's findings as well as surveys of contemporary creative professionals show that advertisers continue to believe comparative advertising is more effective than noncomparative advertising for achieving most cognitive outcomes. Some likely explanations for these beliefs include secondary exposure caused by lawsuits, secondary exposure and buzz via social media, ${ }^{421}$ and the fact that, despite the steady increase in their use during the second half of the twentieth century, comparative ads in most media continue to be in the minority.

Yet, the findings also show that many advertising professionals throughout the past 100 years believed that comparative advertising might encourage attention, but that it was the wrong kind of attention. Sources during every period mentioned that consumers might stop and look, but then move on without processing the advertiser's message. Although it is not entirely clear what they thought the problem was-beyond Claude Hopkins's apparent belief that comparative ads appeared "clownish"-there are at least a few other explanations for this belief: Comparative advertising often (1) failed to address itself to consumers, (2) addressed itself to competitors' advertising instead, or (3) failed to focus on salient benefits or, in many cases, any benefits at all.

Many sources argued in favor of the informativeness of comparative advertising, and such beliefs are consistent with the findings reported in the scholarly research literature that it has a positive effect on message recall and processing. Sources during every period expressed the belief that comparative ads were informative because they often highlighted the differences between competitive products or services. However, the findings also support an important conclusion regarding when comparative advertising will not be informative - many advertisers throughout the past 100 years acknowledged that comparative ads often cause confusion. Moreover, the findings also reveal that confusion is an important, multidimensional construct.

At the simplest level, comparative ads can cause confusion over which advertiser was actually the sponsor of the ad. This finding helps explain the consistent and widely held belief that comparative advertising creates awareness for competitors, and why brand-name recall is one of the few cognitive outcomes for which the findings of empirical research and surveys of advertising creatives remain somewhat contradictory (see Table 1). There were also concerns, though, with regard to confusion caused 
by the message. Confusing messages often occur as a consequence of advertising wars, when advertisers begin focusing their ads on each other's messages and claims, and depart further and further from their own selling points, benefits, and positions. By the final period, the findings show that advertisers had identified numerous reasons why comparative ads can cause confusion, such as consumer lack of knowledge regarding the comparison brand or the old problem with directly conflicting claims. However, the most important would appear to be that comparative ads often lack sufficient sponsor identification.

Table 1's summary of the research literature shows that the effects of comparative ads, versus noncomparative ones, on claim and message believability are inconclusive. The historical findings of this study are consistent with this conclusion. Although advertising professionals during nearly every period expressed the belief that comparative ads are more believable, and surveys of creative executives also show they believe comparative ads are more believable than noncomparative ones, the findings show that concerns about believability were prevalent during every period. In fact, beliefs regarding the believability of comparative advertising were overwhelmingly negative during the first two periods, although these beliefs were associated predominantly with knocking ads and the tactics of criticizing all competitors as inferior or their advertising dishonest.

The findings show that advertisers during almost every period recognized three important problems with believability: (1) Comparative ads are frequently not believable, (2) they cause disbelief of all the advertising of the competitors in a particular product category, and (3) they reflect negatively on the veracity of advertising as an institution. However, it is also important to note that concerns about the effects of comparative advertising on the believability of all advertising peaked during the 1960s to 1970 s, and then almost disappeared during the final period, suggesting an important change over time.

The findings also show that concerns about damage to the institutional veracity of advertising during the first three periods were substantially rooted in concerns about advertising's unseemly past and the desire to advance the professionalism of its practice. Moreover, it also seems apparent that the major industry concerns related to advertising's institutional status occurred concurrently with periods of rising consumerism and heightened public criticism, which were subsequently linked to calls for further government regulation of advertising. Historian Inger Stole has proposed that Americans witnessed the rise of three such influential consumer movements in the 1900s, 1920s to 1930s, and 1960s, ${ }^{422}$ and researchers Fred Beard and Chad Nye reported that the peak periods of concerns and criticisms about comparative advertising among publishers and media owners also followed a similar chronological pattern. ${ }^{423}$

The findings support important conclusions regarding when advertisers believe a comparative ad will likely be less believable than a noncomparative one. First, advertisers believe comparative ads will not be believable if competitors are making directly contradictory claims and, especially, if these occur as part of an ongoing advertising war. This finding is consistent with a recent historical study of advertising wars that 
found that one of their main consequences is that they almost always lead to increasingly exaggerated, and potentially misleading, claims. ${ }^{424}$ These concerns and beliefs about believability are also consistent with empirical research findings confirming that comparative advertising frequently causes counterargument and source derogation (see Table 1). The findings show that advertisers were concerned throughout the past 100 years that the believability of comparative advertising would often be delimited by the inherent cynicism associated with comparative claims and the identification of a competitor.

The problems with believability of comparative advertising itself and the advertising of all the competitors in a product or service category are also linked to the practice, which emerged in the 1930s, of attacking a competitor's advertising or responding directly to it. This finding is especially interesting because advertisers continue to attack each other's advertising even today (e.g., AT\&T's widely criticized response to Verizon's "There's a Map for That," starring actor Luke Wilson), despite the early and almost overwhelming belief that it was rarely, if ever, a good idea. In fact, this tactic became one of the standard means for exploiting an opportunity in a comparative way, especially with the prevalent use in the final period of satire and parody targeting competitors' employees, spokescharacters, slogans, and themes.

The findings show that many advertisers throughout much of the previous century believed that most consumers do not like comparative advertising and that it often encouraged negative attitudes toward their own ads and possibly their brands. Studies of both commercial comparative and political attack advertising also suggest that people do not like them very much. ${ }^{425}$ Indeed, only a few advertisers throughout the past century expressed the belief that consumers like comparative advertising. This is also obviously consistent with the findings reported in the scholarly research literature, which have shown that comparative ads do, on the average, have a negative effect on $\mathrm{A}_{\mathrm{ad}}$.

Among the findings are several valuable insights into what advertising practitioners believe causes negative $A_{a d}$, and findings also suggest they changed somewhat over time. During the first half of the century, advertisers frequently mentioned the belief that comparative advertising would be perceived as excessively competitive and in poor taste. During the 1970s, many argued that name-naming and name-calling were synonymous and would lead to negative attitudes. Yet, it is important to note that there was quite a bit of evidence during the 1970s - few viewer complaints to the television networks, few consumer complaints to advertisers, and the Tueros cigars poll-that suggests advertisers may have been projecting their own dislike of what they viewed as disparagement onto consumers. Beard and Nye similarly reported that there was little evidence that consumers complained much about comparative advertising to either early publishers or the television networks during the 1970s. ${ }^{426}$ Another important finding with regard to $\mathrm{A}_{\mathrm{ad}}$ is that, by the final period, the mere identification of a competitor was never mentioned as a cause of negative attitudes. This likely occurred simply because by this time, as one source reported, "Brand X" comparisons had become much less frequent. 
These findings are also related to positive versus negative attitudes toward the advertiser and brand, or $\mathrm{A}_{\mathrm{br}}$, caused by comparative ads and campaigns. Advertisers recognized the potential for backlash throughout the past 100 years, especially among the users of the comparison product or service. This finding is consistent with empirical research findings supporting a negative effect of comparative advertising on brand loyalty and repeat purchase. It is also consistent with the overall conclusion from Beard's 2011 survey that today's creative executives have less confidence in the favorable effects of comparative advertising on positive branding, when compared with their peers from the 1980s. Moreover, sources during the final period also raised the interesting possibility that the potential for backlash might be affected somewhat by the nature of the product or service category in question (e.g., health care).

With regard to conative advertising outcomes, most advertisers during the first period believed comparative advertising would not have a positive effect on sales, although the Reach for a Lucky campaign was widely held to be a contributing factor to the brand's sales success. As Table 1 shows, the empirical literature supports conclusions that comparative advertising is more effective than noncomparative advertising for achieving $\mathrm{P}_{\mathrm{i}}$ and initial trial. There was a change in these beliefs over time, however, with sources during the first two periods rarely attributing sales effectiveness to comparative ads. But by the 1960s and 1970s, many more frequently began referring to comparative campaigns that had positive effects on sales, and the final period revealed numerous examples of successful comparative campaigns, as well as examples of its more frequent use for initiating trial.

The findings also revealed some interesting and important dynamics regarding advertisers' relationships with channel members. At the simplest level, some did not favor comparative campaigns simply because they happened to sell products manufactured by both the comparative advertiser and the comparison brand. This problem first emerged in the Reach for a Lucky campaign, but then periodically throughout the twentieth century. On the other hand, some channel members - especially franchisees or other exclusive distributors of the advertised product - often favored aggressive comparative campaigns, and their influence on manufacturer advertising campaigns was revealed as significant. In some cases, they even created their own comparative ads and campaigns, when they wanted a more aggressive approach.

This issue has been almost entirely ignored in the academic research literature with a single exception. In 2009, researchers Greg Shaffer and Florian Zettelmeyer sought to develop a game-theory explanation for how channel members might influence an advertiser's decision to use comparative versus noncomparative advertising and how negative the advertising might be. They concluded that an advertiser would be more likely to choose noncomparative advertising if the advertiser had the opportunity to implement in-store displays with retailers because it would only be desirable for retailers to cooperate if the displays would increase their overall profits. And as they observe, this would only be the case "if the manufacturer's advertising message is noncomparative or if the advertising message is comparative but its emphasis is not too negative about the manufacturer's rival." ${ }^{27}$ 
Another interesting finding is that the use of comparative advertising for new products and brands, and the Riding the Coattails and Twisting the Tiger's Tail tactics were rarely mentioned by advertisers prior to the 1960s and 1970s. By the final two periods, however, discussion and use of these approaches had become commonplace. The use of these tactics is, of course, entirely consistent with empirical research findings that comparative advertising is effective for achieving initial brand trial, and will be more effective for new brands and competitors with smaller market shares, and less effective for those with larger shares and those with high levels of brand loyalty.

Among the findings, however, are deep insights into when these conditions hold, or not, and why advertisers believe they do. The findings show that advertisers recognized several strategic and tactical advantages to campaigns that compared new, less popular, or low-end products with well-known, often higher-priced competitors. For instance, advertisers of new products often favored the Riding the Coattails approach simply because it attracted attention, because it exploited the larger advertising expenditures of leading brands, or because associating a product with a popular competitor was an effective means for quickly informing consumers about its features, uses, and benefits. Other tactical advantages are attitudinal and persuasive, such as establishing value or upgrading brand image. And it is also interesting to discover that there was a change over time with regard to this tactic. By the final period, it appears that Twisting the Tiger's Tail had become much more common than mere coattail riding, and that many advertisers had come to believe that comparative campaigns targeting larger competitors should almost always include a differentiative claim of superiority.

Researchers have recently offered additional empirical and theoretical explanations for the effectiveness of these tactics. For instance, and based on the ELM and congruity theory, Joseph Priester and his colleagues started with the widely held assumption that consumers are more likely to elaborate on the claims in such comparative ads because the mere mention of a more familiar comparison brand causes greater perceptions of relevance, which in turn prompts increased elaboration. However, they concluded that the more dissimilar the sponsored and comparison brands are perceived to be, the greater will be the elaboration. As they summarize, "It is not the comparison per se that prompts elaboration, or the presence of a high-market share brand. Rather, it is the presence of relatively incongruent brands that leads to increased elaboration." 428

By the final period, there also emerged a point of difference as to the believability and/or credibility of the claims made by smaller advertisers in tail-twisting comparative ads, especially those targeting much more prestigious faux competitors. Some sources clearly questioned whether such campaigns, frequently employed by automotive advertisers during this period, would be believable. Moreover, one source cited an industry study conducted in 1998, which found some consumers were actually offended by such "apples to oranges" comparisons. This situational factor has received considerable recent empirical and theoretical attention. Researchers Stuart Van Auken and Arthur Adams carried out a series of studies on "across-class" comparative advertising between 1998 and 2006. Basing their research on assimilation theory, they reported that comparative ads creating across-class associations with a leader in a more prestigious class but within the same product category, such as Chrysler's 1998 
comparison with BMW and Lexus, can increase the perceived value for the comparative advertiser's product. In addition, the development of such associations with a leader in a more prestigious class can also result in differentiation from within-class rivals. ${ }^{429}$

The findings do, however, reveal instances in which larger advertisers did target smaller competitors with their comparative advertising. For example, during the computer industry contraction of the early-1990s, some manufacturers actually tried to use comparative advertising to kill off smaller, weaker competitors by exploiting their weaker financial conditions. This finding clearly suggests important advantages to comparative advertising that can occur in specific marketing situations. Still, the findings offer consistent explanations for why advertisers throughout the past 100 years widely agreed that smaller competitors should be ignored-Attacking them is inconsistent with the preferred image for a brand leader (the "bully" effect), it creates awareness for a lesser-known brand, and it can legitimize smaller or weaker competitors (i.e., pull them up on the pedestal with the leader).

The findings support some important conclusions regarding the nature of the claim, comparative advertising creativity, and degree of negativity. The summary of empirical research and survey findings shown in Table 1's model shows that comparative advertising, on the average, will be more effective for products of high quality, and when claims are well substantiated, they focus on salient benefits and are believable. This study's findings show that the majority of advertisers held these beliefs and there was very little change in them over time. However, the findings offer some insights into when and why these situational factors will have positive or negative effects and, more importantly, relationships among them.

With regard to the substantiation of claims made in comparative ads, little was mentioned during the first two periods. There was some favorable reference in the final two periods to the use of what Dhruv Grewal and his colleagues called "credibility enhancers" 430 - the use of credible sources, two-sided messages, or the support of claims with objective versus subjective information-although not a great deal. In addition, though, by the third and fourth periods, perhaps with the more frequent use of explicit comparative advertising, there emerged a definite preference for substantiating claims with side-by-side product demonstrations, the more visual the better. Advertisers similarly had little to say about the relationship between comparative advertising and the salience of benefits, beyond the warning that it is easy for comparative ads to lose focus on them. The belief that this often occurs when advertisers begin addressing their ads to each other's advertising emerged in the 1930s and remained consistently widespread throughout the remaining periods.

One important belief regarding creativity in comparative advertising, and linked to the avoidance of negative attitudes toward both comparative ads and advertisers, that remained consistent throughout the past 100 years was the importance of maintaining a positive tone and of leaving consumers with pleasant brand associations. Of course, the findings also revealed numerous instances in which comparative advertisers apparently found those to be difficult rules to follow. 
Other findings also show that creativity in comparative advertising is closely linked to advertisers' beliefs about the degree of negativity in comparative ads, what advertisers believed characterized it, and how these beliefs changed over time. Advertisers seemed to appreciate the importance of being competitive but also frequently talked about "hitting below the belt" and appearing to be "overly competitive" or "mean." Some of these beliefs were consistently held throughout the more than 100 years represented by the data.

There are theoretical explanations for why criticizing a competitor's product may be less risky for an advertiser, rather than disparaging their brand images - a tactic less likely to be perceived as especially mean-spirited or "nasty" by consumers. Citing Harold Kelley's application of attribution theory, researchers Karen James and Paul Hensel argue that people are more influenced by information they obtain from someone else about a third entity if that information pertains to the entity's factual performance or actions. ${ }^{431}$ Other researchers have found that low-negativity comparative ads and those possessing fewer negative/derogatory references to competitors are perceived more favorably by consumers, ${ }^{432}$ as are comparative ads of moderate "intensity." ${ }^{433}$ More important, both the quantitative and qualitative findings from Beard's survey confirm that top creatives believe the effective execution of a comparative ad critically depends on its tone. The fact that advertisers often mentioned that excessive negativity was bad but frequently produced such ads anyway suggests an important managerial implication of this study's findings - comparative ads should probably be tested more rigorously than just about any other type of ad.

Also with regard to creativity, the findings reveal the frequent use of humor beginning in the second period and consistently thereafter, often with the belief that it would soften the perceived negativity of comparative advertising. The more frequent discussion and apparent use of humorous parody and satire in the final period is a tactic that has been almost entirely ignored in the academic literature. Related tactics, such as the use of a competitor's uniforms and, especially, the satirization and parody of a competitor's creative themes, slogans, and spokescharacters, were consistently used and linked to some tactical advantages, if not merely the capturing of attention. In some cases, the tactic was used to identify competitors without actually naming them. The use of humor in explicit comparative ads is also consistent with predictions of effectiveness based on the ELM and the distraction hypothesis. In addition to leaving consumers with a positive impression, the inclusion of satire or humorous parody could distract consumers from counterarguing with a comparative ad's claims, leading to attitude change by way of the ELM's peripheral route to persuasion.

Perhaps the most interesting finding related to comparative advertising creativity is its use to exploit opportunities. This is a practical advantage encouraging the use of comparative advertising, which emerged during the second period and that had never been examined in the scholarly literature. For instance, advertisers often used comparative advertising to exploit the discovery of a problem or limitation with a competitors' product or service. And although advertisers initially resisted the FTC's efforts to encourage more comparative advertising in the 1970s, this likely led to exactly the kind of consumer benefit the FTC had in mind. On the other hand, although the 
exploitation of uncontrollable events that affected competitors and some purposeful change in a competitor's marketing strategy were frequent, and produced some historically significant campaigns and ads, they were less likely to produce comparative advertising with the same kind of consumer benefit. Indeed, banks' exploitation of the financial crisis of the 1980s and computer marketers' exploitation of the technology slump in the 1990s offer some especially good examples.

It is also likely that the more frequent and tactical uses of comparative advertising in the United States were influenced during the second half of the twentieth century by changes in the law. First, there was the legal precedent that established the acceptable use of a competitor's trademark, even on packaging and in comparative ads. This obviously made it much easier, and legally safer, to use explicit comparative advertising. Second, although sources did not mention it, an important change to the Lanham Trademark Act no doubt helps explain why comparative advertising more frequently led to the unintended consequence of a lawsuit during the final period. When advertisers sue over comparative advertising, it is almost always under Section 43(a) of the Lanham Trademark Act. Prior to November 16, 1989, advertisers could only sue other advertisers for alleged false statements they made about their own products or services. However, the Trademark Law Revision Act of 1988 allowed one advertiser to sue another for comparative advertising that misrepresented the nature, characteristics, or qualities of the complainant's product or service.

As a final, overall conclusion, it is interesting to note that every outcome and situational factor summarized in Table 1's model was evident among the historical data and findings. This suggests that academic researchers over the years have often addressed research questions and topics of importance to advertising practitioners. In addition, though, it is helpful to point out what never got mentioned during approximately 110 years of professional debate over the topic. For instance, beyond users and nonusers of the comparison product or service, advertisers never discussed the target audiences most likely to respond favorably to comparative campaigns. Some research suggests that younger consumers as well as male consumers have more favorable attitudes toward political attack advertising, ${ }^{434}$ yet age and gender were never mentioned. Moreover, some of the most recent research on commercial comparative advertising has confirmed that men and women not only process the ads differently but also respond differently with regard to $\mathrm{A}_{\mathrm{ad}}, \mathrm{A}_{\mathrm{br}}$, and $\mathrm{P}_{\mathrm{i}}{ }^{435}$ Other interesting and important situational factors that were rarely discussed include the use of comparative advertising in different media or its use for various types of products or services.

\section{Limitations and Future Research Recommendations}

The findings and conclusions of this study are, of course, limited in several ways. Some advertising historians, as well as some of this study's sources, suggest that the use of frequently aggressive comparative advertising did occur during the nineteenth century. However, data collection was limited to the twentieth century and the first two decades of the twenty-first. As noted earlier, although the method is consistent with traditional and empirical historical research methods, it does lack strong evidence 
for reliability and validity. This study is also limited by the sources used for the second two periods, mainly in that the beliefs and opinions of advertisers, although still often in their own words, inevitably became somewhat filtered by the trade journalists who interviewed them. Finally, the study is limited somewhat by its conceptual and historical focus on the "Americanization" of advertising, and by the exclusion of professional beliefs and historical practices in other countries and cultures. Historian Stefan Schwarzkoph suggests that this final limitation is one shared by many, if not most, of the advertising histories published between 1980 and 2010.436

The findings suggest several worthy topics for future research on some situational factors that are believed to moderate the effectiveness of comparative advertising. However, perhaps the most important, as suggested above, is the lack of attention paid to different product types. Rogers and Williams's and Beard's surveys are among few recent studies to offer any insight regarding the effectiveness of comparative advertising for different types of products (e.g., consumer durables vs. nondurables). Moreover, of the approximately fifty studies of comparative advertising published between 1998 and 2012, only one examined the effects of product type or product attributesCarolyn White Nye and her colleague's study of brand novelty. ${ }^{437}$ Indeed, a search of the literature and the references of Rogers and Williams's article and Grewal and his colleagues' meta-analysis revealed only two studies of the effectiveness of comparative advertising for nonprofessional consumer services. ${ }^{438}$

Future historical research on comparative advertising could also helpfully replicate and extend this study's findings by comparing them with works written by prominent advertising professionals, such as Charles Austin Bates, Earnest Elmo Calkins, Fairfax M. Cone, David Ogilvy, Rosser Reeves, and James Webb Young. 439

Finally, both the quantitative and qualitative findings for this study confirm that top creatives believe the effectiveness of a comparative ad critically depends on its tactical execution and tone. Yet, sources only rarely discussed how to effectively execute a comparative ad in ways that would overcome the risks they so frequently pointed to. Moreover, negative consumer perceptions of the tone of a comparative ad could be an important reason why today's advertising creatives believe such ads often conflict with positive branding. ${ }^{440}$ However, qualitative tone has rarely been examined, beyond a small handful of works that have focused on "negative" comparative advertising. ${ }^{441}$ Future research could helpfully build on the findings of these studies to more fully explain when a comparative ad will likely be perceived as excessively negative or mean-spirited and more likely to encourage backlash, and how such perceptions might be moderated, as the findings here suggest, by the tactical use of humor.

\section{Declaration of Conflicting Interests}

The author(s) declared no potential conflicts of interest with respect to the research, authorship, and/or publication of this article.

\section{Funding}

The author(s) received no financial support for the research, authorship, and/or publication of this article. 


\section{Notes}

1. Fred K. Beard, "Comparative Advertising Wars: An Historical Analysis of Their Causes and Consequences," Journal of Macromarketing 30 (September 2010): 270-86.

2. Kishore G. Pillai and Ronald E. Goldsmith, "How Brand Attribute Typicality and Consumer Commitment Moderate the Influence of Comparative Advertising," Journal of Business Research 61 (September 2008): 933-41; Mehmet I. Yagci, Abhijit Biswas, and Sujay Dutta, "Effects of Comparative Advertising Format on Consumer Responses: The Moderating Effects of Brand Image and Attribute Relevance," Journal of Business Research 62 (August 2009): 768-74.

3. Fred K. Beard, “An Historical Analysis of the US Advertising Industry's Self-Regulation of Comparative Advertising," Journal of Historical Research in Marketing 4 (2012): 369-86.

4. Thomas E. Barry and Roger L. Tremblay, "Comparative Advertising: Perspectives and Issues," Journal of Advertising 4 (Summer 1975): 15-20; Fred K. Beard, "Practitioner Views of Comparative Advertising: A Twenty-Year Update," Journal of Advertising Research (forthcoming); Robert D. Hisrich, "Executive Advertisers' Views of Comparison Advertising," Sloan Management Review 25 (Fall 1983): 39-50; Darrel D. Muehling, Donald E. Stem Jr., and Peter Raven, "Comparative Advertising: Views from Advertisers, Agencies Media, and Policy Makers," Journal of Advertising Research 29 (October/November 1989): 38-48; John C. Rogers and Terrell G. Williams, "Comparative Advertising Effectiveness: Practitioners' Perceptions versus Academic Research Findings," Journal of Advertising Research (October/November 1989): 22-37.

5. Fred K. Beard and Chad Nye, "A History of the Media Industry's Self-Regulation of Comparative Advertising," Journalism History 37 (Summer 2011): 113-21.

6. Beard, "Comparative Advertising Wars"; Fred K. Beard, "Competition and Combative Advertising: An Historical Analysis," Journal of Macromarketing 31 (December 2011): 387-402.

7. Richard W. Pollay, "The Subsiding Sizzle: A Descriptive History of Print Advertising, 1900-1980," Journal of Marketing 49 (Summer 1985): 24-37.

8. Stephen W. Brown and Donald W. Jackson Jr., "Comparative Television Advertising: Examining Its Nature and Frequency," Journal of Advertising 6 (Fall 1977): 15-18.

9. Brown and Jackson, "Comparative Television Advertising."

10. Peter L. Wright and Frederic Barbour, "The Relevance of Decision Process Models in Structuring Persuasive Messages," Communication Research 2 (July 1975): 246-59.

11. Roobina Taschian and Mark E. Slama, "Involvement and the Effectiveness of Comparative Advertising," Current Issues and Research in Advertising 1 (September 1984): 79-92.

12. Naveen Donthu, "Comparative Advertising Intensity," Journal of Advertising Research 32 (November 1992): 53-58; Susanne M. Robinson, "One Message, Twelve Markets," The Journal of European Business 5, no. 3 (1994): 16-18; David W. Stewart and David H. Furse, Effective TV Advertising: A Study of 1000 Commercials (Lexington: Lexington Books, 1986).

13. Linda E. Swayne and Thomas H. Stevenson, "Comparative Advertising in Horizontal Business Publications,” Industrial Marketing Management 16 (February 1987): 71-76.

14. Fahad S. Al-Olayan and Kiran Karande, "A Content Analysis of Magazine Advertisements from the United States and the Arab World," Journal of Advertising 29 (Autumn 2000): 69-82.

15. Brown and Jackson, "Comparative Television Advertising." 
16. Bill Abrams, "Comparative Ads Are Getting More Popular, Harder Hitting," The Wall Street Journal, March 11, 1982, 27.

17. Robert Levy, "Big Resurgence in Comparative Ads," Dun's Business Month, February, 1987, 56-58.

18. Cornelia Pechmann and David W. Stewart, The Development of a Contingency Model of Comparative Advertising (Cambridge, MA: Marketing Science Institute, 1990).

19. Abrams, "Comparative Ads are Getting More Popular."

20. John Koten, "More Firms File Challenges to Rivals' Comparative Ads," The Wall Street Journal, January 12, 1984, 27.

21. Levy, "Big Resurgence in Comparative Ads."

22. Quoted in Stanley I. Tannenbaum, "For and against Comparative Advertising-For," Advertising Age, July 5, 1976, 1, 28.

23. Emily B. York, "The Gloves Are Off: More Marketers Opt for Attack Ads," Advertising Age, May 25, 2009, 4, 5.

24. Karen E. James and Paul J. Hensel, "Negative Advertising: The Malicious Strain of Comparative Advertising," Journal of Advertising 20 (June 1991): 53-69; Alina B. Sorescu and Betsy D. Gelb, "Negative Comparative Advertising: Evidence Favoring Fine-Tuning," Journal of Advertising 29 (Winter 2000): 25-40.

25. Susan T. Fiske, "Attention and Weight in Person Perceptions: The Impact of Negative and Extreme Behavior," Journal of Personality and Social Psychology 36 (June 1980): 889-906.

26. Karen Johnson-Cartee and Gary Copeland, "Southern Voters' Reaction to Negative Political Ads in the 1986 Election," Journalism Quarterly 66 (Winter 1989): 888-93, 986.

27. David L. Hamilton and Mark P. Zanna, "Differential Weighting of Favorable and Unfavorable Attributes in Impression Formation," Journal of Experimental Research in Psychology 6, no. 2-3 (1972): 204-12.

28. David E. Kanouse, "Explaining Negativity Bias in Evaluation and Choice Behavior: Theory and Research," Advances in Consumer Research 11 (1984): 701-708.

29. John F. Nugent, "Positively Negative," Campaigns and Elections 7 (March 1987): 47-49.

30. Kanouse, "Explaining Negativity Bias"; Kathy Kellerman, "The Negativity Effects and Its Implications for Initial Interaction," Communication Monographs 51 (March 1984): $37-55$.

31. Richard E. Petty and John T. Cacioppo, The Elaboration Likelihood Model of Persuasion (New York: Springer Verlag, 1986).

32. William R. Swinyard, "The Interaction between Comparative Advertising and Copy Claim Variation," Journal of Marketing Research 18 (May 1981): 175-86.

33. Leon Festinger and N. Macoby, "On Resistance to Persuasive Communication," Journal of Abnormal and Social Psychology 68 (April 1964): 359-66.

34. Huiuk Yi, "The Influence of Comparative Advertising and Amount of Information on Attitude Accessibility" (PhD. diss., University of Alabama, 1995).

35. Dhruv Grewal, Sukumar Kavanoor, Edward F. Fern, Carolyn Costley, and James Barnes, "Comparative versus Non-Comparative Advertising: A Meta-Analysis," Journal of Marketing 61 (October 1997): 1-15.

36. Grewal et al., "Comparative versus Non-Comparative Advertising"; Rogers and Williams, "Comparative Advertising Effectiveness"; Beard, "Practitioner Views of Comparative Advertising."

37. Naveen Donthu, "A Cross-Country Investigation of Recall and Attitude toward Comparative Advertising," Journal of Advertising 27 (Summer 1998): 111-22. 
38. Michael J. Barone and Paul W. Miniard, "How and When Factual Ad Claims Mislead Consumers: Examining the Deceptive Consequences of Copy x Copy Interactions for Partial Comparative Advertisements," Journal of Marketing Research 36 (February 1999): 58-74; Michael J. Barone, Kay M. Palan, and Paul W. Miniard, "Brand Usage and Gender as Moderators of the Potential Deception Associated with Partial Comparative Advertising." Journal of Advertising 33 (Spring 2004): 19-28.

39. Amitav Chakravarti and Jinhong Xie, "The Impact of Standards Competition on Consumers: Effectiveness of Product Information and Advertising Formats," Journal of Marketing Research 43 (May 2006): 224-36; Donthu, “A Cross-Country Investigation”; Alan T. Shao, Yeqin Bao, and Elizabeth Gray, "Comparative Advertising Effectiveness: A Cross-Cultural Study," Journal of Current Research \& Issues in Advertising 26 (Fall 2004): 67-80.

40. Chingchang Chang, "The Relative Effectiveness of Comparative and Noncomparative Advertising," Journal of Advertising 36 (Spring 2007): 21-35; Yung Kyun Choi and Gordon E. Miracle, "The Effectiveness of Comparative Advertising in Korea and the United States," Journal of Advertising 33 (Winter 2004): 75-87; Debora V. Thompson and Rebecca W. Hamilton, "The Effects of Information Processing Mode on Consumers' Responses to Comparative Advertising," Journal of Consumer Research 32 (March 2006): 530-40.

41. Chang, "The Relative Effectiveness"; Jung Ok Jeon and Sharon E. Beatty, "Comparative Advertising Effectiveness of Different National Cultures," Journal of Business Research 55 (November 2002): 907-13; A. V. Muthukrishnan, Luk Warlop, and Joseph W. Alba, "The Piecemeal Approach to Comparative Advertising," Marketing Letters 12 (February 2001): 63-73; Thompson and Hamilton, "The Effects of Information Processing."

42. Barone and Miniard, "How and When"; Paul W. Miniard, Michael J. Barone, Randall L. Rose, and Kenneth C. Manning, "A Further Assessment of Indirect Comparative Advertising Claims of Superiority Overall All Competitors," Journal of Advertising 35 (Winter 2006): 53-64

43. Chang, "The Relative Effectiveness"; Choi and Miracle, "The Effectiveness of Comparative Advertising"; Thompson and Hamilton, "The Effects of Information Processing."

44. Barone and Miniard, "How and When"; Jeon and Beatty, "Comparative Advertising Effectiveness."

45. Grewal et al., "Comparative versus Non-Comparative Advertising"; Rogers and Williams, "Comparative Advertising Effectiveness"; Beard, "Practitioner Views of Comparative Advertising."

46. Sorescu and Gelb, "Negative Comparative Advertising."

47. Merle Curti "The Changing Concept of 'Human Nature' in the Literature of American Advertising," Business History Review 41 (Winter 1967): 335-57.

48. Stanley C. Hollander, Kathleen M. Rassuli, D. G. Brian Jones, and Laura F. Dix, "Periodization in Marketing History," Journal of Macromarketing 25 (June 2005): 32-41.

49. Beard, "Comparative Advertising Wars"; Beard and Nye, "A History of the Media Industry's Self-Regulation"; Stephen Fox, The Mirror Makers: A History of American Advertising and Its Creators (New York: Vintage Books, 1984); Pollay, "The Subsiding Sizzle."

50. Frank Presbrey, The History and Development of Advertising (Garden City, NY: Doubleday, 1929).

51. Beard, "Comparative Advertising Wars"; Beard, "An Historical Analysis"; Beard and Nye, "A History of the Media Industry's Self-Regulation." 
52. David P. Nord, "The Nature of Historical Research," in Research Methods in Mass Communication (2nd ed.), ed. Guido H. Stempel III and B. H. Westley (Englewood Cliffs: Prentice-Hall, 1989), 290-315.

53. Quoted in MaryAnn Yodelis Smith, "The Method of History," in Research Methods in Mass Communication (2nd ed.), ed. Guido H. Stempel III and B. H. Westley (Englewood Cliffs: Prentice-Hall, 1989), 316-30.

54. Smith, "The Method of History," 317.

55. Pollay, "The Subsiding Sizzle."

56. Frank T. Hill, “Attacks upon Competitors Shown to be Poor Policy,” Printers' Ink, June 9, $1910,23,25$.

57. Thomas Russell, "Advertises Competitors' Names to Oppose Foreign Competition," Printers' Ink, September 13, 1923, 8.

58. Harry M. Hitchcock, “The 'Knocking' Industrial Advertisement," Printers' Ink, December 15, 1927, 149-52.

59. "Advertising the Knocking Argument: The Cadillac Motor Car Company," Printers' Ink, August 13, 1925, 142.

60. Emil Brisacher, “Are You Riding On The Advertising Merry-Go-Round?" Printers' Ink, January 5, 1928, 161-67.

61. R. T. Hanley, “An Entire Industry Turns to Negative Advertising,” Printers' Ink, December 29, 1927, 10-12.

62. “The Little Schoolmaster's Classroom," Printers' Ink, December 13, 1928, 208.

63. Eugene Pharo, "Is 'Advertising By Attack' to Be Made a Recognized Policy?" Printers' Ink, April 11, 1929, 25-26.

64. "What a Bank Thinks of the Cigarette-Sweets War," Printers' Ink, March 21, 1929, 101.

65. "The Other Fellow," Printers' Ink, July 23, 1902, 21.

66. "The Little Schoolmaster's Classroom," 208.

67. Hill, "Attacks Upon Competitors," 25.

68. Hitchcock, "The 'Knocking' Industrial Advertisement," 150.

69. Thomas Russell, "We'll Pay You If You Buy Competitive Brands," Printers' Ink, October $6,1927,10-12$.

70. William B. Leach, "Is It Ethical to Point Out Weaknesses of Competitors?" Printers' Ink, June 26, 1924, 137-38.

71. “Puff Dairy Ad \& Letter," Printers' Ink 56 (1906): 47.

72. Hill, "Attacks upon Competitors," 25.

73. Brisacher, "Are You Riding," 161.

74. "The Other Fellow," 21.

75. Russell, "We'll Pay You," 8.

76. Hill, "Attacks Upon Competitors," 25.

77. Hitchcock, "The 'Knocking' Industrial Advertisement," 152.

78. Kenneth M. Goode, "Lucky Strike Advertising Tosses Bombs among the Bonbons," Advertising \& Selling, November 14, 1928, 19-20.

79. Pharo, "Is 'Advertising by Attack," 25.

80. Fred K. Beard and Anna Klyeuva, "George Washington Hill and the 'Reach for a Lucky' Campaign," Journal of Historical Research in Marketing 2 (June 2010): 148-65.

81. W. H. Heath, "Keeping Ahead of Your Competitors in Your Advertising," Printers' Ink, March 29, 1923, 146.

82. Pharo, "Is 'Advertising by Attack,"” 83. 
83. Hill, "Attacks Upon Competitors," 24.

84. Hanley, "An Entire Industry," 11.

85. “Jiu Jitsu for the Other Fellow," Printers' Ink, May 27, 1908, 8.

86. Quoted in Leach, "Is It Ethical," 137.

87. Hitchcock, "The 'Knocking' Industrial Advertisement," 152.

88. Appel, quoted in Daniel Pope, The Making of Modern Advertising (New York: Basic Books, 1983).

89. Quoted in Lawrence M. Hughes, “American Tobacco Describes Lucky Strikes 'Sweets' Campaign," Sales Management and Advertisers' Weekly, December 22, 1928, 736-37.

90. Pollay, "The Subsiding Sizzle."

91. Beard, "Competition and Combative Advertising."

92. Claude C. Hopkins, "How Far Can I Go with George Hill," Printers' Ink, April 30, 20.

93. "If Advertisers Must Fight: Why Don't They Protect Themselves against Looking Ridiculous?" Printers' Ink, July 6, 1930, 40-41.

94. “Comparisons Become Invidious in Rivalry for Tire Market," Business Week, April 22, 1931, 9-10.

95. Julian L. Watkins, The 100 Greatest Advertisements: Who Wrote Them and What They Did (Mineola, NY: Dover Publications, 1959).

96. Anthony Chevins, "A Case for Comparative Advertising," Journal of Advertising 4 (Spring, 1975): 31-36.

97. Hopkins, "How Far Can I Go," 20.

98. “Ford Dealers Carry the Flag," Printers' Ink, August 3, 1933, 35.

99. Sarah Lee Gerrish, "Westinghouse's Ad Theme Stirs Up Storm: Sand Test for Laundromat," Printers' Ink, March 29, 1957, 57.

100. Gerrish, "Westinghouse's Ad Theme Stirs Up Storm," 57.

101. Hopkins, "How Far Can I Go," 20.

102. Paul Hollister, "Convalescence-And Custard Pies: Competitive Advertising," Advertising \& Selling, July 6, 1933, 15.

103. William A. McGarry, "Advertise to Prospects-Not to Competitors," Printers' Ink, September 3, 1931, 25-26.

104. Aesop Glim, “Competitive or Positive," Printers' Ink, December 19, 1947, 74.

105. “Tires Throwing Mud,” Printers' Ink, June 10, 1931, 20-21.

106. Paul M. Hahn, “American Tobacco Answers P.I.'s Criticism of Lucky Strike Campaign,” Printers' Ink, December 7, 1951, 46.

107. Charles Luckman, “Pepsodent's 7 Points," Printers' Ink, March 9, 1939, 15-18.

108. "When You Knock Your Competitor, You Knock Advertising" Advertising \& Selling, November 2, 1931, 17-18.

109. William S. Riker, “Retreat!” Printers' Ink, March 13, 1930, 96.

110. "When You Knock Your Competitor," 17.

111. William B. Wisdom, "Putting Punch in Copy vs. Punching Competitors," Printers' Ink, April 24, 1930, 114.

112. S. O. Landry, "Sure, Knock Your Competitor's Advertising, But Fight Fair," Printers' Ink, April 3, 1930, 10.

113. "Tires Throwing Mud," 20.

114. "So He Bought a Horse," Printers Ink, September 21, 1933, 10.

115. P. H. Erbes Jr., "Battle of the Fuels," Printers' Ink, September 20, 1934, 45-46.

116. Joseph A. Ecclestine, "Advertising's Hatfields and McCoys," Advertising Agency, September, 1950, 66. 
117. Riker, "Retreat!" 96.

118. Marsh K. Powers, “Advertising Copy That Kicks Back," Printers' Ink Monthly, April, 1934, 36.

119. "Prima Donnas at War," Printers' Ink, July 8, 1937, 17.

120. Wisdom, "Putting Punch in Copy," 114.

121. "Tires Throwing Mud," 21.

122. Hollister, "Convalescence-And Custard Pies," 15.

123. "Dallas Admen Ask Luckies to Drop Campaign," Editor \& Publisher, December 8, 1951, 16.

124. Frank Braucher, "Calls on Advertising to Battle the Competitive Copy Scourge," Printers' Ink, May 7, 1931, 65-66.

125. “Comparisons Become Invidious," 9.

126. Quoted in "Calls for Showdown on Competitive Copy," Printers' Ink, October 29, $1931,105$.

127. Hopkins, "How Far Can I Go," 20.

128. Mark O’Dea, “Taboos,” Printers' Ink, August 20, 1936, 72.

129. Aesop Glim, "Reading from Left to Right," Printers' Ink, February 16, 1945, 25.

130. Morton J. Simon, “Competitive Advertising," Advertising Agency, September, 1951, 81.

131. Joseph Stone, "What Is Competitive Advertising Today?" Advertising Agency, July, 1951, 77.

132. Quoted in McGarry, "Advertise to Prospects," 26.

133. "If Advertisers Must Fight," 41.

134. Glim, "Competitive or Positive," 74.

135. “Pointed Truths, but No Sting," Printers' Ink Monthly, November, 1941, 22.

136. Glim, "Reading from Left to Right," 76.

137. "Luckies and the Brokers," Printers' Ink, June 5, 1930, 76.

138. Gerrish, "Westinghouse's Ad Theme Stirs Up Storm," 57.

139. William Green, "Concentrate on Your Own, Not Your Competitor's Advertising," Printers' Ink, July 25, 1947, 84.

140. Wisdom, "Putting Punch in Copy," 114.

141. Glim, "Reading from Left to Right," 25.

142. Hopkins, "How Far Can I Go," 20.

143. "Additional Letters about Lucky Strike Advertising," Printers' Ink, December 7, 1951, 108.

144. Gerrish, "Westinghouse's Ad Theme Stirs Up Storm," 57.

145. "Competitive Claims," Printers' Ink, September 17, 1936, 7-9.

146. Erbes, "Battle of the Fuels," 45.

147. Glim, "Reading from Left to Right," 25.

148. "Highlights of the Ford-against-the-Field Fight," Advertising \& Selling, September 14, 1933, 48, 63.

149. Quoted in Karen De Coster, "Henry Ford, FDR, and the Automobile Code," Ludwig Von Mises Institute, 2004, accessed July 1, 2012, http://archive.mises.org/2209/ henry-ford-fdr-and-the-automobile-code/.

150. Hopkins, "How Far Can I Go," 20.

151. Joel Benton, "When Competitive Advertising Need Not Be Destructive," Printers' Ink, December 15, 1932, 53-55.

152. Robert Tinsman, "Competition Jitters," Advertising \& Selling, October, 1941, 64.

153. Landry, "Sure, Knock Your Competitor's Advertising," 10.

154. "If Advertisers Must Fight," 41. 
155. E. B. Weiss, “Advertisers Forget Americans Like Good Sports,” Printers' Ink, November 30, 1951, 39.

156. "Copy Should Avoid Criticism of Competitors," Domestic Engineering, October, 1936, 83-84.

157. Robert L. Philippi, "Hog-Calling and Its Cure," Advertising \& Selling, May 9, 1935, 34.

158. "Pointed Truths, but No Sting," 22.

159. Pollay, "The Subsiding Sizzle."

160. “Naming Competitors in Ads: Forthright, Fair, Foolish?” Printers' Ink, January 28, 1966, $32-34$.

161. Robert Posch Jr., "Comparative Advertising Yesterday and Today," Direct Marketing, May, 1982, 106, 110.

162. “Ad Age Advertising Century: The Top 100 Campaigns," Advertising Age, November 29, 1999, accessed May 29, 2012, http://adage.com/article/special-report-the-advertisingcentury/ad-age-advertising-century-top-100-advertising-campaigns/140150/.

163. Sidney A. Diamond, "Beware of Naming the Competitor," Advertising Age, October 23, $1978,66$.

164. Beard and Nye, "A History of the Media Industry's Self-Regulation."

165. Stanley E. Cohen, "Truth in Ads Self-Regulation in No Danger-FTC's Nye," Advertising Age, March 1, 1976, 1.

166. Federal Trade Commission, "Statement of Policy Regarding Comparative Advertising," August 13, 1979, accessed January 5, 2012, http://www.ftc.gov/bcp/ policystmt/ad-compare.htm.

167. Robert Danielenko, "Ads that Cite the Competition: A New Trend," Product Management, September, 1973, 56-57.

168. Nancy Giges, "Comparative Ads: Battles that Wrote Dos and Don'ts," Advertising Age, September 29, 1980, 59.

169. William D. Tyler, "Let's Expose Misleading Ads before Consumer-Protectors Can," Advertising Age, February 18, 1974, 52.

170. Stanley I. Tannenbaum, "Put Consumerism to Work for You, Use Ad ComparisonsTannenbaum," Marketing News, December 17, 1976, 1, 5.

171. Frank Meyers, "Rivals Find Volkswagen Is Hard Little Car to Belittle," Advertising Age, May 23, 1966, 4.

172. Nancy Giges, "J\&J Readies Effort to Protect Tylenol-New Datril Spot Airs," Advertising Age, July 28, 1975, 1, 61.

173. Nancy Giges, "Comparative Ads: The Headaches of the Analgesics," Advertising Age, October 6, 1980, 63-64, 66.

174. Andrew G. Kershaw, "For and against Comparative Advertising-Against," Advertising Age, July 5, 1976, 25.

175. Tannenbaum, "For and against," 28.

176. Giges, "Comparative Ads," 66.

177. Tannenbaum, "For and against," 28.

178. Ernest Dichter, “Consumers Aren't What They Used to Be-Ads Must Reflect Reaction," Marketing News, October 7, 1977, 8.

179. Quoted in John Consoli, "Comparative Print Ads More Credible-Kershaw," Editor \& Publisher, May 22, 1976, 14.

180. "Naming Competitors in Ads," 32.

181. "Naming Competitors in Ads," 32. 
182. “Advertising: A Bare-Knuckle Brawl,” Printers' Ink, October 9, 1964, 58.

183. Fairfax M. Cone, "Disparaging Ads Will Injure All Business: Cone," Advertising Age, September 27, 1965, 62.

184. Quoted in "Comparative Ads Graded 'F' by CBBB President," Advertising Age, October 17, 1977, 2.

185. Quoted in "Comparative Ads Graded 'F,"” 2.

186. Quoted in Maurine Christopher, "NBBB Hits Ads Naming Competitor as 'Invidious': Not So Fast, Says ANA," Advertising Age, November 8, 1965, 1, 79.

187. "Four A's Hits Derogatory Ads," Advertising Age, February 21, 1966, 1, 187.

188. Quoted in Don Grant, "Be Hard on Comparison Ads-Roberts to Four A's," Advertising Age, November 19, 1973, 1, 61.

189. Quoted in "Name That Competitor," Sales Management, October 15, 1965, 92.

190. Quoted in "Name That Competitor," 92.

191. Quoted in Christopher, "NBBB Hits Ads," 79.

192. Quoted in Tannenbaum, "For and against," 28.

193. Tannenbaum, "For and against," 28.

194. "Tueros Drive Thanks Respondents To Poll on Ethics of Ad Naming Competitor Brands," Advertising Age, March 30, 1970, 28.

195. Quoted in "Advertising: A Bare-Knuckle Brawl," 58.

196. Quoted in Christopher, "NBBB Hits Ads," 79.

197. Quoted in Tannenbaum, "For and against," 28.

198. Quoted in Tannenbaum, "For and against," 28.

199. Quoted in "Sealy's Kaplan Blasts Derogatory Copy as Ad 'Abuse," Advertising Age, May 9, 1966, 32.

200. Kershaw, "For and against," 25.

201. Quoted in "Underdog Advertiser Wins in 'Naming Names': BBDO," Advertising Age, March 10, 1975, 56.

202. Quoted in Consoli, "Comparative Print Ads More Credible," 14.

203. "Naming Competitors in Ads," 33.

204. Tannenbaum, "Put Consumerism to Work for You," 5.

205. Danielenko, "Ads that Cite the Competition."

206. "Tylenol Exec Speaks Out on Datril Price Ad," Advertising Age, March 29, 1976, 1, $61,115$.

207. T. V. Byor, "TV Clutter Makes Right Video Technique for Product a Must,” Advertising Age, January 10, 1977, 42.

208. “Just a Mosquito Bite," Sales Management, January 7, 1966, 78.

209. Nancy Giges, "Coca Cola—Reluctant Entrant into Comparative Ad Warfare," Advertising Age, January 3, 1977, 2, 35.

210. Bob Donath, "Comparative Ad Study Sparks Debate," Advertising Age, November 3, 1975, 3, 32.

211. Stanley M. Ulanoff, Comparison Advertising: An Historical Retrospective (Cambridge, MA: Marketing Science Institute, 1975).

212. "Naming Competitors in Ads," 34.

213. Quoted in Danielenko, "Ads that Cite the Competition," 61.

214. Quoted in "Should an Ad Identify Brand X?" Business Week, September 24, 1979, $156-57$.

215. Quoted in Danielenko, "Ads that Cite the Competition," 65. 
216. "Naming Competitors in Ads," 34.

217. "Four A's Hits Derogatory Ads," 187.

218. Jean J. Boddewyn and Katherin Marton, Comparison Advertising: A Worldwide Study (New York: Hastings House, 1978).

219. Jean J. Boddewyn, "Nations Apply Different Laws to Comparison Ads," Marketing News, October 6, 1978, 3.

220. Quoted in "Renault's Ad Claims True, Adman Tells TV Stations that Turned Down Commercials," Advertising Age, September 6, 1965, 6.

221. Quoted in Danielenko, "Ads that Cite the Competition," 62.

222. William D. Tyler, "Comparative Advertising-A Powerful Selling Tool When It Is Not Abused," Advertising Age, April 21, 1975, 58.

223. Quoted in "Underdog Advertiser Wins," 56.

224. Quoted in Tannenbaum, "For and against," 28.

225. Quoted in "Should an Ad Identify Brand X?" 157.

226. Quoted in "How Ethics Inspired an Ad Treaty," Printers' Ink, November 17, 1961, 37-39.

227. Quoted in "Renault's Ad Claims True," 6.

228. Martin Rockey, "Media Copy," Media-scope, June, 1969, 32.

229. Quoted in Danielenko, "Ads that Cite the Competition," 62.

230. Quoted in "Tylenol Exec Speaks Out," 1.

231. Tannenbaum, "For and against," 28.

232. Byor, "TV Clutter," 42.

233. Quoted in Giges, "Coca Cola—Reluctant Entrant," 35.

234. "ABC Censor Raps Trend to Naming Rivals in Ads," Advertising Age, March 31, 1975, 98.

235. Tyler, "Comparative Advertising," 58.

236. Quoted in Giges, "Coca Cola-Reluctant Entrant," 32.

237. Archie Anderson and Mitchell Koss, "The Seminal Trend: Winning Ads Must Take Risks to Touch Public Nerve," Advertising Age, May 29, 1978, 37-38.

238. Quoted in “Advertising: A Bare-Knuckle Brawl," 58.

239. "Naming Competitors in Ads," 34.

240. "Name That Competitor," 92.

241. "Collier's Encyclopedia Ad Showing Competitor's Volumes Draws Protests," Advertising Age, November 23, 1964, 34.

242. “'E\&P' Ad on 'McCall's'—'Too Competitive,' 'Went Too Far,' Say 'Times,' 'Trib' House Ads," Advertising Age, April 9, 1962, 12.

243. Raymond Serafin, "The Gloves Come Off in Auto Marketing," Advertising Age, October 21, 1985, 76.

244. Joe Flint, "Network Handling of Comparative Ads Causing Concern," Broadcasting, October 29, 1990, 53.

245. "Bring Back 'Brand X.'” Advertising Age, November 8, 1999, 60.

246. Emily B. York, "Brand vs. Brand: Attack Ads on the Rise," Advertising Age, October 27, 2008, 1.

247. Jan Jaben, "Mud Wrestling. Microsoft's Ads Highlight New Prominence of Negative Marketing in Business," Business Marketing, August 31, 1992, 28-32.

248. Jaben, "Mud Wrestling," 28.

249. Gene Koprowski, "Theories of Negativity," Brandweek, February 20, 1995, 20-22. 
250. Doug Wood, “10 Advertising Legal Issues,” Advertising Age, December 20, 2004, 12.

251. Emily B. York and Natalie Zmuda, "So Sue Me: Why Big Brands Are Taking Claims to Court," AdAge.com, January 4, 2010, accessed January 4, 2010, http://www.adage.com.

252. Stuart Emmrich, "Giving Each Other the Business," Advertising Age, May 3, 1982, M1, M5-M6.

253. Joseph M. Winski, "Burger King Gets Awareness Boost," Advertising Age, November 29, 1982, 3.

254. "Perkins Aims to Put Chevy Back on Top," Advertising Age, August 7, 1989, 14.

255. Quoted in "Comparative Ads Paying Off for Burger King/Comparison War Incited Wendy's Ad Campaign," Marketing News, April 27, 1984, 18.

256. Abbey Klaassen, “AT\&T's Verizon Lawsuit Gives 'Map for that' Ad New Life,” AdAge. com, November 19, 2009, accessed November 19, 2009, http://adage.com/article/ the-viral-video-chart/verizon-lawsuit-map-ad-life/140602/.

257. Emmrich, "Giving Each Other the Business," M5.

258. Quoted in Gene Koprowski, "Does Negative Advertising Hang Up on Brand Equity," Brandweek, February 20, 1995, 22.

259. Emmrich, "Giving Each Other the Business," M5.

260. Raymond Serafin, "Pontiac Ads Bring Excitement to Sales," Advertising Age, July 20, 1992, 12.

261. Quoted in Al McClain, "When It Comes to Commercials, Iacocca Wins Out," Advertising Age, June 6, 1983, M1-M2.

262. Quoted in Sidney Bernstein, "Comparative Thinking," Advertising Age, March 20, 1989, 16.

263. Quoted in Natalie Zmuda, "Pepsi Max Drops the Diet, Aims to Rekindle Cola War in Third Bid to Establish Brand Identity in U.S., Max Tries New Position—and Takes Poke at Coke," AdAge.com, August 23, 2011, accessed July 13, 2012, http://adage.com/article/ news/pepsi-max-drops-diet-aims-rekindle-cola-war/145505/.

264. Natalie Zmuda, "Sierra Mist Effort a Not-So-Sweet Attack on Sprite: PepsiCo Plays up Natural Attributes of Brand in Competitive Ads," Advertising Age, March 3, 2011, 1.

265. Bernstein, "Comparative Thinking," 16.

266. Stephen Williams, "Ford vs. Chevy: Did Attack Ad Backfire?" Adage.com, February 12, 2012, accessed June 4, 2012, http://adage.com/article/adages/ chevy-bowl-spot-drew-people-ford-kelley-blue-book/232693/.

267. Herschell Gordon Lewis, "Choose Your Weapons: The Four Faces of Comparatives," Direct Marketing, May, 1990, 1, 34.

268. Giges, "Comparative Ads," 59.

269. Raphel, “Ad Techniques," 60.

270. "Bring Back 'Brand X," 60.

271. Herschell Gordon Lewis, "The Art of Comparative Copy," Catalog Age, April, 1990, 103-104.

272. Patricia Winters, "Diet Colas Drop Comparative Tactic," Advertising Age, January 21, 1991, 24.

273. Jack Neff, "Household Brands Counterpunch," Advertising Age, November 1, 1999, 26; Williams, "Ford vs. Chevy."

274. Shanesy, quoted in Neff, "Household Brands Counterpunch," 26.

275. Lou Morris, "Direct-to-Lou," Pharmaceutical Executive, February, 2000, 130.

276. Quoted in Koprowski, "Does Negative Advertising Hang Up,” 22. 
277. Quoted in Rita Change, "New Verizon Ads Take Direct Aim at IPhone, but What Are They Selling? 'I Don't' Android Campaign Leaves Brand a Mystery," Adage. com, October 19, 2009, accessed October 19, 2009, http://adage.com/article/news/ advertising-verizon-s-android-ads-leave-brand-a-mystery/139780/.

278. "BHC Defies Rules, Zaps Competitor in Ad," Bank Advertising News, December 31, 1984, 3 .

279. Lewis, "The Art of Comparative Copy," 104.

280. Todd Wasserman and Kenneth Hein, "For Some, 'Taste Test' Ads Are Leaving a Bad Taste," Brandweek, January 12, $2009,8$.

281. Quoted in Winters, "Diet Colas Drop Comparative Tactic," 24.

282. Mary Chris Jaklevic, "Healthcare Ads Getting Aggressive," Modern Healthcare, September 23, 1996, 50 .

283. Jean Halliday, "Survey: Comparative Ads Can Dent Car's Credibility," Advertising Age, May 4, 1998, 26.

284. Quoted in Koprowski, "Does Negative Advertising Hang Up," 22.

285. "Perkins Aims to Put Chevy Back on Top," 14.

286. Mark Dolliver, "An Aversion to Ads that Attack a Rival," Adweek, October 19, 2009, 19.

287. Robert Klara, "Is Your Brand 'The Best'? Maybe It Shouldn't Be," Brandweek, September 21, 2009, 38.

288. Natalie Zmuda, "New Pepsi Ad Tweaks Coke with Help from Santa," Adage. com, June 28, 2011, accessed May 29, 2012, http://adage.com/article/news/ pepsi-ad-tweaks-coke-santa/228459/.

289. Murray Raphel, “Ad Techniques: The Danger of 'Can You Top This?”” Bank Marketing, January, 1984, 60.

290. Louise Kramer, “As Sales Flatten, Top Pizza Chains Turn Up the Heat,” Advertising Age, February 23, 1998, 4 .

291. Gerry Khermouch, "Beer Blast," Brandweek, September 23, 1996, 1.

292. "Some Comparative Ads Work, O\&M Concedes," Advertising Age, November 3, 1980, 6 .

293. Rita Chang and Rupal Parekh, "Verizon Vs. AT\&T: Blistering Battle Raging over Map Coverage Fight is Good News for Shops, Media as Wireless Giants Square Off," AdAge. com, November 30, 2009, accessed November 30, 2009, http://adage.com/article/news/ verizon-t-blistering-battle-raging-map/140748/.

294. "Sales, Company and Brand Image Can Suffer if Ad Research Ignores Like/Dislike Dimension," Marketing News, May 16, 1980, 13.

295. Scott Hume, "Mac Chief Explodes 'Burger Wars': Competition to Get Fiercer," Advertising Age, April 14, 1986, 3.

296. Quoted in Neff, "Household Brands Counterpunch," 26.

297. Quoted in Patricia Winters and Wayne Walley, "Coke Seeks Tough TV Ad Watchdog: Herbert Criticizes Comparative Claims," Advertising Age, October 8, 1990, 1.

298. John Bissell, "Politics May Be Negative, but Not Brand Marketing," Brandweek, November 21, 1994, 16.

299. Debra Goldman, "The Pain in Our Head," Adweek, April 15, 1996, 25.

300. Nora Fitzgerald, "Compared to What?" World Trade, January, 1996, 58.

301. Richard Kreisman and Christy Marshall, "Burger King's 'Challenge' Set for Heavy Drive," Advertising Age, September 13, 1982, 1, 74.

302. Steve Miller, "GM Dealers Fight Toyota in the Trenches," Brandweek, March 26, 2007, 4. 
303. Giges, "Comparative Ads," 59.

304. Marvin R. Shanken and David Drum, "These Are the Vintage Years/Marketing Wine Keeps Growing at Taylor Cal.," Advertising Age, July 27, 1981, S-38.

305. Greg W. Prince, "Confrontation, Innovation, Gimmickry Mark First Month of New Year's Advertising," Beverage World, January 31, 1991, 1.

306. Judann Dagnoli, "Ragu, Prego Battle for Share Heats Up," Advertising Age, May 22, $1989,4$.

307. "Chrysler Accelerates Corporate Campaign," Advertising Age, July 9, 1990, 2.

308. Ira Teinowitz, "RC Starts Its Own Cola 'Challenge,"” Advertising Age, November 5, 1990, 20.

309. Serafin, "Pontiac Ads Bring Excitement," 12.

310. Ira Teinowitz, "A-B Spot Throws Rocks at Coors Light," Advertising Age, August 3, 1992, 3 .

311. John Schmeltzer, "Miller Uncaps Beer Ad Battle: New Agency Hired for Aggressive Strategy," Knight Ridder Tribune Business News, May 18, 2007, 1.

312. Kate MacArthur, "Why Big Brands Are Getting into the Ring," Advertising Age, May 21, 2007, 6 .

313. Jamie LaReau, "Ford Truck Campaign Spars with Competition," Automotive News, May 23, 2005, 30.

314. Steve Miller, "Ford Revs Up Comparison Ads, Moves Needle on Sales," Brandweek, April 23, 2007, 6.

315. Emily B. York, "DiGiorno," Advertising Age, November 16, 2009, 12.

316. Jeremy Mullman, "High Life's One-Second Spots Yield 8.6\% Sales Boost after Super Bowl," Advertising Age, February 23, 2009, 3, accessed April 2, 2013, http://proquest. umi.com.ezproxy.lib.ou.edu/pqdweb?RQT $=318 \&$ pmid=28994\&TS=1249058121\&clie ntId=41954\&VInst=PROD\&VName=PQD\&;VType=PQD>,- http://proquest.umi.com . ezproxy.lib.ou.edu/pqdweb?RQT=572\&VType=PQD\&VName=PQD\&VInst=PROD\& pmid $=28994 \&$ pcid $=42049291 \& ;$ SrchMode $=3 ">-$.

317. York, "The Gloves Are Off," 4.

318. York, "The Gloves Are Off," 4.

319. Rupal Parekh and Andrew Hampp, "Dish Network Wages War against DirecTV with New Campaign,” AdAge.com, February 1, 2010, accessed February 2, 2010, http://adage. $\mathrm{com} /$ results? endeca $=1 \&$ return $=$ endeca\&search_offset $=0 \&$ search_order_by $=$ score $\&$; search_phrase=02/01/2010->, http://adage.com/article/news/marketing-dish-networkcampaign-wages-war-directv/141862/.

320. Beth Snyder Bulik, "Sony's PSP Uses Smart Aleck to Lay the Hurt on Smartphones," Advertising Age, September 6, 2010, 6.

321. Prince, "Confrontation, Innovation," 1.

322. Riccardo A. Davis, "Konica Snaps at Kodak over Price," Advertising Age, September 20, 1993, 49.

323. Gregg Cebrzynski, "Taco Bell Ad: Gordita Whips the Whopper," Nation's Restaurant News, July 20, 1998, 3.

324. Gerry Khermouch, "Minute Maid Puts Tropicana to the Test," Brandweek, May 8, 1995, 8.

325. Giges, "Comparative Ads," 59.

326. Michael Wilke, "Claritin's Comparative Ads Take on Seldane," Advertising Age, February 3, 1997, 57.

327. Jaben, "Mud Wrestling," 32. 
328. Bradley Johnson, "PC Giants' Ads Blast Faltering Rivals," Advertising Age, January 25, 1993, 13.

329. Quoted in Stephanie Clifford, "Best Soup Ever? Suits over Ads Demand Proof," The New York Times, November 22, 2009, A1.

330. Al McClain, "When It Comes to Commercials, Iacocca Wins Out," Advertising Age, June 6, 1983, M30, M32.

331. Karen Benezra, "No Holds Barred," Adweek, November 9, 1998, 46.

332. Judann Pollack, "Prego Prevails in Battle over Comparative Ad," Advertising Age, September 16, 1996, 12.

333. Emmrich, "Giving Each Other the Business," M6.

334. Quoted in "Rules of Engagement for Comparative Ads," BtoB, August 11, 2003, 26.

335. Quoted in "Comparative Ads Paying Off," 18.

336. Cebrzynski, "Taco Bell Ad," 3.

337. Gregory James Kennedy, "Michelin Ads Tout Design Feature," Advertising Age's Business Marketing, May, 1994, 11.

338. Herschell Gordon Lewis, "The Future of 'Force-Communication': Power Communication," Direct Marketing, January, 1992, 32.

339. Pat Sloan, "Toiletries \& Beauty Aids: Knock-Offs Deliver Blows to Fragrance Market," Advertising Age, March 2, 1987, S14.

340. Anne B. Fisher, "Mark Laracy's Obsession," Inc., May, 1988, 70.

341. Sloan, "Toiletries \& Beauty Aids," S14.

342. Fisher, "Mark Laracy's Obsession," 80.

343. Quoted in "Comparative Ads Paying Off," 18.

344. Patricia Strnad, "Suburu Takes Comparative Angle," Advertising Age, November 27, 1989, 33.

345. Miller, "Ford Revs Up Comparison Ads," 6.

346. Serafin, "The Gloves Come Off," 76.

347. Patricia Winters, "Small Competitor Feels Coke's Ire," Advertising Age, February 20, 1989, 37.

348. Quoted in Winters, "Small Competitor Feels Coke's Ire," 37.

349. Raymond Serafin and Patricia Strnad, "Truck Tug of War Leaves Dodge in Rut," Advertising Age, November 27, 1989, 32.

350. “Creating a Mass Market for Wine,” Business Week, March 15, 1982, 108-110, 114, 118.

351. Koprowski, "Theories of Negativity," 20.

352. Bissell, "Politics May Be Negative," 16.

353. York, "Brand vs. Brand," 1.

354. Lewis, "Choose Your Weapons," 34.

355. Chang and Parekh, "Verizon vs. AT\&T."

356. “Taking a Swing at Competitors' Loan Procedures” Bank Marketing, July, 1983, 49; "Current Bank Advertising: Taking the Bull by the Horns," Bank Marketing, January, 1985, 39; Kathryn A. Oldfield, "Current Bank Advertising: When the Going Gets Tough,” Bank Marketing, August, 1985, 71; Judith Graham, "Banks' Ads Take Swipes at Rivals," Advertising Age, March 28, 1988, 55.

357. Graham, "Banks' Ads Take Swipes," 55.

358. Quoted in "Comparative Ads Paying Off for Burger King/Comparison War Incited Wendy's Ad Campaign," Marketing News, April 27, 1984, 18.

359. Miller, "Ford Revs Up Comparison Ads," 6. 
360. Serafin, "The Gloves Come Off," 76.

361. Quoted in "Some Comparative Ads Work," 6.

362. Patricia Winters, "BK Resumes Burger Wars, Mulls Smaller Whopper," Advertising Age, October 13, 1986, 3.

363. Mike Shields, "Did Sour Grapes Prompt Verizon's Apple Attack?" Brandweek, October 26, 2009, 36.

364. Quoted in Emmrich, "Giving Each Other the Business," M5.

365. Giges, "Comparative Ads," 66.

366. Quoted in "Comparative Ads Paying Off," 18.

367. Lewis, "The Art of Comparative Copy," 103.

368. Quoted in Bradley Johnson, "Tougher Times Spur Malicious Ads for Computers," Advertising Age, May 24, 1993, 1.

369. Kunur Patel, “AT\&T 'Rethink' Signals Detente in Attack-Ad Battle with Verizon, Luke Wilson Recalled from Front as Carrier Takes on Feel-Good Lifestyle Effort: Will Verizon Follow Suit?" Adage.com, April 12, 2010, accessed April 12, 2010, http://adage.com/results?endeca $=1 \&$ return=endeca\&search_offset=0\&search_order_ by=score \&;search_phrase=04/12/2010" >- http://adage.com/article/news/t-rethinksignals-detente-attack-ad-war-verizon/143222/.

370. "Some Comparative Ads Work," 6.

371. Luther Brock, "How to Put Down Your Competition-Tactfully," Direct Marketing, April, 1982, 92-93; Jundann Pollack and Laura Petrecca, "V8, Tropicana Pump Spending for Juices," Advertising Age, August 18, 1997, 30; "Copy Chasers: Corporate Catfights," Business Marketing, October, 1992, 162-64; Kimberly Kromer, "Is There Really a Cost Difference between the Big Three?" Telecommunications, February, 1995, 28.

372. William T. Neese, "Comparative Ads Work Well Even for 'Help Wanted," Marketing News, January 20, 1992, 13; "Copy Chasers: Corporate Catfights, 162-64”; Kromer, "Is There Really a Cost Difference Between," 28.

373. Kris Aaron, "Advertising Hardball with the Big Boys," Credit Union Management, August, 1989, 8.

374. Quoted in "Ads that 'Evoke Fear and Alarm' Are Cited," Bank Advertising News, June 26, $1989,7$.

375. Karl Hoyle, quoted in "FHLBB Concerned about 'Irresponsible' Advertisers," Bank Advertising News, June 26, 1989, 1.

376. Bradley Johnson, "PC Giants' Ads Blast Faltering Rivals,” Advertising Age, January 25, 1993, 13.

377. Dynan, quoted in “Merger Mania," Bank Marketing, December, 1984, 42.

378. Aaron, "Advertising Hardball," 8.

379. Jeff Green, "Buick Aims 'Challenge' at Rivals," Brandweek, June 21, 1999, 10.

380. Kathy Tyrer, "California BMW Dealers Go Mano a Mano with Lexus," Adweek, May 24, 1993, 2.

381. Khermouch, "Beer Blast," 1.

382. Emily B. York, "Coke: Buy 1 Rival, Get Our Brand Free," Advertising Age, March 9, 2009, 1.

383. Emily B. York, "Ben and Jerry's Calls Out Haagen-Dazs on Shrinkage, Website Says Competitor's Move to Sell 14-Ounce Pints Is 'Downright Wrong," Adage. com, March 9, 2009, accessed March 9, 2009, http://adage.com/article/news/ ben-jerry-s-calls-haagen-dazs-shrinking-packaging/135126/. 
384. Rita Chang, "AT\&T Missteps with Verizon Ad-Claim Lawsuit," Advertising Age, November 9, 2009, 8.

385. "Pepsi Dares to Compare-Everywhere," Beverage World 113, no. 1562 (1994): 18.

386. Fara Warner, "Camel Blows Smoke," Adweek, August 1, 1994, 5.

387. Ted Laperouse, "Kick Off and Funning," Adweek, July 11, 1994, 4.

388. Jack Neff, "P\&G's Millstone Battles Starbucks in Chi. Test," Advertising Age, October 20, 1997, 8.

389. Simon Dumenco, "Social-Media Smackdown: The Disloyal Polar Bears vs. Disloyal Santa in Pepsi's New Anti-Coke Spots," Adage.com, August 3, 2011, accessed May 31, 2012, http:// adage.com/article/the-media-guy/disloyal-polar-bears-disloyal-santa-pepsi-spots/229074/.

390. Gary Levin, "Marketers Get Really Nasty with In-Your-Face Advertising," Advertising Age, October 17, 1994, 2.

391. Levin, "Marketers Get Really Nasty," 2.

392. Jean Halliday, "Volvo's Ad Claims Questioned-Again," Advertising Age, June 10, 1996, 1, 44.

393. "Mr. Mayor, They Beg to Differ," Automotive News, April 22, 2002, 4.

394. Rupal Parekh, "Microsoft vs. Apple Fight Enters New Round In a Sudden Ad Shift, PC Maker Co-Opts Rival's Geeky Character," AdAge.com, September 18, 2008, accessed July 28, 2012, http://adage.com/article/news/microsoft-apple-fight-enters-round/131102/.

395. Jamie LaReau, "Buick Pokes Fun at Lexus in New Billboard Ads, Also Introduces Latest Tagline for LaCrosse: "The New Class of World Class,", Adage.com, September 15, 2009, accessed July 15, 2012, http://adage.com/article/news/ marketing-buick-pokes-fun-lexus-ads/139029/.

396. Klaassen, “AT\&T's Verizon Lawsuit."

397. Quoted in Kathy Thacker, "RC Gets Serious with Laughs," Adweek, March 7, 1994, 2.

398. Benezra, "No Holds Barred," 46.

399. Luther Brock, "How to Put Down Your Competition-Tactfully," Direct Marketing, April, 1982, 92-93.

400. Jaben, "Mud Wrestling," 29.

401. Jaben, "Mud Wrestling," 30.

402. Jaben, "Mud Wrestling," 30.

403. Jan Jaben, "Avoiding Temptation: Not Using Negative Ads Usually is Good Business, Poll Shows," Business Marketing, September, 1992, 36.

404. “A Food Fight Out of Control," Advertising Age, February 1, 1999, 16.

405. Quoted in "Comparative Ads Can Work-but No Mudslinging," Automotive News, June 14, 2010, 12.

406. Quoted in Hume, "Mac Chief Explodes 'Burger Wars,"” 3.

407. Riccardo A. Davis, "Fuji, Kodak Fire Comparative Shots," Advertising Age, July 19, 1993, 13.

408. Lewis, "The Art of Comparative Copy," 103.

409. Quoted in Greg W. Prince, "Pepsi's 'Big Bang' Theory: Super Bucks, Supermodel Spur Super Start to Year," Beverage World, February 28, 1994, 1.

410. Quoted in Alison Fahey and Jim Kirk, "BBDO Shakes Up Diet Pepsi Ads," Adweek, January 31, 1994, 5.

411. Koprowski, "Theories of Negativity," 22.

412. Ellen Koteff, "Better Advertising Campaigns, Better Pizza? Learn to be Judicious or Risk Losing Dough,” Nation's Restaurant News, January 24, 2000, 27. 
413. Quoted in York, "Brand vs. Brand," 1.

414. Ann Marie Kerwin, "Water Cooler," Advertising Age, June 4, 2007, 49.

415. "Did You Know that Domino's and Subway Are in a Food Fight?" PRNewswire, January 22, 2009, accessed May 31, 2012, http://multivu.prnewswire.com/mnr/dominos/36735/.

416. Ulanoff, Comparison Advertising.

417. Pamela W. Laird, Advertising Progress: American Business and the Rise of Consumer Marketing (Baltimore: Johns Hopkins University Press, 1998); Frank Rowsome Jr., They Laughed When I Sat Down: An Informal History of Advertising in Words and Pictures (New York: McGraw-Hill, 1970).

418. Fred Beard, "Hard-Sell 'Killers' and Soft-Sell 'Poets': Modern Advertising's Enduring Message Strategy Debate,” Journalism History 30 (Fall 2004): 141-49.

419. Rogers and Williams, "Comparative Advertising Effectiveness."

420. Donald W. Jackson Jr., Stephen W. Brown, and Robert R. Harmon. "Comparative Magazine Advertisements," Journal of Advertising Research 19 (December 1979): 21-26.

421. Beard, "Practitioner Views of Comparative Advertising."

422. Inger Stole, Advertising on Trial: Corporate Public Relations in the 1930s (Chicago: University of Illinois Press, 2006).

423. Beard and Nye, "A History of the Media Industry's Self-Regulation."

424. Beard, "Comparative Advertising Wars."

425. Cordelia Brabbs, "Two-thirds Find Comparative Ads 'Unacceptable," Marketing, September 20, 2001, 5; Johnson-Cartee and Copeland, "Southern Voters' Reaction."

426. Beard and Nye, "A History of the Media Industry's Self-Regulation."

427. Greg Shaffer and Florian Zettelmeyer, "Comparative Advertising and In-Store Displays," Marketing Science 28 (November-December 2009): 1144-56.

428. Joseph R. Priester, John Godek, D. J. Nayakankuppum, and Kiwan Park, "Brand Congruity and Comparative Advertising: When and Why Comparative Advertisements Lead to Greater Elaboration," Journal of Consumer Psychology 14, no. 1 \& 2 (2004): 115-23.

429. Stuart Van Auken and Arthur J. Adams, "Across- versus Within-Class Comparative Advertising: Insights into Prestige Class Anchoring," Psychology and Marketing 16, (August 1999): 429-50.

430. Grewal et al., "Comparative versus Non-Comparative Advertising."

431. James and Hensel, "Negative Advertising."

432. Shailendra Pratap Jain and Steven S. Posavac, "Valenced Comparisons," Journal of Marketing Research 41 (February 2004): 46-58; Sorescu and Gelb, "Negative Comparative Advertising."

433. Donthu, "Comparative Advertising Intensity."

434. Gina M. Garramone, "Voter Responses to Negative Political Ads," Journalism Quarterly 61 (Summer 1984): 250-59.

435. Chang, "The Relative Effectiveness."

436. Stefan Schwarzkoph, "The Subsiding Sizzle of Advertising History: Methodological and Theoretical Challenges in the Post Advertising Age," Journal of Historical Research in Marketing 3, no. 4 (2011): 528-48.

437. Carolyn White Nye, Martin S. Roth, and Terrence A. Shimp, "Comparative Advertising in Markets where Brands and Comparative Advertising Are Novel," Journal of International Business Studies 39, (July 2008): 851-63. 
438. David M. Boush and Ivan Ross, "The Influence of Substantiation Details on Perception of Comparative Advertising Claims: An Exploratory Investigation," in Proceedings: Educators' Conference, ed. Terrence Shimp (Chicago: American Marketing Association, 1986); Roobina O. Taschian and Mark E. Slama, "Involvement and the Effectiveness of Comparative Advertising," Current Issues \& Research in Advertising 7 (May 1984): 79-92.

439. Charles A. Bates, Good Advertising (New York: Putnam, 1896); Earnest E. Calkins, The Advertising Man (New York: C. Scribner's Sons, 1922); Fairfax M. Cone, With All its Faults: A Candid Account of Forty Years in Advertising (Boston: Little Brown, 1969); David Ogilvy, Confessions of An Advertising Man (New York: Atheneum, 1963); Rosser Reeves, Reality in Advertising (New York: Knopf, 1961); James W. Young, The Diary of an Ad Man: The War Years June 1, 1942-December 31, 1943 (Chicago: Advertising Publications, 1944).

440. Beard, "Practitioner Views of Comparative Advertising."

441. Fred K. Beard, "Negative Comparative Advertising: When Marketers Attack," in Marketing Metaphors and Metamorphosis, ed. Philip J. Kitchen (Hampshire, UK: Palgrave Macmillan, 2008), 42-56; Jain and Posavac, "Valenced Comparisons"; James and Hensel, "Negative Advertising"; Anne Roggeveen, Dhruv Grewal, and Jerry Gotlieb, "Does the Frame of a Comparative Ad Moderate the Effectiveness of Extrinsic Information Cues?" Journal of Consumer Research 33 (June 2006): 115-22; Sorescu and Gelb, "Negative Comparative Advertising."

\section{Author Biography}

Fred K. Beard (Ph.D., University of Oklahoma) is a professor of advertising in the Gaylord College of Journalism and Mass Communication, University of Oklahoma. His work has been published in Journal of Advertising, Journal of Advertising Research, Journal of Business Research, Journal of Business Ethics, Journal of Historical Research in Marketing, Journal of Macromarketing, Journal of Marketing Communications, and Journalism History, among others. 